Campos Venuti, Giuseppe

1971 La Administración del Urbanismo.

Gustavo Gili. Barcelona, España.

CAz, Rosario et ál.

2004 Planes parciales residenciales.

Junta de Castilla y León. Valladolid, España.

De Esteban Alonso, Alfonso

1976 «Los estándares urbanísticos»

Ciudad y Territorio, $\mathrm{n}^{\mathrm{O}}$ 2. Ministerio de Fomento. Madrid, España.

Esteban Noguera, Juli

2003 La ordenación urbanística: conceptos, herramientas y prácticas.

Electa. Barcelona, España.

García de Enterría, Eduardo y Parejo Alfonso, Luciano

1981 Lecciones de derecho urbanístico.

Editorial Civitas. Madrid, España.

Hernández Aja, Agustín (Director)

1997 La ciudad de los ciudadanos.

Centro de Publicaciones. Ministerio de Fomento. Madrid, España.

Hernández Aja, Agustín y Leiva Rodríguez, Amaya

2006 Parámetros dotacionales para la ciudad de los ciudadanos.

Cuadernos del Instituto Juan de Herrera. Madrid, España.

Martínez Sarandeses, José

1999 Guía de diseño urbano.

Centro de publicaciones. Ministerio de Fomento. Madrid, España.

Salvador Palomo, Pedro J.

2003 La planificación verde en las ciudades.

Gustavo Gili. Barcelona, España.

Sámano Bueno, Pablo

2006 «Algunas precisiones en torno al estándar de densidad máxima. En particular, su relación con los sistemas generales»

Revista de Derecho Urbanístico, no 224. Madrid, España.

Saravia Madrigal, Manuel

200245 años de estándares urbanísticos en España (1956-2001).

Informe para el seminario internacional Welfare urbano e standard urbanisciti. Roma, Italia. 


\title{
Los límites territoriales del consumo urbano de agua en la Comunidad de Madrid $^{1}$
}

\author{
Jaime J. Benlliure Conover \\ Madrid (España), 2003-2004.
}

Introducción

$\begin{array}{lr}\text { Marco teórico y metodológico } & 181\end{array}$

La evaluación de los límites . . . . . . . . . . . . . . . . . . . . . . . . . . . . 183

Los límites de los sumideros . . . . . . . . . . . . . . . . . . . . . . . . . . . . . . . 184

Introducción al medio físico de la Comunidad de Madrid a través del ciclo del agua 184

Ubicación . . . . . . . . . . . . . . . . . . . . . . . . . . . . . . . . . . . . . . . 184

Descripción del ciclo hidrológico en la Comunidad de Madrid . . . . . . . . . . . . . . . . . . 185

Disponibilidad total del recurso . . . . . . . . . . . . . . . . . . . . . . . . . . . . . 190

Resumen de la evolución histórica de los límites territoriales del abastecimiento de agua de la ciudad de Madrid

La situación actual: el sobrepasamiento

Marco jurídico y concesional para el abastecimiento y la depuración de aguas en la Comunidad de Madrid197 Análisis del consumo actual de agua en la Comunidad de Madrid . . . . . . . . . . . . . . . . . . . . 204

Los límites de las fuentes actuales: Las infraestructuras de abastecimiento . . . . . . . . . . . . . . . 215

Los límites de los sumideros: la depuración de agua en la Comunidad de Madrid . . . . . . . . . . . 221

$\begin{array}{lr}\text { Conclusiones } & 226\end{array}$

Sobre los límites geográficos . . . . . . . . . . . . . . . . . . . . . . . . . . . . 226

Sobre la incidencia del consumo de agua en el territorio . . . . . . . . . . . . . . . . . . 227

Sobre los límites del consumo . . . . . . . . . . . . . . . . . . . . . . . . . . . . . 227

Sobre los límites de los sumideros y la depuración de aguas residuales . . . . . . . . . . . . . . . . 229

Sobre urbanismo y gestión sostenible del agua . . . . . . . . . . . . . . . . . . . . . . . . . 229

$\begin{array}{lr}\text { Bibliografía } & 230\end{array}$

Anejos
$\mathbf{2 3 5}$

Anejo 1: El consumo de agua en algunas grandes ciudades . . . . . . . . . . . . . . . . . . 235

Anejo 2: Relación precio-consumo del agua por Comunidades Autónomas . . . . . . . . . . . . . 235

\section{Introducción}

Fui sobre agua edificada, mis muros de fuego son.

Cualquier visitante que llegase hoy a Madrid encontraría difícil comprender el significado de esta frase que supuestamente proviene del primer emblema heráldico que tuvo la ciudad. La presencia de agua en la región, que originalmente parece haber cautivado a los fundadores y habitantes primigenios de la ciudad, hoy ha desaparecido bajo la superficie de la urbanización. Su llegada cotidiana a nuestras casas es un hecho al que damos poca importancia y que parece limitarse al breve recorrido entre el grifo y el desagüe, punto de inflexión en el que el 'líquido vital' pasa de ser un recurso a convertirse en un residuo.

Es de sobra conocida la importancia que la presencia de cuerpos superficiales de agua tuvo para la consolidación de los primeros asentamientos humanos y el desarrollo de las civilizaciones. Sin embargo, actualmente el desarrollo tecnológico ha permitido que los distintos sectores encargados de satisfacer los consumos de recursos en las ciudades sobrepasen las barreras de los territorios inmediatos, y que incluso busquen nuevas fuentes más allá de sus fronteras regionales, nacionales o continentales.

\footnotetext{
${ }^{1}$ El presente trabajo es resultado de un Trabajo de Investigación Tutelada dirigido por el profesor Agustín HeRnÁNDEZ AJA dentro del programa de doctorado Periferias, Sostenibilidad y Vitalidad Urbana impartido por el Departamento de Urbanística y Ordenación del Territorio de la Universidad Politécnica de Madrid durante el curso 2003-2004.
} 
La ciudad de Madrid, como todavía algunas en el mundo, presenta la singularidad de abastecerse de agua a partir de las fuentes existentes en su región inmediata, aunque la necesidad siempre creciente de más cantidad del recurso se ha reflejado en el paisaje y en la organización del territorio, principalmente debido a la construcción de embalses y a la alteración del régimen y calidad natural de los caudales de los ríos, arroyos y acuíferos subterráneos.

Con base en lo anterior, la relación entre la ciudad y su territorio, no como objeto y fondo sino como elementos interdependientes y mezclados, ejemplificada en la gestión del consumo urbano de agua, representa para este trabajo de investigación primerizo su tema de estudio general y abstracto. Para poder convertirse en un objeto definido y hasta cierto punto mesurable y cuantificable se utilizará el concepto de límites, aprovechando de igual manera su significado tanto de borde o frontera geográfica como el que se refiere a la finita cantidad de algún elemento o recurso, en este caso el agua. A pesar de guardar ciertas semejanzas y referencias metodológicas, se ha preferido prescindir, tanto en el título del trabajo como en su desarrollo, de los conceptos de impacto ambiental o huella ecológica. Del primero porque esta investigación no tiene la intención de establecer relaciones de causalidad entre las acciones humanas y el orden biológico al que afectan, ni prever los efectos que estas tendrán en algún lapso determinado de tiempo. Del segundo, a pesar de ser el más afín por buscar relacionar las actividades humanas con su sustento natural, porque la huella ecológica se ha establecido como una metodología muy específica que pretende cuantificar en unidades de superficie los efectos de los hábitos de consumo humano, pero sin hacer referencia directa a las condiciones específicas del territorio donde se realizan.

Límite (Del lat. limes, -itis):

1. m. Línea real o imaginaria que separa dos terrenos, dos países, dos territorios.

2. m. Fin, término. Usado en aposición en casos como dimensiones límite, situación límite.

3. m. Extremo a que llega un determinado tiempo. El límite de este plazo es inamovible.

4. m. Extremo que pueden alcanzar lo físico y lo anímico. Llegó al límite de sus fuerzas.

RAE, 2001

A partir de la idea de límite y su relación con el consumo de recursos y el territorio las preguntas fundamentales que se plantea la investigación son:

- ¿Cuáles son los recursos hídricos disponibles en Madrid?

- ¿Cuánto se consume actualmente?

- ¿Hasta dónde ha crecido la influencia de la ciudad en el territorio debida a las necesidades de agua?

- ¿Es posible el abastecimiento de la ciudad con los recursos disponibles en su propia región?

Para describir la interrelación entre ciudad y territorio a través de los límites geográficos y cuantitativos del consumo de agua este trabajo se divide en cuatro capítulos. En el primero se aborda el marco teórico básico que estructurará el resto de la investigación. Se toma como referencia la revisión realizada en 1991 al informe Los límites del crecimiento, planteado originalmente por el Club de Roma con el fin de entender y prever los efectos que la espiral de crecimiento poblacional y de consumo había tenido sobre el medio ambiente. También se revisan algunas publicaciones realizadas por José MANuEL NAREDO acerca de nuevas visiones de la economía que consideran los costes ambientales del sistema de producción actual dentro del orden abastecimiento-consumo. Finalmente, en este capítulo se plantean las líneas metodológicas generales del trabajo. En el segundo capítulo se analiza el medio físico de la Comunidad de Madrid a partir de su estructura y funcionalidad hidrológica, sin hacer aún referencia directa a las alteraciones producidas en el mismo por las actividades humanas, con el fin de hacer una aproximación a la disponibilidad total de agua en la región. En el tercer capítulo se describe la expansión regional que ha sufrido históricamente el área de influencia de los distintos sistemas de abastecimiento de Madrid en relación al modelo de desarrollo de la ciudad y a la evolución de sus necesidades de agua. En el cuarto capítulo se analiza la situación actual del consumo de agua en la Comunidad de Madrid y sus distintos condicionantes, como son el marco jurídico de la gestión del recurso, la demanda por sectores y sus posibles interrelaciones con el modelo de desarrollo actual, el estado de las fuentes y las infraestructuras para su explotación, así como las consecuencias del consumo y los esfuerzos realizados para paliarlas mediante infraestructuras de depuración. Finalmente, se incluyen las conclusiones del trabajo y un anexo con una breve reseña de los sistemas de abastecimiento de algunas de las mayores ciudades del mundo, como simple punto de comparación sobre la influencia territorial de las mismas. 


\section{Marco teórico y metodológico}

El desarrollo sostenible es el desarrollo que satisface las necesidades de la generación presente sin comprometer la capacidad de las generaciones futuras para satisfacer sus propias necesidades.

Comisión Mundial del Medio Ambiente y Desarrollo, 1987

El informe Nuestro futuro común de Naciones Unidas plantea en esta conocida frase dos conceptos fundamentales: la satisfacción de las necesidades y las limitaciones que estas sufren debido al estado de la tecnología, la organización social y la capacidad del medio ambiente.

El mantenimiento de la calidad y cantidad de los recursos naturales implica someter su explotación y consumo a límites que garanticen su correcta renovación y su asimilación al medio natural, una vez aprovechados. En el caso de los no renovables, su explotación deberá compensarse con la búsqueda e implementación de sustitutos renovables.

El enfoque de la economía clásica, regida únicamente por la noción de producción-oferta-consumo, ha mantenido fuera de sus consideraciones desarrollistas los impactos ambientales que producen la sustracción de materias primas y la tecnología utilizada para dicho fin, así como el daño ecológico de la producción de residuos (NAREDO, 1999).

Un modelo de desarrollo económico que no necesariamente implique crecimiento y que contribuya a no comprometer la disponibilidad futura de recursos debe considerar dentro del proceso total de producción los costes ambientales de extracción con reposición y desecho-reutilización-reciclaje-vertido al medio natural.

A partir de esta concepción, los límites no son solamente el volumen de un stock, sino que son también una tasa de reposición que implica un factor calidad y un factor tiempo, así como una tasa de vertido que pueda ser asimilada por el medio natural sin resultar perjudicado.

De ahí que la noción de límite se base en dos conceptos fundamentales que amplían el ciclo extracciónproducción-consumo, que son las fuentes y los sumideros (MEADows, 1993). Las fuentes son los puntos de origen de los flujos de materiales y(/o) energía utilizados en un sistema (de producción, de abastecimiento, etc.). Los sumideros son los puntos de destino último de los materiales y/o energía utilizada en dicho sistema.

Los límites del crecimiento son los límites de la habilidad de las fuentes planetarias para proveer ese flujo de materiales y energía, y los límites de los sumideros planetarios para absorber la contaminación y los residuos.

Meadows, 1993

Aunque cada sistema requiere un nivel de especificidad singular, el impacto producido por el flujo de fuentes a sumideros será proporcional a tres variables fundamentales: la población, la afluencia y la tecnología. Lógicamente, la necesidad de recursos y la producción de residuos son proporcionales al tamaño de las poblaciones, aunque es importante destacar la afluencia de materiales y energía, ya que los habitantes de distintas sociedades no tienen las mismas tasas de consumo y desecho. También son diferentes las alternativas tecnológicas utilizadas en el sistema de producción, de cuya eficiencia dependerá un mayor o menor impacto sobre el medio natural, así como un mejor aprovechamiento de los recursos que obtenga mayores rendimientos a partir de menores insumos.

Rebasar los límites de un sistema provoca una situación de sobrepasamiento. Esta condición suele ser el resultado de ignorar la existencia o magnitud de los límites en sus fuentes y/o sumideros. Puede producirse también por eventos coyunturales en los que no existe una debida capacidad de respuesta, o por inercias en las que no se produce una correcta retroalimentación de información (MEADOws, 1993).

La condición óptima para lograr un desarrollo que garantice la preservación de los recursos consiste en que los extremos del flujo (fuentes y sumideros) se acerquen lo más posible, es decir, que los desechos sirvan para generar más recursos que a su vez permitan disminuir la tasa de explotación de materias primas. Aunque el cierre total y perfecto del ciclo de los materiales resulta casi imposible en la práctica, como explica la tercera ley de la termodinámica (entropía), la alternativa más cercana para evitar el sobrepasamiento de los límites de las fuentes y de los sumideros implica el reciclaje y la reutilización de los recursos, basado en la eficiencia de los procesos de producción y en el conocimiento de los stocks naturales y del impacto de las actividades humanas sobre estos (NAREDO, 1999).

Buscar el agua cada vez más lejos, cada vez más profunda, sin sanear la que está debajo de nuestra propia casa, supone sólo trasladar el problema de una parte a otra del territorio y retardar la necesidad de afrontar la causa y no sólo los efectos de su degradación y de la conflictividad entre los usuarios de este recurso. 
A partir del enfoque eco-integrador de la economía, que concilia las nociones de desarrollo con la durabilidad cualitativa y cuantitativa de los recursos naturales, se deriva una visión consecuente del ciclo hidrológico: de la tradicional visión mecánica ordinaria del ciclo del agua a la concepción de este como un proceso abierto de energía y de desarrollo entrópico que cambia constantemente sus condiciones de calidad y cantidad (NAREDO, 1996).

La gestión del ciclo del agua ha sido tradicionalmente concebida como el esfuerzo de aportar la cantidad de agua suficiente y de calidad necesaria a un precio accesible para las crecientes demandas de los asentamientos humanos y sus núcleos de producción, y ha tenido como centro gravitacional la construcción y gestión de infraestructuras para el mantenimiento de los caudales, sin reparar demasiado en los efectos producidos en las fuentes y en los sumideros.

La aplicación del concepto de límites a la intervención humana en el ciclo del agua implica entender este fenómeno natural como un proceso abierto de energía y desequilibrado en cuanto a calidad y cantidad (NAREDo, 1996). A nivel global, las aguas continentales tienen su fuente en las precipitaciones pluviales producidas sobre todo en tierras altas, donde se originan las escorrentías superficiales y subterráneas, y tienen su sumidero último en el mar. Este ciclo-sistema se desarrolla gracias a la gravedad que mueve el agua de las cotas altas hacia la cota cero (el mar), y se recicla constantemente mediante la acción de la energía solar que evapora parte del agua de los sumideros hacia la atmósfera para que posteriormente se precipite de nuevo y así renovar continuamente la fuente del sistema.

Durante su tránsito de las fuentes a los sumideros, el camino del agua está sujeto a pérdidas constantes de cantidad y de calidad, es decir, que es un proceso entrópico. A las pérdidas de cantidad naturales producidas por la evapotranspiración de las especies vegetales, el consumo animal, la filtración al subsuelo, el estancamiento en cuerpos lacustres, la actividad antrópica añade la sustracción para consumo humano y actividades productivas como la agricultura y la industria.

La consecuencia fundamental de la pérdida de cantidad en este ciclo es la escasez. Ésta puede ser producida por los fenómenos meteorológicos y condiciones climáticas específicas de cada región (escasez física), pero también puede ser producida por los hábitos de la población consumidora, los sistemas de producción locales o la gestión de los organismos responsables (NAREDO, 1996).

La pérdida de calidad natural de un río es producida por el arrastre en las corrientes de organismos en descomposición y sales y minerales existentes en la composición geológica de los cauces; sin embargo, la velocidad (que puede variar entre 0,5 a $3 \mathrm{~m} / \mathrm{s}$ ) y el volumen del caudal evitan que estos residuos se conviertan en poblaciones. La pendiente del terreno por la que discurre el cauce determinará la velocidad del fluido, y de esta dependerá la temperatura del agua y el volumen de los materiales que suelen encontrarse en el caudal. Es por eso que en zonas montañosas donde el caudal corre más rápido el agua suele ser de mayor calidad, mientras que en zonas más bajas, de flujo más lento y de mayor temperatura, es donde se desarrolla gran parte de la diversidad de especies animales y vegetales (MARGALEF, 1992).

CuAdro 1: Tiempos de renovación de una partícula de agua Fuente: R. MARGALEF, 1992.

\begin{tabular}{|l|l|}
\hline En la atmósfera & 9 a 10 días \\
\hline En un río & 12 a 20 días \\
\hline En un lago de agua dulce & 1 a 100 años \\
\hline En un acuífero subterráneo & 300 años \\
\hline En el Océano & 3.000 años \\
\hline
\end{tabular}

Este proceso natural de pérdida de calidad se complementa por la acción del ser humano al verter grandes cantidades de desechos orgánicos e inorgánicos producidos en los núcleos de población, así como por los vertidos químicos de la industria. La incorporación de volúmenes elevados de materia orgánica a los caudales fomenta la reproducción de bacterias, lo que requiere la aportación de una cantidad proporcional de oxígeno para que los microorganismos que habitan en el cauce puedan asimilarlas - es por esto que los niveles de calidad se midan en Demanda Biológica de Oxígeno (DBO). Cuando se sobrepasa esta capacidad de autodepuración, el caudal se vuelve turbio y maloliente y no apto para el desarrollo de especies piscícolas. En un tramo de río con una DBO de 1 a 3 existen menos de cien mil bacterias por $\mathrm{cm}^{3}$; en uno de 3,5 a 12 se encuentran de cien mil a un millón y en un tramo de DBO de 15 a 100 habrá más de dos millones. 
Pero la complejidad del ciclo del agua implica que sus condiciones cualitativas no se límiten simplemente al recurso mismo, sino que mantienen una estrecha relación con los sistemas que soporta y con la calidad de su entorno físico. El mantenimiento de la calidad del agua, entendida desde el punto de vista del consumo humano, requiere a su vez el mantenimiento de la calidad del suelo por el que discurre, así como la subsistencia de numerosos ecosistemas depende de la preservación del régimen natural de calidad y cantidad de las escorrentías.

El enfoque eco-integrador de la gestión del agua implica la distinción entre dos aspectos cualitativos del agua: por un lado, la calidad que debe tener al salir por el grifo, necesaria para el consumo humano sin riesgo para la salud, y por otro lado, la calidad ecológica que permita el mantenimiento de los ecosistemas que dependen directamente de las aguas continentales (GASCO Y SAA, 1996).

La evaluación de los límites del sistema de abastecimiento y depuración de aguas de la ciudad debe considerar la repercusión territorial de la sustracción de caudales y vertido de residuos.

\section{La evaluación de los límites}

Para la realización de este trabajo se ha elegido el concepto de límite expresamente para aprovechar la ambigüedad del mismo. Por un lado, un límite puede referirse al final de una cosa y al principio de otra, semejante a una frontera o a un borde, lo que sugiere que el límite puede tener un contenido geográfico cuantificable en coordenadas de latitud, longitud, altitud, metros lineales o metros cuadrados, y que puede ser cartografiado.

Por otro lado, un límite también hace referencia a aspectos cuantitativos, a recursos existentes que son finitos. Un recurso limitado puede ser semejante a uno escaso, es decir, del que existe sólo cierta cantidad que puede ser aprovechada, y en ciertos casos, cuantificada.

Partiendo de la importancia que tiene el recurso agua tanto para la estructuración natural del territorio como para el consumo humano y el crecimiento de la ciudad, se plantea el concepto de límite para establecer una relación entre ambos aspectos: el geográfico y el cuantitativo.

Los límites geográficos del abastecimiento y depuración del agua se dividen en dos aspectos fundamentales, que implican por un lado el límite de la cuenca que abastece de manera natural a la región de la ciudad, y por el otro la extensión del área de influencia de la ciudad provocada por sus infraestructuras de captación y conducción.

Los límites geográficos de la cuenca natural de abastecimiento de la ciudad están condicionados básicamente por sus características climáticas, topográficas e hidrográficas. El clima de la cuenca, marcado por el índice de precipitaciones, evapotranspiración y temperaturas condiciona la cantidad de agua que a partir de las características locales del ciclo hidrológico logrará incorporarse a las escorrentías superficiales y subterráneas que posteriormente se podrán explotar para el consumo humano. Sin embargo, la utilización sostenible de estos recursos a su vez está condicionada por el mantenimiento indispensable de los caudales suficientes para el soporte de los ecosistemas ligados a ellos.

La topografía es la encargada de conducir el agua a través del territorio, desde las cotas más elevadas hasta el nivel cero correspondiente al mar. En una situación óptima, la acción de la gravedad permite la captación y la conducción del agua hacia los puntos de consumo. Sin embargo, una vez rebasados los límites de la cuenca natural de abastecimiento, es necesaria la introducción de sistemas tecnológicos que permitan elevar y conducir el agua desde otras cuencas, lo que implicará un consumo energético generalmente basado en el consumo de combustibles no renovables y su consecuente emisión de contaminantes a la atmósfera.

Los límites geográficos de las infraestructuras de la ciudad, a diferencia de la cuenca natural, no suponen un límite fijo e implícito en el territorio, sino que, por el contrario, están sujetos a las necesidades de crecimiento de la urbe y pueden transformarse, generalmente de manera expansiva, en el transcurso de unos pocos años. El límite, en este sentido, está marcado por la posición geográfica de las infraestructuras de captación y regulación, como pueden ser los embalses y azudes, y por la cantidad de kilómetros de conducciones que surcan el territorio.

En lo que se refiere al área de influencia de los vertidos de la ciudad, el límite no se puede cuantificar por la posición de sus infraestructuras (en este caso, las depuradoras y los focos de contaminación) sino por la extensión de sus efectos a lo largo de los cauces de los ríos utilizados como sumideros.

Los límites cuantitativos de las fuentes se refieren al conocimiento del stock de los recursos: la cantidad de agua existente en la región que es susceptible de ser aprovechada para el consumo humano, considerando el mantenimiento de los caudales necesarios para la subsistencia de los ecosistemas ligados a las aguas superficiales y subterráneas, así como la inestabilidad debida a elementos climáticos y meteorológicos.

Los límites cuantitativos de las fuentes están condicionados tanto por la disponibilidad del recurso en la región como por la capacidad técnica de aprovecharlo de forma eficiente mediante las infraestructuras existentes y su gestión adecuada. Cabe destacar la importancia de las tendencias de consumo del recurso 
que finalmente son las responsables de acercar o sobrepasar las necesidades humanas a la capacidad del territorio.

El aprovechamiento humano también está marcado por límites concesionales, que son los marcados dentro del marco legal de la administración de los recursos hídricos y que impiden la explotación de fuentes más lejanas supraregionales, de las que se podrían importar mayores caudales con el consiguiente gasto económico y energético.

\section{Los límites de los sumideros}

Los cauces fluviales naturales tienen una capacidad limitada para asimilar los vertidos de materia orgánica. El exceso de desechos provoca que la población de microorganismos y bacterias requiera una cantidad muy elevada de oxígeno para poder procesarlos (DBO). El sobrepasamiento de la capacidad de asimilación de estos microorganismos produce la muerte biológica de los ríos y los transforma en nada más que cloacas superficiales.

La depuración responsable de devolver al agua la calidad suficiente para poder ser reincorporada al ciclo natural sin riesgos de contaminación implica, en proporción directa al volumen consumido que requiere ser depurado, construir las infraestructuras suficientes y aportar la energía necesaria para hacerlas funcionar de manera eficiente.

\section{Introducción al medio físico de la Comunidad de Madrid a través del ciclo del agua}

El abastecimiento actual de agua en la Comunidad de Madrid se encuentra condicionado por las características físicas de la región, tanto por la disponibilidad de agua a consecuencia de sus condiciones climáticas, como por la topografía y la conformación del subsuelo que alberga una parte importante de este recurso. Por eso se considera importante, como un primer paso obligado, la aproximación al conocimiento del funcionamiento de este territorio desde el punto de vista del ciclo hidrológico.

\section{Ubicación}

La Comunidad de Madrid se ubica prácticamente en el centro de la península Ibérica. Está delimitada por las provincias de Ávila, Segovia, Guadalajara, Cuenca y Toledo. Su forma asemeja a la de un triángulo equilátero, en cuyo lado noroeste se encuentra parte de la vertiente suroeste de la cordillera central. Este es también el límite entre las cuencas del Tajo y del Duero. En la mitad sureste de la base de dicho triángulo discurre parte del río Tajo, formando así el apéndice que envuelve al Real Sitio de Aranjuez.

A partir de la Ley de Aguas de 1985, para la gestión de las aguas continentales el territorio español se divide en ocho cuencas hidrográficas: del río Duero, del río Ebro, del río Guadalquivir, del río Guadiana, del río Júcar, del río Segura, del Sur y del río Tajo. Cada cuenca está definida por el territorio de captación y flujo hacia el mar de un cauce principal único alimentado por varios cauces secundarios.

A partir del criterio anterior, la Comunidad de Madrid se sitúa íntegramente en la cuenca del Tajo, junto con parte de Aragón, Castilla La Mancha, Castilla León y Extremadura; dentro de ella se incluyen cuatro capitales provinciales: Madrid, Toledo, Guadalajara y Cáceres. Esta cuenca se caracteriza por ser la más larga de España, la que incluye a mayor población y la tercera en superficie total, después de las del Ebro y el Duero. Otra característica importante es su carácter internacional al estar compartida con Portugal y desembocar finalmente en el Océano Atlántico.

Estos son algunos datos importantes de la cuenca del Tajo en su tramo español:

- Superficie: $55.810 \mathrm{~km}^{2}$ (11,02\% del territorio español).

- Población: 6,094 millones de habitantes (15,53\% del total de España).

- Precipitación Media: 655 mm (95,76\% en relación a la media española).

- Recursos hidráulicos régimen natural: $12.230 \mathrm{hm}^{3}$ (10,75\% del total nacional).

- Aportación específica: 0,219 $\mathrm{hm}^{3} / \mathrm{Km}^{2}$ (97,33\% en relación a la media española).

- Capacidad de embalse: $12.000 \mathrm{hm}^{3}$ (21,40\% del total nacional).

- Escorrentía subterránea: $1.565 \mathrm{hm}^{3}$ (7,49\% del total nacional).

- Reservas subterráneas: $4.700 \mathrm{hm}^{3}$ (2,61\% del total nacional). 


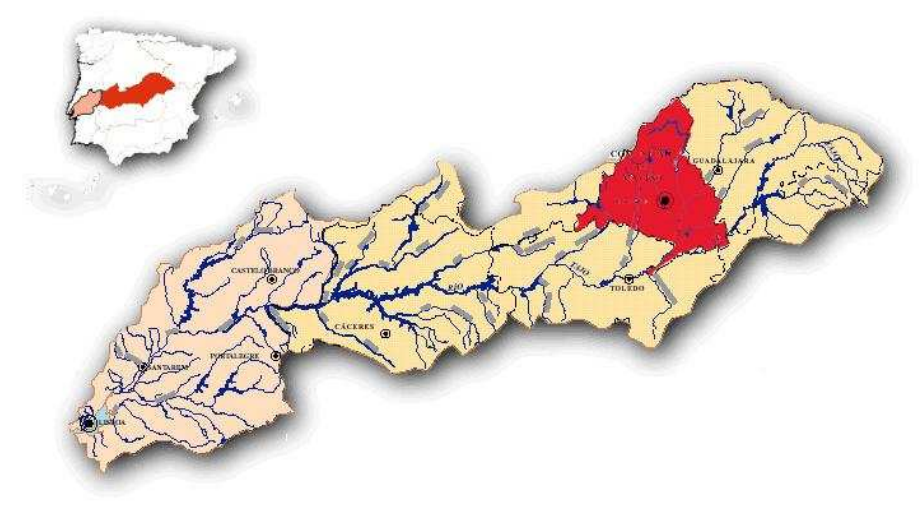

Figura 1: Ubicación de la cuenca hidrográfica del Tajo, y de la Comunidad de Madrid dentro de la misma

Fuente: Confederación Hidrográfica del TAJo.

Con el objeto de inventariar los recursos naturales de la Cuenca del Tajo, se ha dividido en catorce zonas a lo largo de su recorrido, siendo la primera la denominada Cabecera del Tajo y la última la de Salor, que incluye su entrada a Portugal. El territorio madrileño comprende parte de la cuarta zona (que corresponde al río Henares hasta su confluencia con el Jarama), la zona cinco por completo (que corresponde a las cuencas de los ríos Jarama y Manzanares), la zona seis (que corresponde al Guadarrama) y parte de la siete (la del Alberche).

Dentro de estas zonas, con el fin de la asignación de recursos, el Plan Hidrológico de la Cuenca del Tajo establece tres sistemas de abastecimiento: el del Henares, que incluye las ciudades de Guadalajara y Alcalá de Henares, el del Alberche y el del sistema Jarama-Guadarrama, responsable del abastecimiento de la ciudad de Madrid.

\section{Descripción del ciclo hidrológico en la Comunidad de Madrid}

\section{Zonas de captación: la sierra norte de Madrid}

La Cordillera Central, que se alinea en dirección noreste-suroeste, además de ser el límite de la región, es también el límite norte de la cabecera de la cuenca hidrográfica del río Tajo, y funciona como 'parte aguas' entre la cuenca de este y la del río Duero. Su punto más alto dentro de la Comunidad de Madrid es Peñalara, a 2.429 metros de altitud, casi dos mil por encima del punto más bajo situado en la confluencia del Tajo y el Algodor, a 465 metros.

La sierra madrileña es en realidad parte de tres sistemas montañosos que componen el Sistema Central peninsular. El núcleo central y de mayor relevancia topográfica es el correspondiente a la sierra de Guadarrama, que a su vez se divide en tres subsectores: el oriental, entre los puertos de Navafría y Navacerrada, contiene al valle del Lozoya entre las alineaciones de Cuerda Larga y de los Montes Carpetanos y es también donde se ubica el pico de Peñalara; el sector central va del puerto de Navacerrada al del León, contiene también varias cimas de entre 1.900 y 2.200 metros de altitud y sus alineaciones forman los valles de la Acebeda, Moros, Eresma y el Guadarrama; por último, el sector occidental, más bajo que los dos anteriores, termina en la garganta del río Cofio y contiene las planicies de Villalba y El Escorial.

El siguiente subsistema de la sierra madrileña son las Sierras Occidentales. Se ubica al suroeste de la Sierra del Guadarrama y actúa como articulación entre ésta y la Sierra de Gredos. El último conjunto montañoso es el de Somosierra y la Sierra de Ayllón, que se ubican al noreste de la sierra de Guadarrama y mantienen cierta continuidad con su línea de cumbres, aunque disminuye en altura.

Todos estos sistemas serranos se unen hacia la parte baja de su ladera sur en una extensa plataforma conocida como Piedemonte o Zócalo serrano. Tiene una altitud media de 1.000 metros que decrece hacia el suroeste. En esta zona destacan algunos relieves como las sierras de Hoyo, La Cabrera y el Cerro de San Pedro, y también algunas fosas como las de Guadalix y Santillana.

La Sierra es el principal punto de captación de agua de la región, ya que los sistemas montañosos suelen producir la condensación de la humedad atmosférica. Su orientación permite la entrada de flujos de viento sur orientales y bloquea los noroccidentales, lo que provoca que el clima de la región sea de carácter mediterráneo con fuertes episodios de calor y sequía durante el verano. 


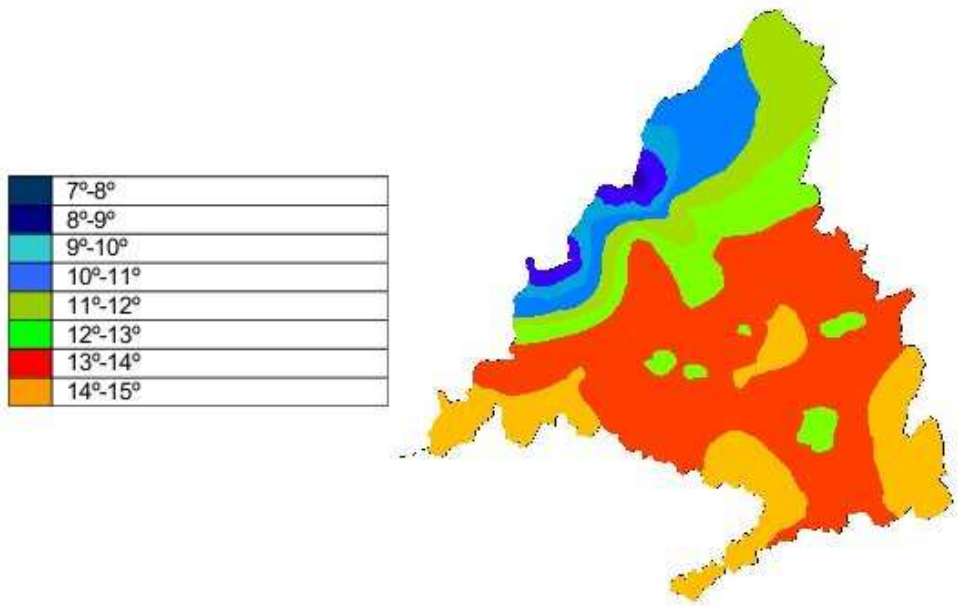

FigurA 2: Temperaturas medias anuales

Fuente: Elaboración propia a partir de Atlas de la Comunidad de Madrid.

El gradiente de temperatura se desarrolla de manera perpendicular a la dirección de la sierra, encontrando las temperaturas más bajas en la zona de montaña, que oscilan entre algunos grados bajo cero en invierno y los $14^{\circ} \mathrm{C}$ en verano, con una media cercana a los $8^{\circ} \mathrm{C}$. Hacia el sureste, en la Depresión del Tajo, la temperatura puede variar de invierno a verano de 5 a $24^{\circ} \mathrm{C}$, con una media de $14^{\circ} \mathrm{C}$.

Mientras que la lluvia media anual en la zona central de la Comunidad se encuentra en torno a los $600 \mathrm{~mm}$, en la sierra alcanza los $1.100 \mathrm{~mm}$, en el puerto de Navacerrada. En la mayor parte de la región, a excepción de puntos específicos como el de Navacerrada, la evapotranspiración potencial supera la precipitación. Los observatorios ubicados al pie de la sierra muestran un déficit de $100 \mathrm{~mm}$, superándose los $300 \mathrm{~mm}$ en el resto de la planicie y siendo el mes de julio el más deficitario. Esto quiere decir que la mayor parte del agua de las precipitaciones se emplea en funciones de evapotranspiración y de acumulación de reservas y sólo una parte mínima se incorpora a las escorrentías. La mayor saturación de la reserva útil de agua se produce en octubre y comienza a perderse entre abril y mayo, agotándose entre junio y julio, cuando la pluviometría registra valores mínimos.

\begin{tabular}{|l|l|}
\hline $1000-2000$ \\
\hline $900-1000$ \\
\hline $800-900$ \\
\hline $700-800$ \\
\hline $600-700$ \\
\hline $500-600$ \\
\hline $450-500$ \\
\hline $400-450$ \\
\hline $300-400$ \\
\hline
\end{tabular}

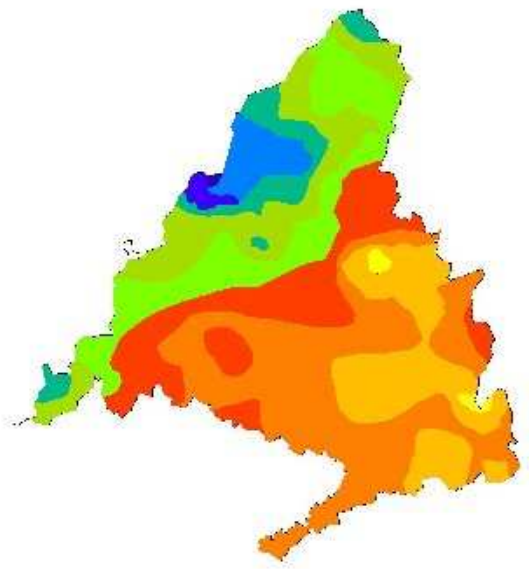

Figura 3: Precipitación media.

Fuente: Elaboración propia a partir de Atlas de la Comunidad de Madrid.

Debido a su alto valor de precipitaciones pluviales con respecto al resto de la región y su situación elevada y escarpada, es en la zona serrana donde nacen la mayoría de los ríos que discurren por suelo 


\begin{tabular}{|l|l|}
\hline & menor de 550 \\
\hline $550-600$ \\
\hline $600-650$ \\
\hline $650-700$ \\
\hline $700-750$ \\
\hline mayor de 750 \\
\hline
\end{tabular}

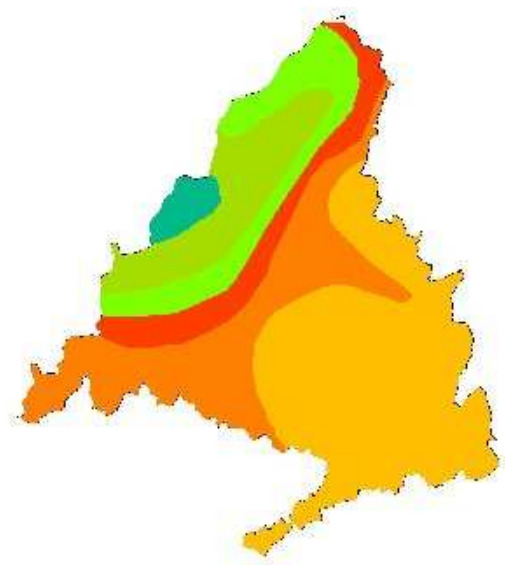

FigurA 4: Evapotranspiración potencial (mm. anuales)

Fuente: Elaboración propia a partir de Atlas de la Comunidad de Madrid.

madrileño. Durante el invierno, gran parte de estas precipitaciones se produce en forma de nieve, actuando como una reserva natural de agua que se almacena durante el invierno y fluye en el verano, lo que ayuda a mantener durante todo el año la regulación natural de los ríos serranos, siendo febrero y marzo los meses de mayor escorrentía debido al deshielo.

El paisaje serrano está constituido por bloques fracturados de macizos graníticos encajados en un conjunto de materiales geológicos afines al Paleozoico (pizarras y cuarcitas). Este contorno duro y accidentado de picos, alineaciones, fosas tectónicas y bloques basales, y de escasa permeabilidad, permite la acumulación de agua en pequeñas fosas interiores y, con ayuda de la gravedad, su posterior circulación superficial hacia el sur hacia tierras más bajas.

La sierra constituye sin duda uno de los parajes de mayor riqueza natural de la región, gracias a su abundante vegetación arbórea constituida por formaciones de pinares, robledales, encinares y enebrales. La difícil accesibilidad de sus cumbres ha permitido el mantenimiento de su fauna y vegetación original casi intacta. Por encima de los 1.900 metros se encuentran sobre todo pastizales y matorrales. Por debajo de este nivel las laderas están recubiertas de pinares de pino silvestre, especialmente en los valles del Lozoya, Fuenfría, Siete Picos y Malagón. En las zonas de mayor precipitación destaca la presencia de robledales agrupados entre los pinares. También se encuentran zonas de hayas y abedules provenientes del sistema ibérico. En el piedemonte, los antiguos encinares actualmente se alternan con tomillares, jarales, romerales y superficies de secano y pastizal para el ganado. La presencia de la vegetación es causa y también consecuencia de un mayor porcentaje de humedad relativa y un menor grado de evaporación en comparación con las tierras más bajas.

La parte baja de la región madrileña se conoce como la Cuenca o la Llanura y tiene como altitud media los 650 metros, en ella se sitúa la ciudad de Madrid. Está formada por varias lomas y campiñas relativamente homogéneas y horizontales, surcadas por una intrincada red de arroyos, algunos de los cuales han desaparecido bajo las redes de infraestructuras urbanas. Estas características topográficas se rompen hacia la confluencia de los ríos Jarama y Henares, donde la erosión provocada por el agua ha generado algunas escarpaduras y barrancos de hasta 150 metros de profundidad. Finalmente, al sureste de la región se encuentra la zona de páramos, de paisaje relativamente árido y desolado en comparación con el resto de la región, cuyos casi únicos grupos de vegetación verde y frondosa se ubican en las vegas lineales de los ríos.

En la cuenca predominan las grandes superficies de secanos, solamente interrumpidas por los encinares de Viñuelas y el Pardo. Esta última zona alberga diversas especies de aves rapaces nidificantes. En la confluencia de los ríos Manzanares y Jarama existen también importantes comunidades de aves características de zonas húmedas.

\section{Ríos}

La sierra norte de Madrid es el lugar de origen de la mayor parte de las escorrentías de agua, superficiales y subterráneas, que atraviesan la región de norte a sur. Es en esta zona donde nacen los principales 
ríos que abastecen e irrigan el resto de la comunidad, formando un intrincado sistema hídrico de forma semejante a la hoja de un árbol, conformando tres subcuencas principales que abastecen al Tajo: la del Jarama al este y al centro, la del Guadarrama al centro-oeste y la del Alberche en el extremo oeste.

\section{Cuenca del río Jarama}

- El Jarama fluye de norte a sur y se ubica al este de la Comunidad. Es el río más caudaloso de la región y nace en Peña Cebollera. Sus superficies de vertiente y aportación son mayores que las del Tajo en el punto de encuentro de los dos ríos, ya que tras haber recorrido 161 kilómetros recibe las aguas del Lozoya, el Guadalix, el Manzanares (estos tres de origen en la misma provincia), el Henares y el Tajuña (que tienen su origen en la provincia de Guadalajara).

- El Lozoya recorre 74 kilómetros desde su nacimiento en la confluencia de los arroyos Cerradillas y Guarramillas, hasta desembocar en el Jarama cerca del embalse de Valdentales. Este río ha sido históricamente la fuente más importante de agua potable para el abastecimiento de la ciudad de Madrid. A lo largo de su cauce se encuentran los embalses de Pinilla, Riosequillo, Puentes Viejas, el Villar y el Atazar.

- El Guadalix se extiende a lo largo de 33 kilómetros de la Comunidad de Madrid, desde la Morcuera hasta el Jarama, a la altura del circuito del mismo nombre.

- El Henares nace en la provincia de Guadalajara y entra a la Comunidad de Madrid por los Santos de Humosa. A lo largo de sus 36 kilómetros de recorrido madrileño pasa por las ciudades de Alcalá de Henares y Torrejón de Ardóz, hasta desembocar en el Jarama a la altura de Mejorada del Campo.

- El Manzanares tiene un recorrido norte-sur de 92 kilómetros de longitud que discurren íntegramente dentro de la Comunidad de Madrid. Sin duda es de los ríos más emblemáticos de la región, ya que limitaba y ahora atraviesa el centro de la capital, pasando por varios sitios simbólicos madrileños, como Manzanares el Real o El Pardo. Nace en la ladera meridional de la Sierra de la Cuerda Larga, cerca de la formación geológica conocida como la Bola del Mundo, y desemboca en el Jarama cerca de la Presa del Rey, al sureste del área metropolitana.

- El Tajuña nace en la provincia de Guadalajara y entra en la Comunidad por Pezuela de las Torres; vuelve a dejar Madrid tras un corto recorrido en el que sirve como límite entre las dos provincias, hasta reingresar definitivamente en las cercanías de Ambite y finalmente desembocar en el Jarama cerca de Titulcia, tras 43 kilómetros de recorrido madrileño.

\section{Cuenca del río Guadarrama}

El Guadarrama nace gracias a las escorrentías producidas en el puerto de Fuenfría, Cerro Ventoso y Siete Picos y a las aguas de los arroyos de la Vega y Navalmedio, que drenan la rampa del Escorial. Pasa por las localidades de Cercedilla, Los Molinos y Guadarrama (de la que recibe su nombre), recibe las aguas de su afluente más importante que es el Aulencia y sale de la provincia en las proximidades de Batres, tras haber recorrido 77 kilómetros dentro de la Comunidad, hasta desembocar en las aguas del Tajo una vez pasado Toledo.

\section{Cuenca del río Alberche}

El río Alberche nace en la provincia de Ávila, en el Puerto del Pico. Entra en Madrid por el embalse de San Juan, en la zona de la Garganta de Picadas, corre entre las sierras de Guadarrama y de Gredos y sus principales afluentes son el Cofio y el Perales. Forma el límite provincial con Toledo y posteriormente abandona la Comunidad por Villa del Prado, tras haber recorrido 40 kilómetros dentro de Madrid.

En total, las aguas que entran a Madrid son conducidas antes de su ingreso a la Comunidad por una superficie de $19.000 \mathrm{~km}^{2}$, a lo que se añaden otros 8.000 que representan la superficie de captación de la provincia. En un año medio, en un hipotético régimen natural sin embalses o derivaciones, esto representa una entrada de $3.000 \mathrm{hm}^{3}$, a los que se suman otros 1.000 producidos dentro del territorio provincial (AGUILÓ, 1983), aunque esta cifra puede variar drásticamente, ya que según las series históricas de aportaciones de los ríos de Madrid, que datan desde 1914, han registrado un mínimo de $213 \mathrm{hm}^{3}$ en el año 1991-1992, y una máxima de $1.707 \mathrm{hm}^{3}$ en el año 1940-1941. 


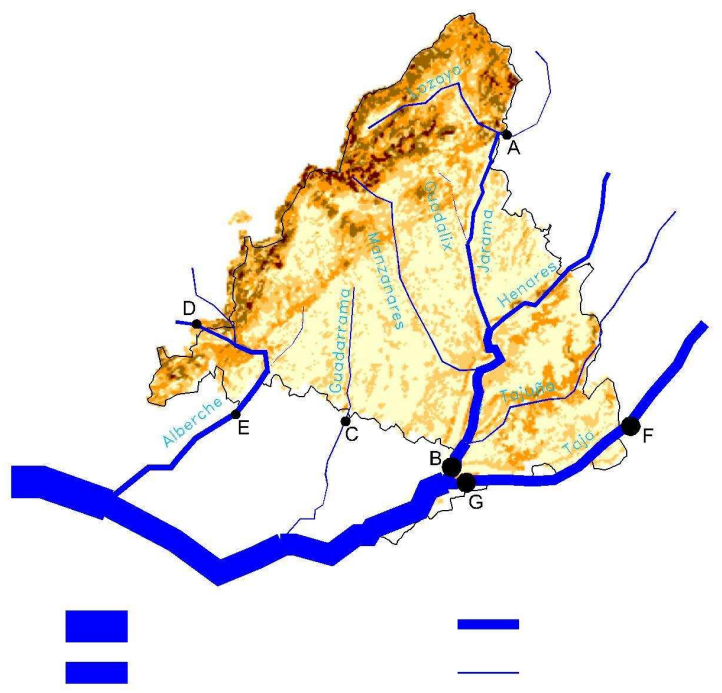

\begin{tabular}{|l|r|r|r|}
\hline Cuenca & Aportación en entrada & Aportación en salida & Aportación interior \\
\hline Jarama & $(\mathrm{A}) 187$ & $(\mathrm{~B}) 1.559$ & $(\mathrm{~B}-\mathrm{A}) 1.372$ \\
\hline Guadarrama & - & $(\mathrm{C}) 153$ & 153 \\
\hline Alberche & $(\mathrm{D}) 604$ & $(\mathrm{E}) 766$ & $(\mathrm{E}-\mathrm{D}) 162$ \\
\hline Tajo & $(\mathrm{F}) 1.485$ & $(\mathrm{G}) 1.508$ & $(\mathrm{G}-\mathrm{F}) 23$ \\
\hline Total & 2.979 & 3.986 & 1.007 \\
\hline
\end{tabular}

Figura 5: Aportaciones medias anuales en régimen natural $\left(\mathrm{hm}^{3}\right)$

Fuente: Elaboración propia a partir de Aguiló, 1983 y Confederación Hidrográfica del Tajo.

\section{Acuíferos}

Los distintas unidades hidrogeológicas que se encuentran en la Comunidad de Madrid se alinean casi de manera paralela a al dirección de la Sierra.

- Sustrato granítico paleozoico: también conocido como zócalo serrano. Ubicado en la franja de dirección suroeste-noreste correspondiente a la zona de la sierra, abarca una superficie de unos $2.700 \mathrm{~km}^{2}$. Se compone de un conjunto de materiales graníticos, gnéisicos y paleozoicos de carácter sólido y masivo. Este tipo de composición se caracteriza por su permeabilidad baja y localizada, básicamente a través de grietas y fracturas que desembocan en los valles, dando origen a mantos acuíferos discontinuos de gran pureza y calidad pero de escaso volumen de reserva, que pueden cubrir demandas muy pequeñas, del orden de los 100 metros cúbicos por día.

- Calizas mesozoicas del borde del Guadarrama: dentro de la región ocupan una superficie muy reducida, específicamente en los alrededores de Torrelaguna, comprendiendo una superficie de afloración de unos $75 \mathrm{~km}^{2}$, y en la fosa del Lozoya, junto al embalse de Pinilla, cubriendo apenas $25 \mathrm{~km}^{2}$. Sus aguas son potables, a excepción de algunos pozos en los alrededores de Torrelaguna como consecuencia de la presencia de materiales yesíferos. Los terrenos de estas zonas son altamente permeables debido a fisuras en la roca, con niveles freáticos que generalmente se sitúan entre 20 y 30 metros de profundidad. Se caracteriza por ser un acuífero altamente vulnerable a la contaminación, ya que su composición tiene una casi nula capacidad de filtración.

- Terciario detrítico: es el acuífero más importante de la región por su superficie, que rebasa los $2.600 \mathrm{~km}^{2}$, y por la cantidad de agua contenida. Esta constituido por acumulación de materiales detríticos procedentes de la denudación del Guadarrama. Está compuesto por capas arenosas y areno-arcillosas englobadas en una matriz arcillosa, lo que le confiere una textura general porosa, de permeabilidad media y baja. La profundidad de este acuífero varia en gran medida, siendo muy poca en las proximidades de los cauces y llegando incluso hasta los centenares de metros en los interfluvios. Parte de los recursos acuíferos que componen el terciario detrítico se incorporan a éste después de infiltrarse en las terrazas cuaternarias que lo recubren en algunas áreas. Y parte de sus aguas alimentan los aluviales de los fondos de los valles. 
Contiene un gran volumen de agua almacenada, representando en promedio que por cada metro descendido de la extensión total del acuífero se pueden encontrar $200 \mathrm{hm}^{3}$. La calidad química de sus aguas permite que sean potables, a excepción de aquellas próximas a materiales margo-yesíferos, que presentan un alto índice de salinidad.

En total, el acuífero Terciario Detrítico cuenta con unas reservas utilizables de entre 2.000 y 4.000 $\mathrm{hm}^{3}$, en teoría de factible extracción. Sin embargo, los recursos renovables en un periodo interanual no superan los $130-150 \mathrm{hm}^{3}$.

- Terciario margo-yesífero: está compuesto por materiales miocenos en capas evaporíticas y paleógenos adosados a las calizas mesozoicas, y aflora en los alrededores de Torrelaguna y Patones, al oriente de la provincia. Se trata de materiales poco permeables. Sus aguas tienen un alto contenido de salinidad, lo que las hace impotables.

- Calizas del páramo: los dos afloramientos más importantes se ubican en la parte sur de la Alcarria y en la mesa de Chinchón, cubriendo una superficie aproximada de $450 \mathrm{~km}^{2}$ en el primer caso y de 150 en el segundo. Se trata de calizas entre las que se intercalan niveles detríticos. Esta condición origina que el sistema esté constituido por una serie de acuíferos libres, independientes entre sí, y cuyo nivel basal se sitúa por encima del de los valles circundantes, que oscilan entre los veinte y sesenta metros de profundidad.

- Cuaternario aluvial: son acuíferos muy superficiales y altamente permeables debido a su constitución porosa de gravas y arenas. Se extienden por los valles de los ríos principales de la región, cubriendo una superficie total cercana a los $1.350 \mathrm{~km}^{2}$ y con un espesor general menor a los 10 metros, a excepción de las aguas bajas del Jarama, donde alcanza los 40 metros.

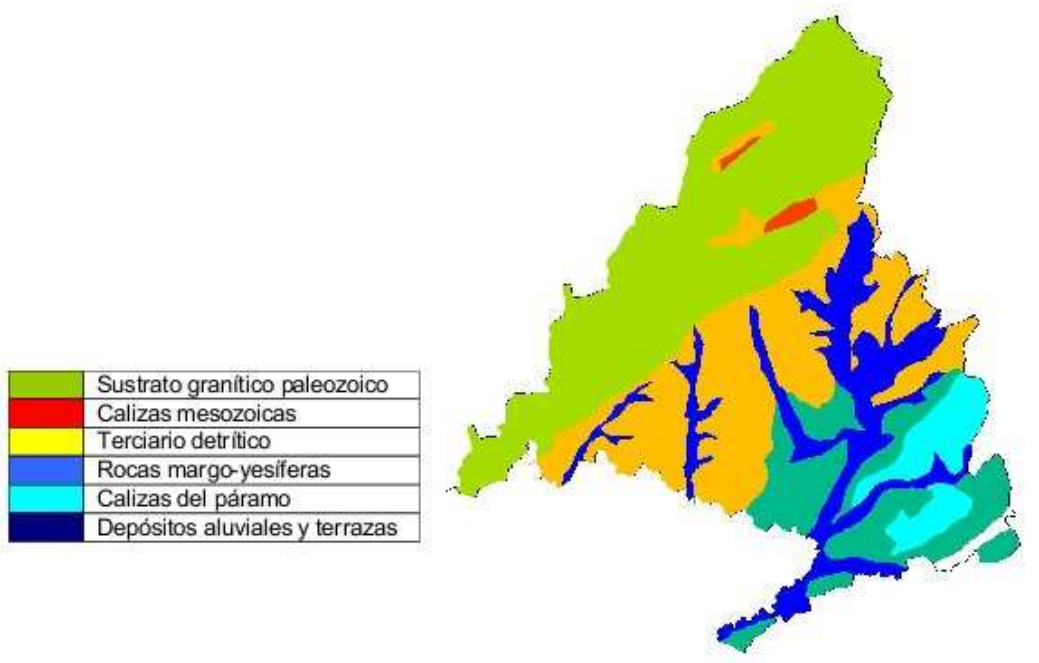

Figura 6: Acuíferos subterráneos.

Fuente: elaboración propia a partir de AguiLó, 1983.

\section{Disponibilidad total del recurso}

La característica principal de la disponibilidad de agua en la región madrileña es sin duda la inestabilidad climática. La aportación media dentro de la provincia en régimen natural se encuentra en torno a los $1.000 \mathrm{hm}^{3}$ (AguiLó, 1983), de los cuales el $66 \%$ corresponde a la cuenca del Jarama, el $15 \%$ a la del Guadarrama, el $16 \%$ a la del Alberche y el restante $3 \%$ a la del mismo Tajo. Sin embargo, las aportaciones de los años 1999 y 2000 han llegado escasamente a los 362 y $650 \mathrm{hm}^{3}$ respectivamente (CONSEJERÍA Del Medio Ambiente, 2003), y es posible que en las próximas décadas, debido a los efectos del cambio climático global, la tendencia sea a la baja ${ }^{2}$.

\footnotetext{
${ }^{2}$ Aunque la mayoría de estudios realizados acerca del cambio climático global coinciden en lo difícil e inexacto que resulta calcular sus efectos, parece existir la certeza de que la cuenca mediterránea sufrirá un descenso sensible en sus índices de precipitaciones pluviales.
} 


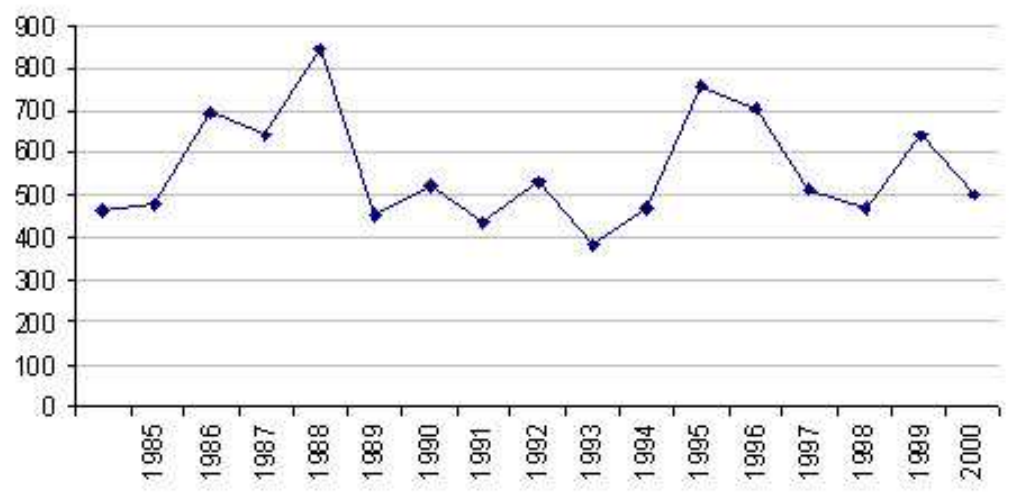

Figura 7: Promedio histórico de precipitaciones pluviales en la Comunidad de Madrid $\left(\mathrm{lts} / \mathrm{m}^{2}\right)$.

Fuente: Elaboración propia a partir de Anuario Estadístico de la Comunidad de Madrid.

Por el contrario, las reservas de los acuíferos suelen considerarse más estables debido a su lenta tasa de renovación, que en la totalidad de la Comunidad de Madrid equivale a 150-200 hm ${ }^{3}$. De esta forma, sin otro método disponible más que una simple suma de cantidades al más puro estilo de la economía hidráulica clásica, se puede considerar como recurso disponible de agua en la Comunidad de Madrid una aportación natural combinada de recursos subterráneos y superficiales de entre un mínimo de $365 \mathrm{hm}^{3}$ y un máximo de $1.850 \mathrm{hm}^{3}$ al año, considerando únicamente las aportaciones de los ríos dentro ${ }^{3}$ de la Comunidad y solamente la tasa renovable del acuífero.

CuAdro 2: Aportaciones en régimen natural de las fuentes $\left(\mathrm{hm}^{3}\right.$ al año)

\begin{tabular}{lrrr} 
& Máxima & Mínima & Normal \\
\hline Ríos & 1.700 & 213 & 1.000 \\
Acuíferos & 4.000 & 150 & 200 \\
\hline Total & 5.700 & 363 & 1.200
\end{tabular}

\section{Resumen de la evolución histórica de los límites territoriales del abastecimiento de agua de la ciudad de Madrid}

Los primeros pobladores de lo que después se convertiría en la ciudad de Madrid eligieron para su fundación un sitio muy cercano al río Manzanares, pero en una meseta a unos cincuenta o sesenta metros por encima del cauce de éste, lo que con el tiempo desencadenó que el crecimiento de la villa, en vez de involucrar al río cercano, le diera su espalda y prefiriera extenderse en dirección al Jarama. El asentamiento original se desarrolló sobre los cerros del Palacio de Oriente y el de Las Vistillas, que se encontraban separados por el arroyo que se ubicaba en lo que hoy es la calle Segovia. El límite norte del emplazamiento lo establecía el barranco de las Hontanillas, por donde discurría el arroyo del Arenal.

Aunque se conocen varios asentamientos en la zona correspondientes a la Edad de Bronce, se sabe actualmente con certeza que los primeros relatos que hablan de la ciudad corresponden al siglo IX (MACÍAS Y SEGURA, 2000). Este pequeño asentamiento de carácter militar, cuya superficie inicial no rebasaba las nueve hectáreas, formaba parte de la línea que defendía la España musulmana de la cristiana, junto con

\footnotetext{
${ }^{3}$ Las principales aportaciones provenientes del exterior de la Comunidad de Madrid corresponden en casi un $50 \%$ al río Tajo y el resto al Henares (que actualmente es un caudal de poca calidad debido a los vertidos industriales) y al Alberche (este último se encuentra en cotas de altitud menores a las del área metropolitana madrileña, lo que implica que cualquier aprovechamiento se debe realizar mediante sistemas de elevación del caudal).
} 
Guadalajara, Talamanca y Alcalá. En esta época la ciudad se conocía como Mayrit (equivalente en árabe a 'lugar de viajes de agua'), término que probablemente haya sido heredado de la palabra bajolatina visigótica Matrice, que significa 'arroyo matriz' o 'madre'.

Ya sea que el nombre original haya trascendido al árabe por su significado o por su semejanza fonética, resulta evidente la importancia que tenían en la topografía del sitio el gran número de arroyos que recorrían las pendientes desde las zonas altas donde se realizó la fundación (en el lugar que ocupa actualmente el Palacio Real) hasta el cauce del Manzanares. Seguramente la abundancia de agua en el lugar, tanto en arroyos, como en el Manzanares y en el subsuelo, fue un factor decisivo para el desarrollo del asentamiento (TERÁn, 1992).

Durante la época musulmana la ciudad se abastecía de agua potable gracias a pozos de planta circular y paredes de mampostería construidos dentro del casco urbano. Esta fuente se complementaba con los 'viajes del agua' (en árabe Mayras o qanats), que consistían en la excavación de pozos a las afueras del núcleo urbano, desde los cuales se conducía el agua mediante minas o galerías subterráneas lo suficientemente amplias para acomodar a una persona de pie que pudiera darles mantenimiento y limpieza. A lo largo del recorrido se abrían varios pozos más, a manera de respiraderos que permitieran la oxigenación y ventilación de los viajes.

La peculiaridad de los viajes del agua reside en el aprovechamiento que éstos hacían de las características del subsuelo madrileño, compuesto por arenas permeables que descansan sobre capas de otras impermeables, de manera que las galerías simplemente encauzaban el flujo constante de agua que descendía por gravedad por la pendiente natural del terreno a través del subsuelo arenoso.

Desafortunadamente, hoy quedan muy pocos vestigios de lo que fue el Madrid musulmán. De los viajes del agua se conoce actualmente sólo un tramo original de la época, encontrado por CABALLERO, PRIEGO y Retuerce en 1984, en la céntrica plaza de Carros. Entonces se desenterró un tramo de unos 10 metros aproximadamente de una galería de conducción, cuyas características principales eran un pequeño canal con grava y pequeñas represas que filtraban el agua durante el recorrido, y un andén lateral de piedra que permitía el paso para el registro de la galería. Sobre el uso dado a estas aguas se puede deducir mediante la comparación con otras ciudades análogas (MACíAS Y SEGURA, 2000), que sería principalmente para consumo humano, baños domésticos y públicos y riego de algunos jardines o huertas particulares. Para el riego de cultivos lo más probable es que se utilizara directamente el agua de los arroyos cercanos, como el de Atocha o el Abroñigal.

Durante su etapa medieval, tanto musulmana como cristiana, la ciudad crece constantemente en importancia y población, debido tanto a la prosperidad agrícola y comercial como a su carácter de centro de poder, contando a principios del siglo XV con cerca de cinco mil habitantes. Sin embargo, a partir de 1560, debido a la decisión del monarca Felipe II de establecer definitivamente la capital del reino en la Villa de Madrid, se produce un notable y repentino crecimiento de la población de la ciudad, pasando de los diez mil a los veinte mil habitantes en pocos meses. En ese momento las fuentes de abastecimiento de agua potable que hasta entonces se habían utilizado comienzan a quedarse insuficientes.

A pesar de que el abastecimiento mediante los viajes del agua se asocia a la época musulmana de Madrid, es en realidad durante el reinado de los Austrias cuando este sistema realmente se consolida como la principal fuente de agua potable de la ciudad (MACíAS Y SEGURA, 2000), y cuando se construyen las traídas del recurso más importantes por longitud y caudal.

El primero de estos nuevos viajes es el del Amaniel, realizado a principios del siglo XVII. Este traía el agua desde las cercanías del pueblo de Fuencarral, situado al norte de la ciudad, y llegaba hasta el Palacio Real, completando un trayecto de seis kilómetros de longitud. Posteriormente en ese siglo se realizan también los viajes del Alto y Bajo Abroñigal; el primero nacía en la zona de Canillas y el segundo entre ésta y Canillejas. Finalmente, en 1621 se construye el viaje de la Fuente de la Castellana, ${ }^{4}$ que nacía en la zona de Chamartín, concretamente en la finca de Maudes, y que recorría un total de 18 kilómetros.

Cabe destacar que del espectacular aumento en la red de traída de agua potable constituida principalmente por los viajes del agua, solo los personajes poderosos de la aristocracia y del clero contaban con abastecimiento dentro de su propia parcela, que se lograba a partir de derivaciones hechas desde los viajes principales. La mayor parte de la población debía de abastecerse de las fuentes públicas (34 fuentes existían en la ciudad según el plano de TEXEIRA de 1656) ubicadas en distintos puntos del núcleo urbano, y gracias a los aguadores que se ganaban la vida vendiendo el agua que transportaban a cuestas en un bidón.

\footnotetext{
${ }^{4}$ La construcción de estos viajes coincide con la realización de importantes obras urbanas promovidas durante los reinados de Felipe III y Felipe IV, como fueron la Plaza Mayor (1617-1619) y la fachada meridional del Palacio Real (1621) entre otras, que consolidan la fisonomía de lo que hoy conocemos como el Madrid antiguo (TERÁN, 1992). En esta época la ciudad había alcanzado ya una superficie aproximada de 770 hectáreas, que era el área comprendida dentro de la cerca de Felipe IV.
} 


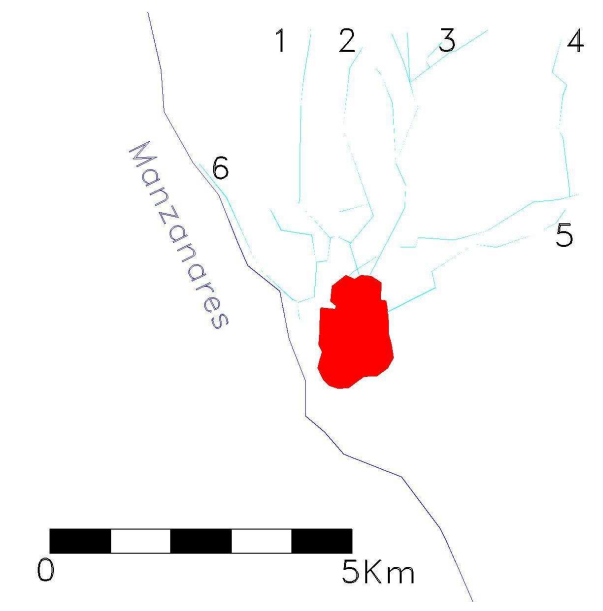

\begin{tabular}{|l|r|}
\hline Población & 70.000 habitantes \\
\hline Superficie & 770 hectáreas \\
\hline Consumo & \multicolumn{1}{|c}{ 10-15 lts /hab/día } \\
\hline Abastecimiento & $\begin{array}{l}\text { 'Viajes del agua' desde Fuencarral, Chamartín, Ca- } \\
\text { nillas y Canillejas. Pozos. }\end{array}$ \\
\hline
\end{tabular}

FiguRA 8: Límites territoriales del abastecimiento de agua hasta $\mathbf{1 6 5 0}$

Viajes del agua: 1 Amaniel; 2 Alcubilla; 3 Castellana; 4 Alto Abroñigal; 5 Bajo Abroñigal; 6 Fuente de la Reina.

Esta distribución inequitativa queda reflejada en los tres grupos de usuarios que se tienen registrados de la época (Macías y SEgura, 2000):

Primero estaban los particulares que recibían el agua directamente en sus parcelas o edificios, para aquellos que tenían el poder político o económico de pagarla. Por otro lado se encontraban aquellas personas o instituciones, como la Iglesia, que recibían por parte del Rey o del Ayuntamiento la concesión del abastecimiento. Y, finalmente, se encontraba el resto de la población, que debía recurrir a las fuentes públicas para abastecerse y acarrear el agua hasta el lugar de consumo o aprovechamiento. Esta desigualdad perduró hasta bien entrado el siglo XIX, cuando todavía de los diez distritos que conformaban la capital sólo dos recibían la cantidad adecuada de agua, el de Palacio y el de Audiencia; el resto presentaba graves carencias de suministro. En los primeros dos, la dotación diaria por persona equivalía a entre 20 y 25 litros, mientras que los demás recibían los más precarios desde 5 litros y el resto entre 10 y 15 .

A mediados del siglo XIX los viajes del agua eran el único sistema de abastecimiento de la creciente ciudad, que contaba ya con una población superior a los 200.000 habitantes. Su capacidad de suministro en teoría rondaba los $3.500 \mathrm{~m}^{3}$, pero los problemas de deterioro de los mismos provocaban que la ciudad sólo pudiese recibir $2.000 \mathrm{~m}^{3}$. El déficit de agua en la capital se trataba de paliar entonces con la construcción de nuevos viajes o la ampliación de los existentes. En 1855 se construye el viaje de la Fuente de la Reina (el último que se realizó), con el que Madrid totalizó 124 kilómetros lineales de estas infraestructuras.

Cabe destacar que no todos los viajes del agua conducían agua potables, ya que algunos se construyeron para el traslado de aguas de menor calidad conocidas como 'aguas gordas', que se utilizaban principalmente para usos que no implicaban su consumo, aunque en épocas de sequía llegaban a utilizarse con este fin. Los principales viajes construidos hasta el siglo XIX fueron:

\begin{tabular}{ll} 
Aguas finas o dulces & Aguas gordas \\
\hline Alto Abroñigal (1613) & Harinas (1591) \\
Fuente de la Castellana & Fuente de la Salud (s. XVIII) \\
Alcubilla & Gremios \\
San Dámaso (1819) & Fuente de la Reina (1855) \\
Conde de Salinas (1821) & Pascualas \\
Retamar (1829) & Pajaritos \\
Fuente del Rey &
\end{tabular}

A pesar de la existencia de los viajes del agua, el abastecimiento de la ciudad de Madrid (especialmente tras convertirse en capital) resultaba insuficiente para las necesidades de una población creciente, de la 


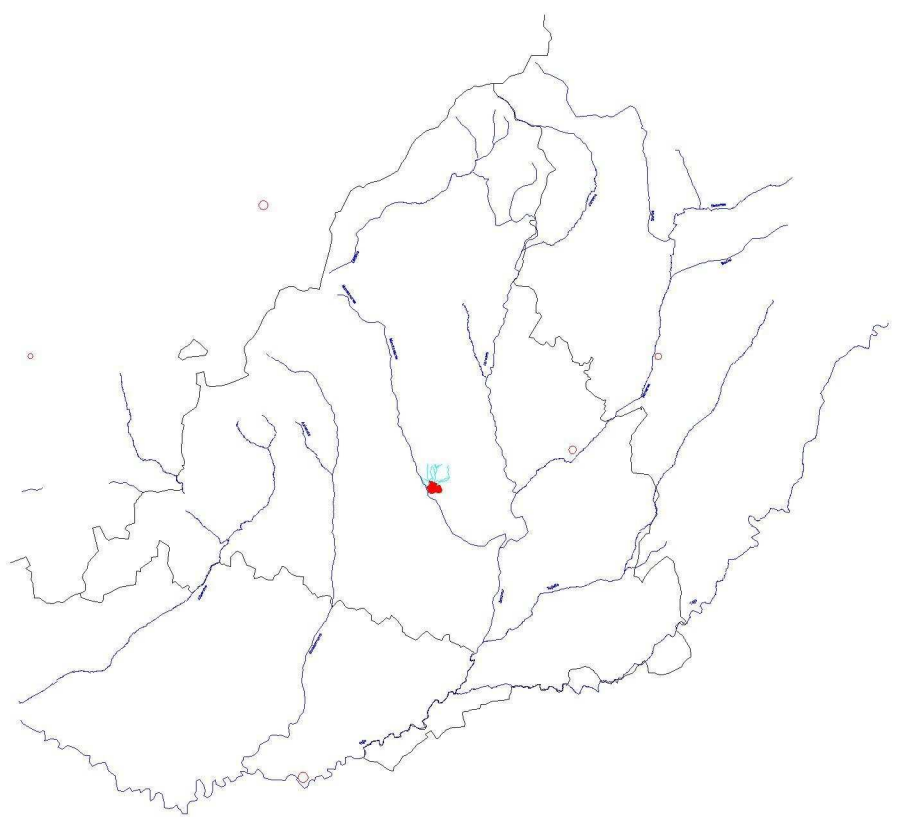

\begin{tabular}{|l|r|}
\hline Población & 200.000 habitantes \\
\hline Superficie & 800 hectáreas \\
\hline Consumo & \multicolumn{1}{|c|}{ 5-15 lts /hab/día } \\
\hline Abastecimiento & $\begin{array}{l}\text { 'Viajes del agua': 14 de aguas finas, 7 de aguas gor- } \\
\text { das. }\end{array}$ \\
\hline
\end{tabular}

FiguRA 9: Límites territoriales del abastecimiento de agua hasta 1850

misma forma que lo hacía la superficie urbana. Desde el siglo XV y hasta mediados del XIX se contempló en distintas ocasiones la idea de encauzar las aguas del Jarama, lo cual fue relegado siempre en favor de la construcción de nuevos viajes.

Es el 24 de junio de 1858 cuando por fin se inaugura el nuevo sistema de abastecimiento de la ciudad de Madrid, bautizado como Canal de Isabel II, que trae las aguas desde el río Lozoya por ser el más caudaloso de la región, ya que colecta aguas del deshielo, garantizando así la afluencia de caudal durante los meses secos. La obra consiste básicamente en la construcción de la presa del Pontón de Oliva, ubicada a poco más de 70 kilómetros del centro de Madrid, del canal de conducción hacia la ciudad y del primer depósito elevado, ubicado en el Campo de Guardias.

Durante esta primera etapa de consolidación del nuevo sistema de suministro de agua de la capital, que va desde el inicio de la construcción en 1851 hasta la conclusión del depósito en 1866, la población de la ciudad aumenta de 200.000 a 270.000 habitantes, lo cual muestra el acelerado índice de crecimiento de la época y la apremiante necesidad del recurso. Pero además de aportar una dotación de agua suficiente para la población, la construcción del Canal supuso también un impacto significativo en el costo de la misma, ya que antes de la monumental obra el líquido costaba al consumidor el equivalente a 2,32 pesetas el metro cúbico y tras su inauguración el precio bajó a 50 céntimos.

Además de lo anterior, el nuevo abastecimiento de agua debido a la construcción del Canal Isabel II significó la plataforma necesaria para el inicio de un proceso de transformación y renovación de la ciudad, permitiendo la realización de varios proyectos de infraestructuras, inmobiliarios e industriales para los que resultaba fundamental una mayor dotación de agua. Esto queda ilustrado en la memoria del proyecto del Canal Isabel II realizada por José García OTERo en 1852, donde se menciona la intención de aprovechar la nueva traída de aguas para fines más ambiciosos que el simple consumo doméstico:

El decreto orgánico fijaba en el mínimo de diez mil reales fontaneros ${ }^{5}$ la cantidad de agua que debía conducirse a Madrid. Aún suponiendo que la población, que no pasa hoy de doscientas cuarenta mil almas, llegue algún día a ascender a cuatrocientas mil, los diez mil reales fontaneros proporcionarán a cada individuo cincuenta litros de agua. Pero esta cantidad, que parecerá excesiva si se atiende sólo a las necesidades del uso doméstico, viene a ser

\footnotetext{
${ }^{5}$ Un real fontanero equivale a 3.245 litros diarios.
} 
insuficiente si ha de destinarse también a los importantes objetos que el Gobierno se ha propuesto al disponer la ejecución del proyecto que nos ocupa.

Otero, 1852.

El mismo texto comienza su siguiente párrafo con una interesante observación acerca de los posibles beneficios económicos de la obra:

Mirada esta cuestión bajo el punto de vista económico, fácilmente se concibe que si con un determinado capital se logra cierto caudal de agua, siempre que se pueda aumentar notablemente este último sin acrecer sensiblemente aquel, las ventajas que se obtienen son indudables.

Otero, 1852.

Lo anterior hace referencia, como se explicita más adelante en el mismo texto, a que durante la realización del proyecto se descubrió que mediante la introducción de pequeñas modificaciones sin variar sustancialmente las características de éste (y por lo tanto su coste) se podía aumentar el caudal de los diez mil reales fontaneros previstos originalmente hasta un total de sesenta mil $\left(194.700 \mathrm{~m}^{3} \mathrm{diarios}\right.$.

Durante el reinado isabelino se emprenden numerosas obras de infraestructura además del Canal, entre las que destaca fundamentalmente el ferrocarril, pero también la renovación y ampliación de más de cien kilómetros de redes municipales de distribución y saneamiento de aguas. Pero, sin lugar a dudas, el proyecto más ambicioso de la época es el ensanche de la ciudad, proyectado por CARLOs MARÍA DE CAstro, que contemplaba casi triplicar la superficie urbana. Esta etapa del crecimiento de Madrid se caracteriza por una visión planificada y racional de hacer ciudad, promovida, ya no por la Corona, sino por una pujante clase burguesa con grandes intereses inmobiliarios (TERÁN, 1992).

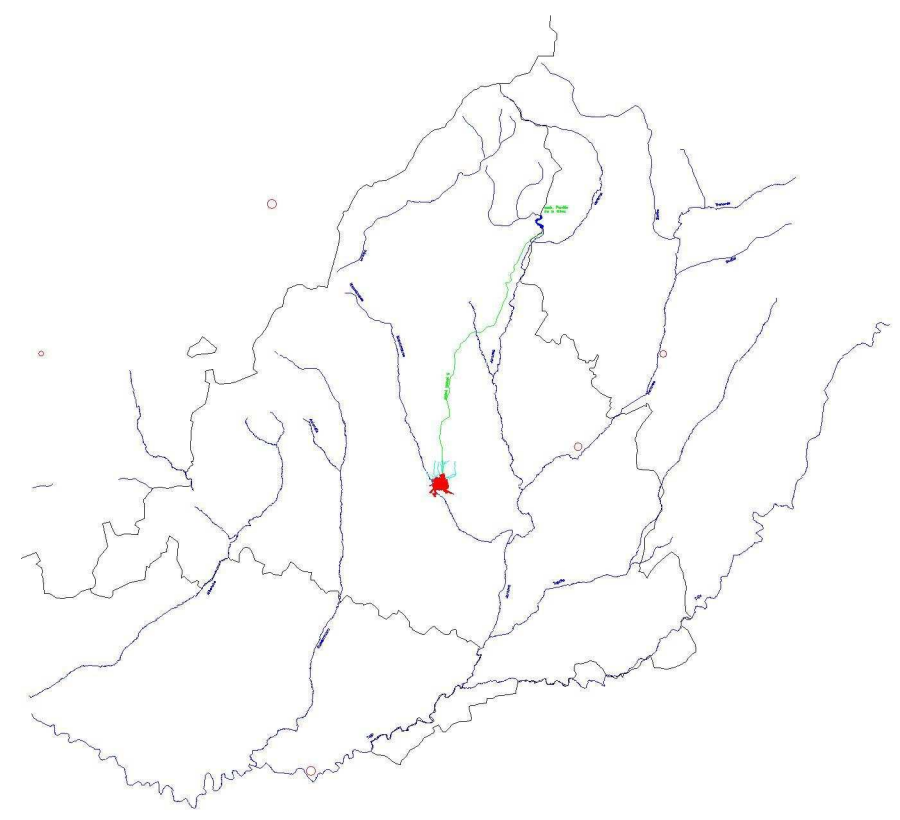

\begin{tabular}{|l|r|}
\hline Población & 387.800 habitantes \\
\hline Superficie & 2.200 hectáreas \\
\hline Consumo & 75 lts / hab/día \\
\hline Abastecimiento & $\begin{array}{l}\text { Canal Isabel II desde el embalse de Pontón de Oliva } \\
\text { en la cuenca del Lozoya. Se mantienen en uso los } \\
\text { viajes del agua. }\end{array}$ \\
\hline
\end{tabular}

Figura 10: Límites territoriales del abastecimiento de agua hasta 1875

En 1879 los problemas de filtraciones en la presa del Pontón de Oliva —ocasionados por problemas de hundimientos del subsuelo sobre el que se construye - obligan a la realización de un nuevo embalse 30 kilómetros aguas arriba, el del Villar, que se terminó en 1882. Fue esta la obra hidráulica más importante 
de su tiempo en España, sobre todo por la forma en la que se aplicaron los entonces nuevos principios ${ }^{6}$ de la mecánica racional (DiEZ-CASCón, 2003). La construcción de este embalse, de mayor capacidad que el original, se complementa entonces con las obras del canal transversal, que llevaba el agua desde la presa hasta el canal original, y con el segundo depósito, construido a un lado del primero en la esquina de lo que hoy son las calles de Santa Engracia y Bravo Murillo. También de esta época data el proyecto para la distribución de agua en el nuevo ensanche de Madrid. La ciudad de Madrid comienza el siglo XX con poco más de 600.000 mil habitantes y con un ritmo rápido de crecimiento debido a la inmigración desde otras regiones de España. Es una época dura para la ciudad, marcada por la pobreza y el crecimiento del extrarradio basado en la urbanización marginal (TERÁn, 1992). Debido al crecimiento hacia el norte de la mancha urbana, en zonas de mayor cota que la del centro de la ciudad, el abastecimiento de agua comienza a sufrir problemas de presión. Para solucionar este problema, en el año 1912 se construye en las inmediaciones del pueblo de Manzanares Real la presa de Santillana, con capacidad de embalse de $20 \mathrm{hm}^{3}$, y su respectivo canal de conducción, ambos de titularidad privada, a cargo de la Compañía Hidráulica de Santillana (estas infraestructuras fueron adquiridas posteriormente por el Canal Isabel II).

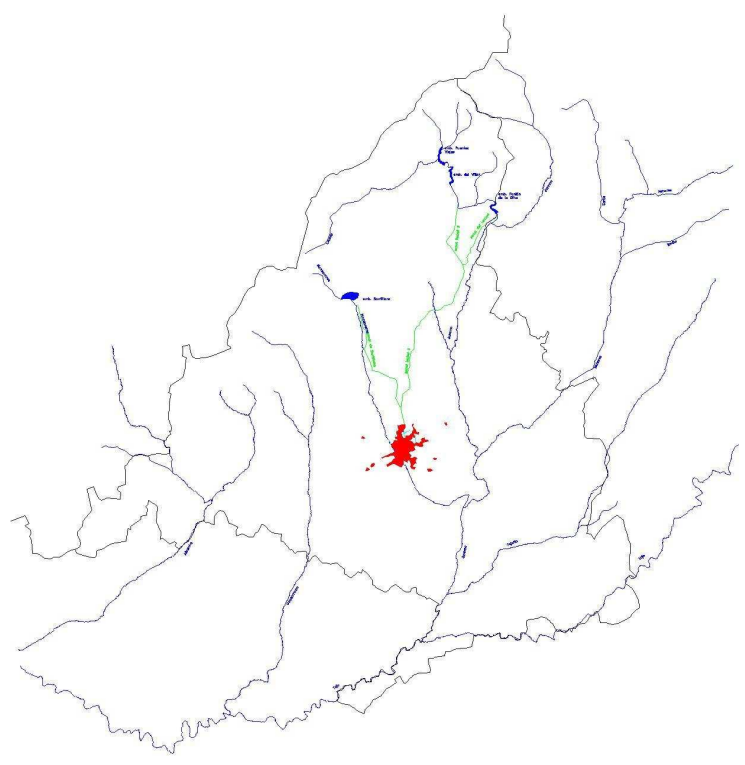

\begin{tabular}{|l|r|}
\hline Población & 1.088 .600 habitantes \\
\hline Superficie & 6.600 hectáreas \\
\hline Consumo & 240 lts /hab/día \\
\hline Abastecimiento & $\begin{array}{l}\text { Embalses de Puentes Viejas y el Villar en la cuen- } \\
\text { ca del Lozoya. Presa del Santillana en la cuenca del } \\
\text { Manzanares. (capacidad total:122Hm }{ }^{3} \text { ). }\end{array}$ \\
\hline
\end{tabular}

FiguRA 11: Límites territoriales del abastecimiento de agua hasta 1939

Durante la corta y truncada vida del ayuntamiento republicano, las obras hidráulicas se dirigen sobre todo al saneamiento de las aguas negras de la ciudad, cuyo destino directo y final era hasta entonces el río Manzanares, que ya en esas fechas padecía de serios problemas de contaminación. Para tratar de paliar esta situación, se construye en 1934 la planta depuradora de La China, ubicada en el extremo sur del río, la cual se destruiría durante la guerra. Tras la crisis económica de principios de siglo y las oscuras etapas de guerra y posguerra, en la década de los sesenta se inicia un nuevo proceso de crecimiento demográfico y económico. El primero se concreta con casi 3,2 millones de habitantes en la capital al principio de la década, mientras que el segundo se logra gracias a un impulso de la producción industrial y a la participación de la iniciativa privada en el sector inmobiliario, en especial en la construcción de vivienda.

De manera semejante a los anteriores procesos de crecimiento, las expansiones demográfica y urbana implicaron un nuevo salto territorial en el campo de las infraestructuras de abastecimiento, y fueron

\footnotetext{
${ }^{6}$ La presa del Pontón de Oliva aparentemente fue construida sobre una base más empírica, lo cual queda reflejado en su muro de planta recta y de paramentos verticales y el espaldón situado aguas arriba, lo que denota la confusión de la época sobre el perfil adecuado de las obras de este tipo, y que fueron corregidos en la construcción del embalse de El Villar (DieZ-Cascón, 2003).
} 
precisamente las décadas de los sesenta y setenta las que vieron un crecimiento significativo en el número y la capacidad de los embalses, pasando de $125,4 \mathrm{hm}^{3}$ a finales de los años 50 a $900 \mathrm{hm}^{3}$ tan sólo veinte años después, y conformando así la base de la capacidad actual del sistema. La rápida evolución del territorio embalsado significaba para el régimen autor de las obras tanto un alarde de capacidad tecnológica como de poder y dominio sobre el entorno.

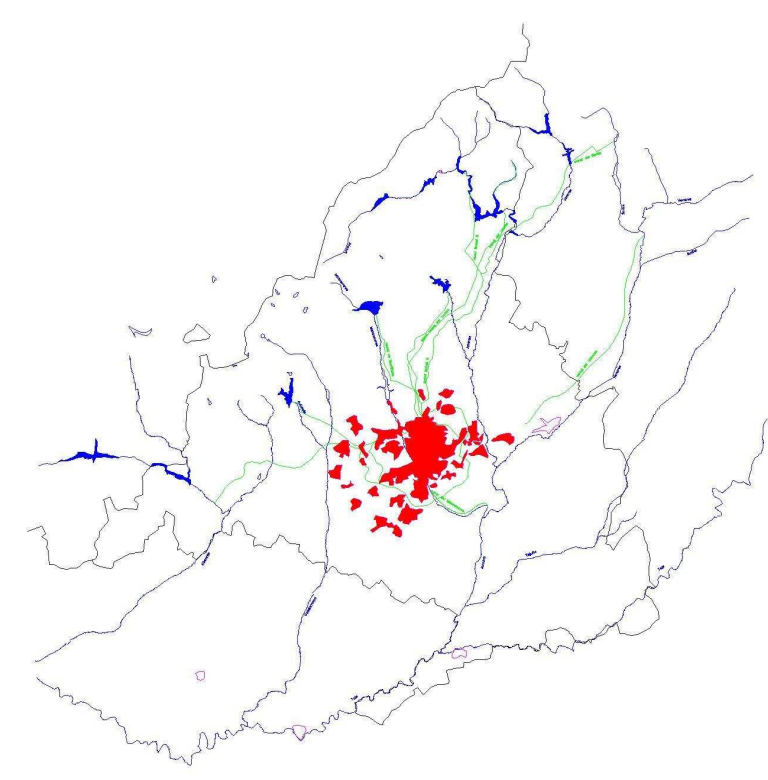

\begin{tabular}{|l|r|}
\hline Población & 5.700 .000 habitantes \\
\hline Superficie & 6.600 hectáreas \\
\hline Consumo & 295 lts /hab/día \\
\hline Abastecimiento & $\begin{array}{l}\text { 14 Embalses. 22 canales. 22 depósitos. 12 estaciones } \\
\text { de tratamiento. 18 estaciones de elevación. 122 pozos. } \\
\text { 62 depuradoras. }\end{array}$ \\
\hline
\end{tabular}

FIGURA 12: Límites territoriales del abastecimiento de agua hasta 2003

\section{La situación actual: el sobrepasamiento}

\section{Marco jurídico y concesional para el abastecimiento y la depuración de aguas en la Comunidad de Madrid}

El abastecimiento y saneamiento de agua en la Comunidad de Madrid, así como la gestión hidrológica a nivel local, nacional y europeo, está regida por una compleja serie de ordenanzas, planes, leyes y directivas, cuyo principal objetivo es regular el dominio del recurso y su calidad para el consumo humano; sin embargo, cada vez con mayor énfasis este marco jurídico hidráulico se dirige a la protección, conservación y regeneración de las funciones ambientales del agua.

La estructura de competencias dentro del marco legislativo español, establecida por la Constitución actual, que se basa en la organización territorial en autonomías y municipios de amplio poder y soberanía local, trasciende también al contexto de las aguas. En este caso, el Estado, a través del Ministerio de Medio Ambiente, es el responsable de la planificación hidrológica, que establece las bases de acción, gestión, protección, conservación y mejora de los aspectos cuantitativos y cualitativos de los recursos hídricos, basándose en el concepto fundamental del Dominio Público Hidraúlico. Sus principales instrumentos de gestión son el Plan Hidrológico Nacional (PHN) y los planes hidrológicos de las distintas cuencas hidrográficas.

Debido a que la estructura hidrográfica del territorio no corresponde con su división política, para la gestión del agua se subdivide el suelo español en cuencas hidrográficas, que incluyen las zonas de captación de aguas de los ríos que fluyen hacia el mar, atravesando parte de varias comunidades autónomas a su paso, y en ocasiones, atravesando también territorios internacionales; las cuencas constituyen la unidad 
básica de gestión del recurso y se consideran indivisibles. Los organismos de cuenca, llamados Confederaciones Hidrográficas, son los responsables de la elaboración y seguimiento de los planes hidrológicos de la cuenca correspondiente, que consisten básicamente en la aplicación de los criterios y directrices del Plan Hidrológico Nacional a las condiciones de especificidad de cada zona. Entre sus competencias destacan: el proyecto, construcción y explotación de las obras realizadas con los fondos del mismo organismo; la protección de los recursos, de los acuíferos y de las zonas húmedas; el establecimiento de los regímenes de explotación y la elaboración de estudios sobre calidades y demás características físicas, químicas y biológicas de las aguas.

Las comunidades autónomas son responsables de los proyectos, la construcción y la explotación de las infraestructuras hidráulicas que estén dentro del interés de las mismas. También les corresponde la legislación, concesión y aprovechamiento del recurso cuando las aguas discurren íntegramente por el territorio de la comunidad autónoma. En el caso de la Comunidad Autónoma de Madrid, la elaboración de proyectos, construcción y explotación de aprovechamientos hidráulicos queda encomendada al Canal de Isabel II.

En 1977 el Canal de Isabel II recibe su carácter jurídico actual, que lo define como empresa pública dependiente del Ministerio de Obras Públicas y Urbanismo, a través de la Dirección General de Obras Hidráulicas. Actúa en régimen de empresa mercantil y a la que el Estado le confía la gestión del servicio público de suministro de agua potable del área de Madrid, dotándole de personalidad jurídica independiente. Se rige por un Consejo de Administración en el que están representados los municipios afectados y la Comunidad de Madrid.

Los Municipios representan la entidad básica de organización y participación local y gozan de autonomía reconocida por la Constitución. Les corresponde la prestación y gestión de servicios públicos, que generalmente incluyen las redes de suministro y saneamiento de agua y, en el caso del municipio de Madrid, también la depuración.

\section{La Directiva Europea Marco del Agua}

El marco legislativo actual de la gestión de los recursos hidrológicos en España se encuentra regido por la Directiva Europea Marco de Aguas 2000/60 C.E.E., dirigida hacia un amplio margen de temas relacionados con el agua, que incluyen el suministro de agua para el consumo humano y para otras necesidades económicas, la defensa del medio ambiente a partir de la protección, conservación y rescate de las aguas superficiales y subterráneas y la atenuación de los efectos de las inundaciones y las sequías. En esta Directiva se establece la gestión a través de las cuencas fluviales como unidad básica y la necesidad de evaluar las características de las mismas, el control de su estado, el programa de medidas para alcanzar los objetivos cualitativos fijados en el documento y la necesidad de la participación pública respecto a los planes de gestión hidrológica.

La Directiva Marco del Agua recoge, complementa y, en ciertos casos, deroga una larga serie de directivas europeas que se han promulgado desde 1975, enfocadas básicamente a la calidad de las aguas para consumo, para el baño, para la vida acuática y para el control de sustancias contaminantes.

Los aspectos innovadores de la Directiva en relación a los instrumentos legislativos anteriores (BAUTISTA PAREJo, 2002) en cuanto a contaminación son el interés puesto en los problemas provocados por contaminantes específicos, los valores límite y los objetivos de calidad, así como la inclusión de la preocupación por la contaminación difusa, en especial la de origen agrícola. También otorga especial importancia a que una estructura tarifaria correcta del agua debe incluir los costes de los servicios de distribución y saneamiento, pero también los medioambientales vinculados al agotamiento de recursos.

Esta Directiva implica un cambio de visión con respecto a la concepción tradicional acerca de la gestión del agua, que se entendía como la construcción y explotación de las infraestructuras para satisfacer la demanda urbana e industrial indispensable para el crecimiento económico, y que planteaba el problema de la depuración como forma de paliar las agresiones producidas por el hombre al medio ambiente con el fin de no tener que verlas ni olerlas. Desde su primer párrafo, refiriéndose a las consideraciones que sientan las bases de la Directiva, establece:

Considerando lo siguiente:

(1) El agua no es un bien comercial como los demás, sino un patrimonio que hay que proteger, defender y tratar como tal.

En teoría, esta consideración despoja al agua de cualquier connotación económica que pudiese implicar un mercado especulativo similar al de cualquier otro producto de consumo. 
El Artículo 1 de la Directiva explica el objeto de la misma, y es de destacar la importancia que se le da al agua como elemento en sí mismo y como sustento de la calidad del medio ambiente, no existiendo prácticamente referencias directas a la satisfacción de las distintas demandas antrópicas:

Artículo 1. Objeto

El objeto de la presente Directiva es establecer un marco para la protección de las aguas superficiales continentales, las aguas de transición, las aguas costeras y las aguas subterráneas que:

a. prevenga todo deterioro adicional y proteja y mejore el estado de los ecosistemas acuáticos y, con respecto a sus necesidades de agua, de los ecosistemas terrestres y humedales directamente dependientes de los ecosistemas acuáticos;

b. promueva un uso sostenible del agua basado en la protección a largo plazo de los recursos hídricos disponibles;

c. tenga por objeto una mayor protección y mejora del medio acuático, entre otras formas mediante medidas específicas de reducción progresiva de los vertidos, las emisiones y las pérdidas de sustancias prioritarias, y mediante la interrupción o la supresión gradual de los vertidos, las emisiones y las pérdidas de sustancias peligrosas prioritarias;

d. garantice la reducción progresiva de la contaminación del agua subterránea y evite nuevas contaminaciones; y

e. contribuya a paliar los efectos de las inundaciones y sequías.

Los principios que rigen la Directiva Europea pueden resumirse (BAUTISTA PAREJo, 2002) en: un alto grado de protección de la salud humana, de la calidad de las aguas, y de los ecosistemas ligados a ellas; la reparación de los daños directamente en el origen de estos y el modelo disuasorio «el que contamina paga»; la integración de la planificación hidrológica a nivel local y nacional y a la del uso del suelo, con un énfasis importante en la participación pública y, finalmente, el análisis coste-beneficio a partir de los estándares de calidad, las mejoras tecnológicas y la inclusión de los costes de la contaminación.

\section{La Ley de Aguas de 1985}

La legislación española sobre materia de aguas tiene su base en la Ley 29/1985, de Aguas y su posterior modificación con la Ley 46/1999. El aspecto fundamental de esta ley reside en el Dominio Público Hidráulico que otorga al Estado el control de todos los recursos hídricos entendidos como unitarios, que son básicamente las aguas continentales, superficiales y subterráneas y las provenientes de la desalación. Antes de 1985, la ley de aguas vigente databa de 1879. Sin embargo, la nueva estructura política española promulgada por la Constitución exigió una nueva ordenación de los recursos hidráulicos basada en la distribución territorial, en las nuevas competencias para el Estado y las Comunidades Autónomas y en la necesidad de la planificación hidrológica.

En 1999 se reforma la Ley de Aguas, justificando dicha modificación ${ }^{7}$ en la necesidad de buscar alternativas que permitan incrementar la producción de agua para abastecimiento mediante nuevas tecnologías, otorgando rango legal a los procesos de reutilización y desalación; también busca la flexibilización del régimen concesional, las políticas de ahorro y la obligación de medición de consumos mediante sistemas homologados. La principal herramienta introducida por esta reforma para lograr los objetivos mencionados es la apertura a la participación de capitales privados para la construcción y explotación de infraestructuras.

Anteriormente a esta reforma existía una ausencia de regulación sobre obra hidráulica, por lo que mediante esta modificación se pretende equipararla a otro tipo de obras que ya gozaban de legislación específica, como las de carreteras, puertos y ferrocarriles. A partir de entonces, cualquier tipo de infraestructura hidráulica que se construyese (siempre y cuando fuese en favor del interés general, como lo marca la ley) podría ser de titularidad pública o privada y contemplaría la cesión temporal de los derechos de uso del agua al organismo privado.

La Ley de aguas de 1985 contempla la planificación hidrológica con el fin de unificar y racionalizar criterios de gestión (BAutista PAREJo, 2002) y en su artículo 40 detalla lo que debe contener obligatoriamente cada plan, donde destacan los usos y demandas existentes y previsibles, la prioridad y compatibilidad entre estos y la asignación de recursos para cada uno.

\section{El Plan Hidrológico de la Cuenca del Tajo}

El Plan Hidrológico de la cuenca del Tajo (PHT) tiene básicamente tres líneas de objetivos ${ }^{8}: \operatorname{los}$ primeros consisten en la satisfacción de las demandas actuales y futuras con el fin de promover el «desarrollo regional y sectorial» mediante la aplicación de las innovaciones técnicas disponibles que permitan el

\footnotetext{
${ }^{7}$ Ley 46/1999, de modificación de la Ley 29/1985, de Aguas. Exposición de motivos.

${ }^{8}$ Plan Hidrológico de la Cuenca del Tajo (PHT). Artículo 0. Objetivos, horizontes y datos básicos del Plan.
} 
mayor aprovechamiento a partir de la menor cantidad de recursos; en segundo orden, tras los objetivos de desarrollo, se encuentran los concernientes a la protección del medio ambiente, las garantías de calidad del recurso y la protección del territorio de fenómenos extremos como las avenidas y las sequías. Finalmente, se establecen como objetivos la conservación de las infraestructuras y del patrimonio hidráulico, así como los objetivos particulares para la regulación del trasvase Tajo-Segura.

En el Plan se establecen los parámetros de usos y dotaciones que deberán aplicarse en cada subsistema de explotación, entre los que se incluye el de Jarama-Guadarrama, gestionado por el Canal Isabel II para el abastecimiento de la mayoría de la población de la Comunidad de Madrid. De todos los parámetros indicados por el Plan cabe mencionar aquellos que condicionan de manera directa la gestión del recurso de esta región.

En cuanto a los recursos disponibles para los distintos usos en el horizonte de diez años, se establece que el subsistema Jarama-Guadarrama cuente con una asignación total ${ }^{9}$ de $950 \mathrm{hm}^{3}$, de los cuales 665,57 corresponden a la demanda urbana e industrial, 216,78 a la agrícola y 68,30 a la medioambiental. Según su prioridad ${ }^{10}$, los usos se ordenan de mayor a menor empezando por el abastecimiento a la población, usos agrarios, usos industriales para la producción de energía eléctrica y otros usos industriales no incluidos en los apartados anteriores, usos medioambientales, acuicultura, recreación, navegación y otros aprovechamientos.

En cuanto a la previsión de demandas internas de abastecimiento, el PHT establece como actual una demanda urbana e industrial de $616,16 \mathrm{hm}^{3}$, en el horizonte de diez años prevé una demanda de esos sectores de $665,57 \mathrm{hm}^{3}$ y en el horizonte de veinte años de $735,77 \mathrm{hm}^{3}$. Para la satisfacción de estas demandas, que deberá lograrse con las infraestructuras existentes, el Plan establece una serie de concesiones que actúan como reservas para el uso urbano. Como reservas destinadas a cubrir la demanda de la región de Madrid se indican:

- Los recursos regulados por el embalse de la Tajera y el resto de los recursos controlados en el río Ungría.

- Todos los recursos que se regulen en el Alto Sorbe, antes del embalse de Beleña.

- Todos los recursos que se regulen en el Alto Jarama, aguas arriba de la confluencia con el río Lozoya.

- El volumen de reserva en las presas de San Juan y Burguillo que no haya sido trasladado al Bajo Alberche.

Otra de las funciones primordiales del PHT consiste en establecer la calidad objetivo de las aguas en cada tramo de río de la cuenca, a partir de su condición actual. Para esto, el Plan utiliza criterios de calidad consistentes en indicar el tipo de tratamiento que debe tener el agua dependiendo del uso al que se vaya a destinar. Para el abastecimiento y consumo de la población, dependiendo de la cantidad de contaminantes que presenten en suspensión, las categorías de calidad de las aguas quedan establecidas como A1, A2 y A3, siendo las primeras aquellas que sólo necesitan tratamiento físico simple y desinfección, las segundas las que necesitan, además del tratamiento anterior, tratamiento químico y las últimas las que requerirán tratamiento físico y químico intensivos, afino y desinfección.

Para los ríos de la Comunidad de Madrid, los objetivos de calidad se establecen de la siguiente manera:

- Río Tajo: calidad de abastecimiento A2 y que además sus aguas sean susceptibles de albergar vida acuática y sean aptas para el baño.

- Río Manzanares: calidad de abastecimiento A2 y que además sean susceptibles de alimentar al ganado caprino y aptas para el baño.

- Río Tajuña: calidad de abastecimiento A3 y que además sean susceptibles de alimentar al ganado caprino.

- Río Jarama: calidad de abastecimiento A2 y que además sean susceptibles de alimentar al ganado caprino y aptas para el baño.

- Río Guadarrama: calidad de abastecimiento A3 y que además sean susceptibles de alimentar al ganado caprino.

- Río Alberche: calidad de abastecimiento A2 y que además sus aguas sean susceptibles de albergar vida acuática y sean aptas para el baño.

\footnotetext{
${ }^{9}$ PHT. Artículo 4. Recursos hidráulicos naturales.

${ }^{10} \mathrm{PHT}$. Artículo 6. Usos del agua a considerar según destino.
} 
En materia de saneamiento, el PHT establece de manera general, y según lo indicado en la directiva europea, que todos los vertidos urbanos con una carga superior a los 15.000 habitantes equivalentes deberán contar antes del 31 de diciembre de 2000 con tratamiento secundario, con un rendimiento mínimo del 70 al $75 \%$. Aquellos de volumen contaminante superior a los 2.000 habitantes equivalentes deberán contar con el mismo tipo de tratamiento antes del 31 de diciembre de 2005. En cuanto a normas que pueden afectar al proceso de urbanización, el Plan indica que los nuevos desarrollos urbanos deben contar preferentemente con redes de saneamiento separativas de aguas negras y pluviales, y que en cualquier caso, el alcantarillado para pluviales y redes unitarias debe tener como mínimo capacidad suficiente para poder evacuar el máximo chubasco de frecuencia quinquenal. Por último, la reutilización directa de aguas residuales depuradas queda pendiente de estudio durante el primer horizonte temporal del Plan.

En cuanto a la protección, conservación y recuperación de las funciones de la red fluvial, el PHT establece el orden de prioridad de aquellos tramos fluviales que precisen estudios específicos por presentar un riesgo elevado de ocurrencia de inundaciones o por soportar presión antrópica elevada. Como funciones de la red fluvial se especifican en el Plan:

- Función hidráulica: trata de la satisfacción de las demandas ambientales necesarias para el cumplimiento de las funciones biofísicas del río, así como de asegurar la capacidad del cauce para permitir el paso de avenidas en régimen natural.

- Función biofísica: es la que permite el desarrollo de los ecosistemas ligados al cauce.

- Función socioeconómica: es soporte de los aprovechamientos y apoyo al desarrollo territorial.

- Función paisajística: configuración del entorno paisajístico a conservar.

A continuación se indican los tramos de ríos madrileños en los que, según el PHT, es prioritario el desarrollo de estudios específicos encaminados a la protección, conservación y recuperación de las funciones fluviales antes especificadas. Cabe destacar que de los 19 tramos fluviales indicados como de primera prioridad en la cuenca hidrográfica del Tajo, nueve pertenecen o atraviesan la Comunidad de Madrid, siendo un total de 651 kilómetros de los 781 a estudiar:

- Henares: desde Humanes hasta su desembocadura en el Jarama.

- Guadarrama: desde Los Molinos hasta su desembocadura en el Tajo.

- Jarama: desde la confluencia del Henares hasta su desembocadura en el Tajo.

- Arroyo de la Vega: desde Alcobendas hasta su desembocadura en el Jarama.

- Arroyo Culebro: desde Las Arenas de Pinto hasta el Manzanares.

- Manzanares: entre la presa de El Pardo y el Puente de los Franceses, y desde el nudo sur hasta su desembocadura en el Jarama.

- Tajo: entre Bolareque y Talavera de la Reina.

- Alberche: desde Piacadas hasta su desembocadura.

- Tajuña: Desde Ambite hasta su desembocadura en el Jarama.

Dentro del Plan, también se indica la necesidad de elaborar planes de ordenación y de gestión de los embalses, con el fin de diagnosticar su calidad y su nivel de eutrofización ${ }^{11}$, identificar los posibles focos de contaminación que los amenazan y determinar las medidas correctivas necesarias.

\footnotetext{
${ }^{11}$ Eutrofización es un fenómeno común en los lagos que reciben influencia del ser humano, especialmente por la extracción de agua y vertido de residuos, lo que provoca que el aumento en la cantidad de materia orgánica y nutrientes rebase la capacidad de asimilación del ciclo natural del lago. Las capas superficiales de éste se saturan de oxígeno y de fitoplancton, lo que le da una apariencia turbia y verdosa al agua, mientras que los residuos se depositan en el fondo sin poder ser oxidados (MARGalef, 1992.)
} 


\section{Legislación de la Comunidad de Madrid en materia de aguas}

El Plan Hidrológico de la cuenca del Tajo (PHT) dentro del ámbito madrileño se complementa con la legislación propia de la Comunidad de Madrid relativa a las materias de abastecimiento, saneamiento y vertidos industriales. Sus principales instrumentos son el Plan de Saneamiento y Depuración de Aguas Residuales de la Comunidad de Madrid 1995-2005 (PSD) y los planes de ordenación de embalses.

La realización de los planes de ordenación de embalses queda establecida en la Ley 7/1990 de Protección de Embalses y Zonas Húmedas de la Comunidad de Madrid. El objetivo principal de estos planes es hacer compatible el potencial paisajístico y recreativo de estas infraestructuras con su vulnerabilidad a la contaminación y su carácter estratégico para el abastecimiento de agua de la población. Su contenido, según la propia ley, debe incluir el análisis de las funciones ecológicas del cuerpo de agua y su relación con las comunidades biológicas que habiten en o cerca de él, así como las amenazas que pueden representar las distintas actividades antrópicas en su entorno y, por último, deben definir las zonas de influencia, policía y servidumbre del embalse y los usos y actividades que se puedan dar en estas áreas.

El criterio de zonificación es común para todos los planes de ordenación de embalses, y consiste en definir seis tipos de zonas en el entorno inmediato de la infraestructura, que son:

- Zona de máxima protección: donde solamente se permiten actividades de restauración ecológica, pesca, investigación y educación.

- Zona natural de conservación: que puede dividirse en zonas a conservar y zonas a regenerar. Además de los usos anteriores, se permite el pastoreo de ganado y la explotación forestal, mejora de la vegetación y tendido de tapias.

- Zona de mantenimiento del uso ganadero tradicional: además de los anteriores, se permite el pastoreo extensivo de ganado y la explotación agraria de regadío en circunstancias específicas.

- Zona de uso agrario: además de las anteriores, se permite la creación de explotaciones agrarias de cultivos de regadío.

- Zona recreativa de uso social: se adaptarán a lo dispuesto en la Ley del Suelo. En estas zonas se permiten edificaciones que se integren en el entorno respetando las características de la arquitectura tradicional de las inmediaciones, y deben depurar sus aguas residuales o estar conectadas a la red municipal de saneamiento.

- Zona a ordenar por planeamiento urbanístico: los usos en estas zonas se regirán por el planeamiento urbanístico local, pero deberán cumplir las mismas características de estilo y saneamiento del apartado anterior.

La Consejería de Medio Ambiente de la Comunidad de Madrid ha elaborado planes para los embalses más importantes de la Comunidad, que, según lo indica la ley antes mencionada, ya se debían someter a revisión periódica cada cuatro años, habiendo sido la última en el año 2002. Las infraestructuras que cuentan con su propio plan de ordenación de embalses son: Pinilla, Picadas, Valmayor, La Jarosa, Los Arroyos, Navacerrada, Puentes Viejas, El Atazar, Pedrezuela, Riosequillo y El Villar. El embalse de Santillana (Manzanares el Real) no cuenta con uno propio por estar incluido dentro del ámbito de planeamiento del Parque Regional de la Cuenca Alta del Manzanares, mientras que el embalse de El Pardo tampoco cuenta con uno por pertenecer al Patrimonio Nacional.

El Ayuntamiento de Madrid, a través de su Ordenanza General de Protección del Medio Ambiente Urbano, libro $\mathrm{V}$, hace referencia a su papel en la gestión del ciclo hidrológico, enfocada básicamente a la protección de los recursos hídricos mediante el control de vertidos contaminantes y a la depuración de la totalidad de las aguas residuales. Para este fin, el Ayuntamiento ha elaborado el Plan de Saneamiento Integral de Madrid (PSIM), que se divide en dos etapas.

\section{El esfuerzo global: los programas hidrológicos internacionales de la UNESCO}

Para finalizar este capítulo, conviene mencionar el esfuerzo que realiza desde hace treinta años la Organización de las Naciones Unidas (ONU) a través de la UNESCO en la investigación, conservación y preservación de los valores hidrológicos globales, tanto ambientales como sociales. Aunque no son directamente vinculantes, estos programas han servido de importante referencia en la evolución de la visión de la gestión del agua, que, entre otras cosas, ha dado origen a la Directiva Europea Marco.

El primer Programa Hidrológico Internacional (PHI) data de 1975, y fue la concreción de un decenio dedicado por esta organización a la investigación sobre la situación de los recursos hidráulicos en el mundo. Desde entonces se han puesto en marcha siete PHI con un horizonte temporal de seis años cada uno, 
Cuadro 3: Resumen del marco jurídico en materia de aguas

\begin{tabular}{|c|c|c|}
\hline Legislación europea & $\begin{array}{l}\text { Directiva Marco del agua } \\
(2000 / 60 \text { C.E.E. })\end{array}$ & $\begin{array}{l}\text { Directivas: } \\
\\
\text { - Aguas de consumo: } 440 / 75 ; \\
\quad 480 / 75 ; 869 / 79 ; 778 / 80 ; 271 / 91 ; \\
83 / 98 \text {. } \\
\text { - Vertidos y contaminantes: } \\
\quad 464 / 76 ; 68 / 80 ; 176 / 82 ; 513 / 83 ; \\
\quad 156 / 84 ; 491 / 84 ; 280 / 86 ; 347 / 88 ; \\
\\
415 / 90 ; 676 / 91 ; 61 / 96 .\end{array}$ \\
\hline $\begin{array}{l}\text { Legislación del Estado } \\
\text { español }\end{array}$ & $\begin{array}{l}\text { Ley de aguas (29/1985, Modifi- } \\
\text { cación Ley } 46 / 1999)\end{array}$ & $\begin{array}{l}\text { Reales Decretos: } \\
\text { - Dominio público del agua: } \\
\text { 849/1986; } 1315 / 1992 ; 927 / 1988 ; \\
\text { - Vertidos y contaminantes: } \\
261 / 1996 ; \quad 484 / 1985 ; 11 / 1995 ; \\
509 / 1996 ; 995 / 2000\end{array}$ \\
\hline & Plan Hidrológico Nacional & Planes hidrológicos de cuencas \\
\hline $\begin{array}{l}\text { Legislación autonómi- } \\
\text { ca }\end{array}$ & $\begin{array}{l}\text { Legislación de la Comunidad de } \\
\text { Madrid }\end{array}$ & $\begin{array}{l}\text { Leyes: } 17 / 1984 \text { (abastecimiento y sa- } \\
\text { neamiento), } 10 / 1993 \text { (vertidos indus- } \\
\text { triales). } \\
\begin{array}{l}\text { Decretos: } \quad 127 / 1994 ; 154 / 1997 ; \\
\text { 170/1998; } 345 / 199 .\end{array}\end{array}$ \\
\hline Legislación municipal & $\begin{array}{l}\text { Legislación del Ayuntamiento de } \\
\text { Madrid }\end{array}$ & $\begin{array}{l}\text { Ordenanza General de Protección del } \\
\text { Medio Ambiente / } 2^{\circ} \text { Plan de Sanea- } \\
\text { miento Integral de Madrid / Plan Ge- } \\
\text { neral de Ordenación Urbana. }\end{array}$ \\
\hline
\end{tabular}


siendo el actual el que corresponde al sexenio 2002-2007. Cada programa ha tenido sus metodologías y objetivos propios en los que, según la misma organización, «ha ido cobrando mayor importancia el reconocimiento del papel que desempeña la gestión de los recursos hídricos en el desarrollo sostenible y en la adaptación de las ciencias del agua a los cambios de las condiciones climáticas y medioambientales. Otra evolución considerable ha sido la integración de los países subdesarrollados en las iniciativas mundiales de investigación y formación».

Los primeros tres PHI (1975-1989) fueron enfocados hacia el tema de los fundamentos científicos para la gestión racional del agua, dentro de un marco muy específico y monodisciplinar. A partir del cuarto PHI (1990-1995) la temática ha sido abierta a consideraciones más generales e incluyentes, trabajando con temas como «la hidrología y los recursos hídricos para el desarrollo sostenible en un medio ambiente en evolución», o el correspondiente al quinto PHI (1996-2001), que estuvo dedicado a «la hidrología y el desarrollo de los recursos hídricos en un medio ambiente vulnerable».

El Programa actual (PHI-VI, 2002-2007) lleva por título «El agua, fenómeno de interacción: sistemas en peligro y problemas sociales», y toma como línea de investigación las tensiones e interacciones identificables entre el ciclo natural del agua con todas sus implicaciones biológicas y las actividades humanas y su impacto global, para lo cual implementa la idea de márgenes como puntos a investigar: los márgenes entre aguas superficiales y subterráneas, entre continentales y costeras, entre locales y mundiales, entre cantidad y calidad, entre ciencia y política, etc.

Como estructura, el PHI-VI cuenta con cinco áreas temáticas generales:

- Tema 1. «Los cambios mundiales y los recursos hídricos». Dentro de esta área temática se pretende estudiar el impacto que han tenido sobre los recursos hídricos a nivel global los cambios más importantes en la sociedad y sus respectivos impactos, como la industrialización, el crecimiento poblacional, el calentamiento global y el dominio del recurso mediante la ingeniería hidráulica. Como herramienta principal el programa pretende fomentar los estudios a nivel local en las distintas cuencas.

- Tema 2. «La dinámica integrada de las cuencas y los acuíferos». Como continuación del tema anterior, se pretende estudiar a nivel de cuenca local las interrelaciones entre el ciclo hidrológico y otros elementos medioambientales, así como las interrelaciones con las actividades y los hábitats humanos.

- Tema 3. «La hidrología de los hábitats terrestres». En esta área de estudio se plantea la investigación regional a partir de la interrelación entre tres temas fundamentales: las categorías climáticas (zonas áridas, templadas, húmedas y frías), la topografía (tierras de secano, humedales, montañas, islas) y el uso de la tierra (urbano, rural, natural).

- Tema 4. «El agua y la sociedad». En este tema se pretende hacer especial énfasis a el componente humano de las interrelaciones planteadas en los temas anteriores, especialmente en la importancia que tienen en torno al agua los hábitos, las costumbres, las creencias y las prácticas.

- Tema 5. «La educación y la formación en recursos hídricos». Mediante esta línea se pretende utilizar el conocimiento adquirido para programas de educación, formación y concienciación general, con un importante énfasis en los sistemas de acceso a la información.

Junto con los planes hidrológicos internacionales, la ONU ha hecho énfasis durante los últimos años en el problema ambiental y social del agua mediante varios programas y eventos, como el Programa Mundial de Evaluación de Recursos Hídricos.

\section{Análisis del consumo actual de agua en la Comunidad de Madrid}

\section{Breve introducción al modelo de desarrollo actual de la Comunidad de Madrid}

\section{A.Desarrollo demográfico}

La Comunidad de Madrid tiene una superficie de $8.028 \mathrm{~km}^{2}$ y cuenta con una población de 5.625.019 habitantes, según datos referentes al año 2002. Del total de la población de la Comunidad, el 54\% (3.059.703 habitantes) reside en el municipio de Madrid, un 35\% (1.966.142 habitantes) habita en los municipios periféricos del área metropolitana, mientras que el $11 \%$ restante (599.169) lo hace en los municipios no metropolitanos. Como se aprecia en la Figura 13, la población de la Comunidad aumentó casi un $9 \%$ entre 1991 y 2001. Esta tendencia se refleja sobre todo en el crecimiento de los municipios periféricos del área metropolitana, mientras que la población del municipio de Madrid se mantuvo prácticamente estable, e incluso perdió población, entre los años 1991 y 1999. 


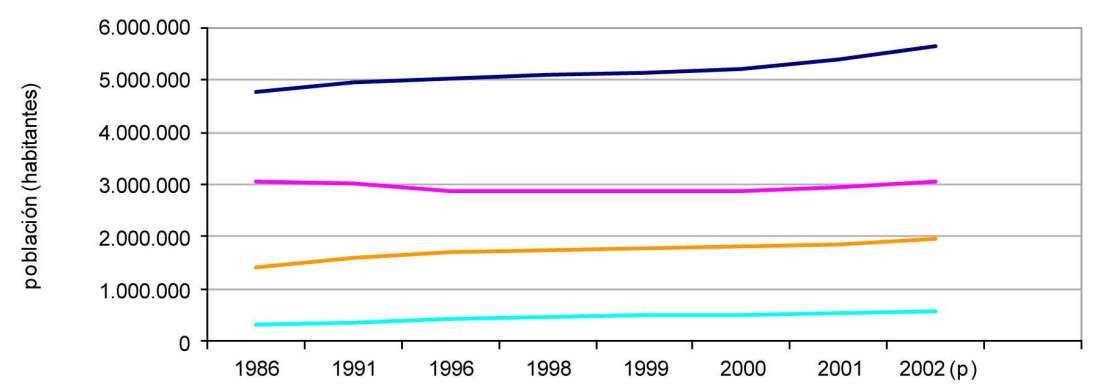

\begin{tabular}{|ll|}
\hline- Comunidad de Madrid & \\
- Corona metropolitana & Municipio de Madrid \\
\hline & Municipios no metropolitanos \\
\hline
\end{tabular}

\section{Figura 13: Crecimiento poblacional en la Comunidad de Madrid} Fuente: Anuario Estadístico de la Comunidad de Madrid.

Como se puede intuir a partir del gráfico anterior, la Comunidad se caracteriza por una concentración de población altamente centralizada en la zona metropolitana. Esto se puede corroborar al observar los índices de densidad poblacional de la Comunidad (ver Figura 14), que se manifiestan como una secuencia de círculos concéntricos de densidad descendente, estando la mayor en el centro correspondiendo al municipio de Madrid y a los municipios adyacentes a él, con una distribución mayor de 1.000 habitantes por kilómetro cuadrado. A continuación se encuentran los municipios que rodean al área metropolitana, que registran una densidad variable entre los 100 y los 1.000 habitantes por kilómetro cuadrado. El resto de los municipios de la Comunidad registran entre 10 y 100 habitantes por kilómetro cuadrado y, finalmente, los municipios del norte de la Comunidad, ubicados en plena zona serrana, registran una densidad menor de diez.
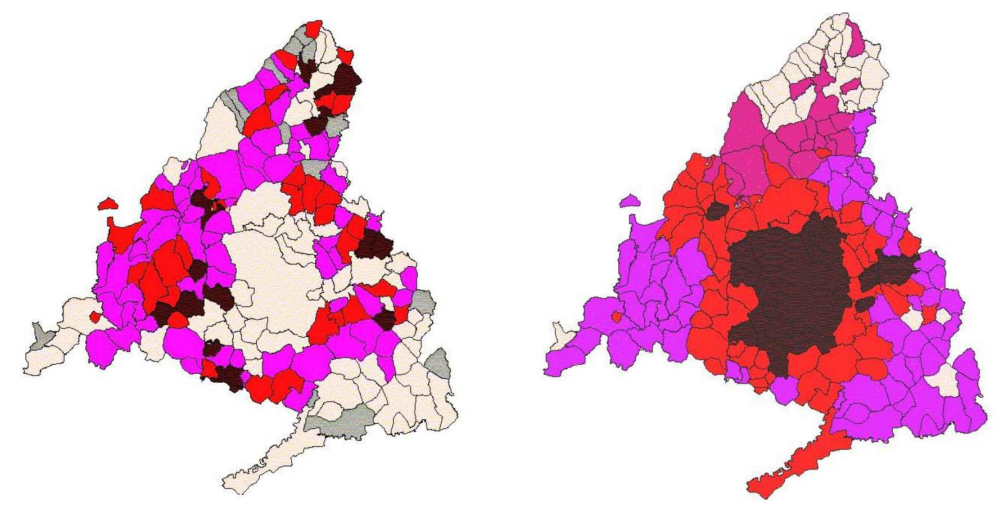

\begin{tabular}{|l|l|}
\hline & Variación negativa \\
\hline & Aumento menor al 5\% \\
\hline & Aumento del 5 al $9,99 \%$ \\
\hline Aumento del 10 al $14,99 \%$ \\
\hline Aumento del15\% y más \\
\hline
\end{tabular}

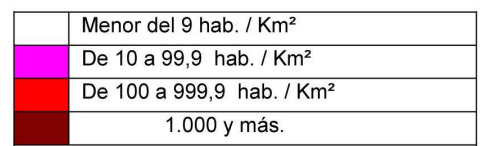

Figura 14: Crecimiento poblacional y densidad poblacional

Fuente: Instituto Estadístico de la Comunidad Autónoma de Madrid.

Según la Proyección de la población de la Comunidad de Madrid 2002-2017 realizada por el Instituto de Estadística de la Comunidad de Madrid, la tendencia actual de crecimiento de población se mantendrá 
e incluso llegará a aumentar hasta una tasa del 15,7\% en el periodo reseñado, lo que significa que para el año 2017 la población madrileña alcanzará los 6,7 millones de personas. Según el mismo estudio, el mayor incremento de la población se ubicará en los municipios de la corona metropolitana, que absorberán un $43,8 \%$ del crecimiento, mientras que los extra-metropolitanos contendrán el 35,6\% y, finalmente, el municipio de Madrid el 20,6\%. Este hipotético crecimiento alterará levemente la distribución actual de la población, ya que de cumplirse sus previsiones, el municipio de Madrid albergará al $49 \%$ del total de la población de la Comunidad, mientras que un 36\% será para la Corona y un $15 \%$ para los municipios no metropolitanos.

\section{B.Desarrollo socioeconómico}

El modelo de desarrollo actual de la Comunidad de Madrid comienza a conformarse a finales de los años setenta, cuando la crisis económica global, marcada por el aumento en los precios de petróleo, propicia la decadencia del sector industrial, sobre el cual estaba basado el crecimiento económico madrileño hasta entonces.

A partir de ese momento, el modelo de desarrollo económico y social de Madrid se puede explicar a través de tres etapas cronológicas (LóPEZ DE LUCiO, 1999). La primera va de 1979 a 1985 y se caracteriza por una profunda crisis que trasciende a todos los sectores productivos y en especial a la industria. La segunda, hasta 1981, donde la apertura al contexto europeo permite la recuperación de los sectores más atrasados, especialmente el de servicios y el de la construcción, acompañado de una fuerte emigración desde el centro de la ciudad hacia la periferia en busca de suelo barato. Finalmente, a partir de 1991 se genera un proceso de recuperación sustentado en la Unión Europea, durante el cual las principales inversiones se destinaron a infraestructuras de transporte y al desarrollo inmobiliario, especialmente al de la vivienda. En esta última etapa se ha generalizado el consumo como «acto social por excelencia», lo que ha motivado el rápido crecimiento de las grandes superficies comerciales en la periferia de la ciudad.

Actualmente, el modelo de desarrollo económico reflejado en el PIB de la Comunidad de Madrid se caracteriza por el dominio del sector terciario (ver Cuadro 4), constituido principalmente por actividades comerciales (incluyendo la hostelería y las comunicaciones) y por servicios financieros e inmobiliarios. Por detrás se encuentra el sector industrial (incluido el energético) y la agricultura (incluidas la ganadería y la caza). Por último, pero no por ello menos importante, se encuentra el sector de la construcción, que ha sido el único que ha crecido más del $100 \%$ durante el periodo 1993-2002.

Cuadro 4: Producto Interior Bruto de la Comunidad de Madrid. (precios corrientes)

Fuente: Instituto Estadístico de la Comunidad de Madrid.

\begin{tabular}{|c|c|c|c|c|}
\hline Sector & $\begin{array}{l}\text { Valor en mi- } \\
\text { les de euros. } \\
1993 .\end{array}$ & $\begin{array}{l}\text { Valor en mi- } \\
\text { les de euros. } \\
2002 \text {. }\end{array}$ & $\%$ PIB 2002 & $\begin{array}{l}\% \text { empleos } \\
\text { por }\end{array}$ \\
\hline $\begin{array}{l}\text { Agricultura, ganade- } \\
\text { ría, caza y selvicultura } \\
\text { y pesca }\end{array}$ & 118.357 & 127.752 & 0,10 & 0,79 \\
\hline $\begin{array}{l}\text { Industria, incluida la } \\
\text { energía }\end{array}$ & 12.643 .071 & 19.640 .548 & 15,27 & 14,95 \\
\hline Construcción & 4.639 .306 & 9.588 .357 & 7,15 & 9,52 \\
\hline $\begin{array}{l}\text { Comercio, hostelería y } \\
\text { transporte; almacena- } \\
\text { miento y comunicacio- } \\
\text { nes }\end{array}$ & 17.461 .576 & 32.616 .995 & 25,75 & \\
\hline $\begin{array}{l}\text { Intermediación finan- } \\
\text { ciera, actividades in- } \\
\text { mobiliarias y servicios } \\
\text { empresariales }\end{array}$ & 16.071 .488 & 31.907 .476 & 25,28 & 74,74 \\
\hline $\begin{array}{l}\text { Otras actividades de } \\
\text { los servicios }\end{array}$ & 15.655 .398 & 25.636 .557 & 20,21 & \\
\hline $\begin{array}{ll}\text { Imp. } & \text { Netos } \\
\text { s/productos } & \\
\end{array}$ & 4.840 .907 & 8.350 .696 & 6,24 & \\
\hline $\begin{array}{l}\text { Total Producto In- } \\
\text { terior Bruto (PIB) }\end{array}$ & 68.338 .958 & 123.752 .716 & 100 & 100 \\
\hline
\end{tabular}




\section{La demanda de agua en la Comunidad de Madrid}

Dentro de la Unión Europea, España, los países mediterráneos (Italia y Grecia) y Portugal se caracterizan por una demanda de agua en la que predomina el uso agrícola, a diferencia de los países nórdicos, que destinan la mayor parte de su recurso disponible a la refrigeración de estaciones productoras de energía eléctrica (Libro blanco del agua, 1998). Esto se refleja en la diferencia de consumo por habitante de los países del sur del continente, con altos índices de volúmenes abastecidos, con los del norte, en teoría más industrializados y de clima más húmedo y frío, que presentan consumos más moderados (Cuadro 5).

CUADRO 5: Consumo por sectores de producción y por países

Fuente: MMA. Libro blanco del agua

\begin{tabular}{|c|c|c|c|c|}
\hline & Urbano (\%) & Industrial (\%) & Agricultura ( \%) & Refrigeración (\%) \\
\hline España & 13 & 5 & 68 & 14 \\
\hline Media Europea & 14 & 10 & 30 & 46 \\
\hline
\end{tabular}

\begin{tabular}{|l|c|c|c|c|c|c|c|l|}
\hline & España & Grecia & Italia & Portugal & Reino Unido & Alemania & Francia & $\begin{array}{l}\text { Media Euro- } \\
\text { pea }\end{array}$ \\
\hline $\begin{array}{l}\text { Consumo } \\
\mathrm{m}^{3} / \text { hab } / \mathrm{año}\end{array}$ & $530^{12}$ & 334 & 523 & 339 & 51 & 71 & 124 & 207 \\
\hline
\end{tabular}

$\mathrm{Al}$ contrario que la media nacional española, en la que el principal sector consumidor de agua es por un amplio margen el que se dedica a la actividad agropecuaria, la Comunidad de Madrid se caracteriza por un consumo predominantemente urbano. Hasta cierto punto, esta peculiaridad resulta evidente al entender que la distribución de superficies de suelo en la región presenta un marcado carácter urbano, industrial y de servicios terciarios, en detrimento de las superficies de producción agrícola, cuya tendencia es reducirse en los últimos años.

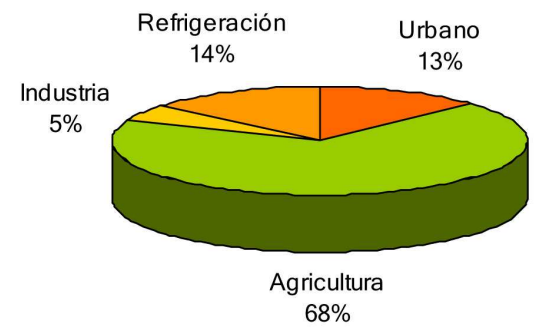

FIGURA 15: Distribución del consumo de agua por sectores en España Fuente: MMA. Libro blanco del agua

\section{A.Demanda urbana}

Desde la inauguración del Canal de Isabel II en 1858 la demanda urbana de agua se ha incrementado sostenidamente, alcanzando su máximo ritmo de crecimiento a partir de la década de los años cincuenta y hasta principios de la de los noventa, cuando las fuertes sequías ocasionadas por las escasas precipitaciones de esos años obligaron a una reducción drástica de los consumos. Este crecimiento del consumo, que se duplicó en tan sólo veinticinco años, pasando de cerca de $300 \mathrm{hm}^{3}$ en 1965 a $600 \mathrm{hm}^{3}$ en 1990, puede explicarse por tres razones. La primera y más evidente es el acelerado crecimiento demográfico registrado durante esos años, que se desarrolló casi al mismo ritmo (de 2,6 millones de habitantes en 1960 a 5 millones en 1991).

Por otro lado, coincide en esta época el desarrollo de la industria pesada y altamente consumidora del recurso y, finalmente, debido a la divulgación de hábitos consumistas respaldados por el énfasis dado 


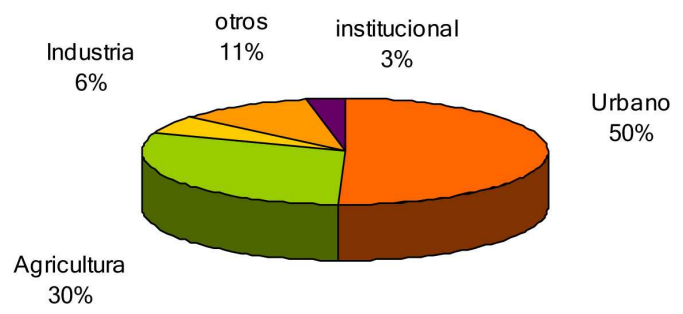

Figura 16: Distribución del consumo de agua por sectores en la Comunidad de Madrid Fuente: INE y CANAL DE ISABEL II

\begin{tabular}{|l|l|}
\hline- & Consumo de agua $\left(\mathrm{Hm}^{3}\right)$ \\
\hline-- & Proyección Canal Isabel II \\
\hline- & Población (miles de habitantes) \\
\hline
\end{tabular}

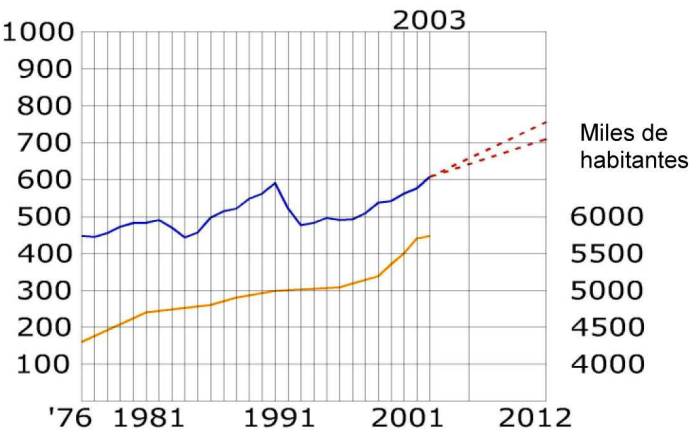

Figura 17: Evolución del consumo urbano de agua y de la población Fuente: INE y CANAL DE ISABEL II 
por el régimen a la construcción de grandes obras hidráulicas, que contribuyeron a fortalecer la idea de que el abastecimiento era prácticamente ilimitado gracias al desarrollo de la tecnología.

Este proceso consumista, sin embargo, sufre una importante contracción durante la primera mitad de los años noventa debido a gravísimas sequías, que obligaron a la modificación de algunos aspectos de la gestión, como la reestructuración del sistema tarifario y de medición, y a la difusión de la cultura del ahorro mediante campañas publicitarias y de concienciación. De 1991 a 1993 se logra una reducción en el consumo de casi $115 \mathrm{hm}^{3}$ (de un punto máximo de $590 \mathrm{hm}^{3}$ hasta el mínimo registrado desde 1985 hasta la fecha de 476). Desde entonces, el total abastecido por el Canal de Isabel II a la Comunidad de Madrid ha retomado una tendencia alcista, aunque mucho menos acelerada, alcanzando en 2001 un volumen semejante al suministrado en 1990 (aunque con un crecimiento poblacional de casi 340.000 personas durante esos once años).

CuAdro 6: Consumo por sectores en la Comunidad de Madrid ( $\mathrm{hm}^{3}$ /año en 2001) Fuente: INE y CANAL ISABEL II

\begin{tabular}{|l|l|l|l|l|l|l|l|l|}
\hline Agrario & Doméstico & Comercial & Industrial & Institucional & $\begin{array}{l}\text { Otros } \\
\text { usos }\end{array}$ & $\begin{array}{l}\text { Operación } \\
\text { del siste- } \\
\text { ma }\end{array}$ & $\begin{array}{l}\text { Perdidas } \\
\text { y fugas }\end{array}$ & \begin{tabular}{l} 
Total \\
\hline 207,76
\end{tabular} 287,167 \\
\hline
\end{tabular}

Durante el año 2001, el Canal de Isabel II derivó desde sus embalses un total de 561,653 $\mathrm{hm}^{3}$, de los cuales sólo llegaron a suministrarse 549,097 y fueron controlados y facturados en su destino final $450,086 \mathrm{hm}^{3}$. Esta pérdida de $110 \mathrm{hm}^{3}$ en el camino, que equivalen a casi un $20 \%$ del total derivado, se debe principalmente a roturas y fallos en los sistemas, tanto de suministro como de distribución, aunque también cuenta de manera importante pero difícil de cuantificar el agua no controlada debido a sistemas de contadores inadecuados, o, en otros casos, al pillaje de agua sustraída desde diversos puntos de la red. Las diferencias anteriormente mencionadas implican que, aunque el consumo de agua promedio por habitante al día en Madrid es de 296 litros, al contabilizar el total de agua derivada, se observa una reducción a 232 litros si se mide el agua suministrada en sus destinos y hasta 149 litros si se cuenta sólo el agua suministrada a los hogares, lo cual representa un consumo doméstico moderado tratándose de una ciudad con un nivel de desarrollo alto.

Tomando como muestra los datos para el consumo de agua en 2001, podemos observar que de los $561,653 \mathrm{hm}^{3}$ derivados desde los embalses del Canal de Isabel II, 287,167 se destinaron al consumo doméstico, 42,147 al consumo comercial, 36,630 al industrial, 21,397 al institucional y 77,940 a otros usos. Además, se perdieron 57,595 en roturas y desperfectos de la red de suministro, 50,226 en la red de

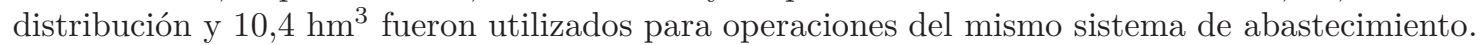

\section{B.Consumo doméstico}

Dentro del consumo doméstico es importante recalcar las diferencias de consumo debidas a las dos principales tipologías de vivienda. Por un lado, las viviendas en bloques plurifamiliares consumieron $241,028 \mathrm{hm}^{3}$ (el 83,9\% del total del consumo doméstico), mientras que las unifamiliares demandaron $46,139 \mathrm{hm}^{3}$ (un 16,1\%).

Tomando en cuenta que el total de viviendas abastecidas ${ }^{13}$ por el Canal de Isabel II en 2001 fue de 1.974.939, de las cuales 1.728 .649 (el $88 \%$ del total) son plurifamiliares y 246.240 unifamiliares (el $12 \%$ del total), se puede distinguir que, a pesar de ser la vivienda plurifamiliar la mayor demandante de abastecimiento por ser la tipología más numerosa en la región, es la residencia unifamiliar la que presenta el mayor consumo por unidad de vivienda. La relación entre la demanda de ambas tipologías, tomando los datos de 2001, muestra que el consumo medio por vivienda plurifamiliar ese año fue de $139 \mathrm{~m}^{3}$, mientras que el de las unidades unifamiliares fue de $189 \mathrm{~m}^{3}$. Por otro lado, esta diferencia es aún más marcada cuando se trata de viviendas nuevas, provistas de dispositivos hidráulicos de ahorro y contadores individualizados por vivienda, lo cual ha tenido una gran repercusión sobre la vivienda plurifamiliar, logrando un descenso considerable del consumo. Desde que en 1993 se pusieran en marcha

\footnotetext{
${ }^{13}$ Para la elaboración de las proyecciones de demanda futura, el Canal de Isabel II toma como referencia las figuras de crecimiento contenidas en los Planes Generales de Ordenación Urbana, debido a la inexactitud histórica de las predicciones estadísticas de crecimiento poblacional. Además del posible crecimiento, la referencia al planeamiento permite intuir a los gestores del agua, no solamente la cantidad que se demandará, sino también dónde se demandará.
} 


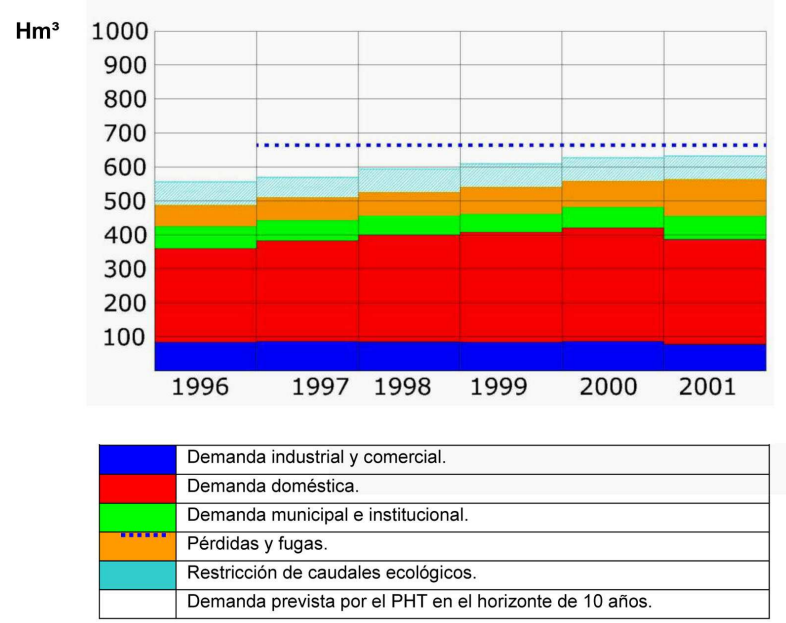

FigurA 18: Evolución de la demanda urbana por sectores

Fuente: Elaboración propia a partir de Canal de Isabel II.

estas medidas, y hasta 2001, el consumo en las viviendas nuevas se ha reducido hasta los $120 \mathrm{~m}^{3}(350$ litros por vivienda al día) mientras que en las unifamiliares se ha mantenido el mismo rango de consumo (520 litros por vivienda al día).

\section{Cuadro 7: Previsiones de crecimiento en la Comunidad de Madrid según el planeamiento} urbano.

Fuente: CuBillo, 2001

\begin{tabular}{|c|l|l|l|r|r|r|}
\hline Año & $\begin{array}{l}\text { Vivienda } \\
\text { Plurifamiliar } \\
\text { (unidades) }\end{array}$ & $\begin{array}{l}\text { Viviendas } \\
\text { Unifa- } \\
\text { miliares } \\
\text { (unidades) }\end{array}$ & $\begin{array}{l}\text { Superficie } \\
\text { Terciario } \\
\left(\mathrm{m}^{2}\right)\end{array}$ & $\begin{array}{l}\text { Superficie } \\
\text { Dotacional } \\
\left(\mathrm{m}^{2}\right)\end{array}$ & $\begin{array}{l}\text { Zonas Verdes } \\
\left(\mathrm{m}^{2}\right)\end{array}$ \\
\hline 2001 & 1.782 .649 & 246.290 & 8.366 .760 & 29.870 .141 & 16.268 .441 & 7.802 .830 \\
\hline 2006 & 1.870 .986 & 521.623 & 10.247 .402 & 38.297 .457 & 19.179 .152 & 9.248 .347 \\
\hline 2010 & 1.995 .623 & 561.827 & 14.480 .211 & 47.524 .384 & 23.469 .815 & 14.169 .492 \\
\hline 2014 & 2.193 .987 & 710.479 & 21.958 .640 & 70.143 .125 & 30.796 .567 & 20.769 .066 \\
\hline
\end{tabular}

Según el Estudio de la demanda de agua para uso urbano en la Comunidad de Madrid, publicado por el Canal de Isabel II en 2001, el consumo de agua en las viviendas llega a alcanzar los 800 litros por vivienda al día en los meses de verano, cuando hace más calor ( $3 \mathrm{hm}^{3}$ en el total anual). Este incremento se reporta casi íntegramente en las viviendas unifamiliares, y puede deberse principalmente al riego de jardines, llenado de piscinas y funcionamiento de sistemas de aire acondicionado.

El uso doméstico ha aumentado de forma constante desde 1987, de casi $200 \mathrm{hm}^{3}$ al año hasta los 287 $\mathrm{hm}^{3}$ registrados en 2001. En este mismo periodo de tiempo las unidades de vivienda abastecidas han crecido de manera igualmente espectacular: de 1.200 .000 viviendas plurifamiliares que se abastecían en 1987 a 1.600 .000 abastecidas en 2001. Sin embargo, la evolución más significativa es la presentada por la vivienda unifamiliar, ya que en el mismo lapso de tiempo aumentó su número desde las 30.000 hasta las 200.000 unidades.

Tratando de matizar aún más este cambio, resulta muy ilustrativo observar la evolución del consumo doméstico unifamiliar según las zonas de abastecimiento establecidas por el Canal de Isabel II. Tomando como muestra el lapso de tiempo anteriormente mencionado (1987-2001), se observa que en la zona industrial (municipio de Madrid y Madrid Sur) el consumo se ha elevado de 10 a $16 \mathrm{hm}^{3}$ (incremento del $60 \%$ ); en la zona residencial (Municipios del norte y del oeste madrileño) el crecimiento ha sido de 4 a 
$14 \mathrm{hm}^{3} \mathrm{y}$, finalmente, en el resto de municipios de la periferia abastecidos por el Canal, el crecimiento ha sido de 1 a $15 \mathrm{hm}^{3}$ (ver Figura 19).

El Cabal Isabel II ha basado sus hipótesis para consumos futuros en la Comunidad de Madrid a partir del supuesto de crecimiento urbano según el total previsto en los planes de desarrollo regionales. Estas previsiones se caracterizan por el crecimiento continuo del consumo de agua a un ritmo semejante al de los años anteriores a las sequías de principios de los noventa. Según el Manual para el abastecimiento de agua publicado por esa institución, la demanda de agua previsible para 2012 (fecha especialmente significativa por el proyecto olímpico y sus implicaciones urbanas) será de entre 709 y $755 \mathrm{hm}^{3}$, dependiendo de que las características climáticas sean inhibidoras o potenciadoras del consumo.

\begin{tabular}{|l|}
\hline Madrid + zona industrial \\
\hline Corona residencial
\end{tabular}

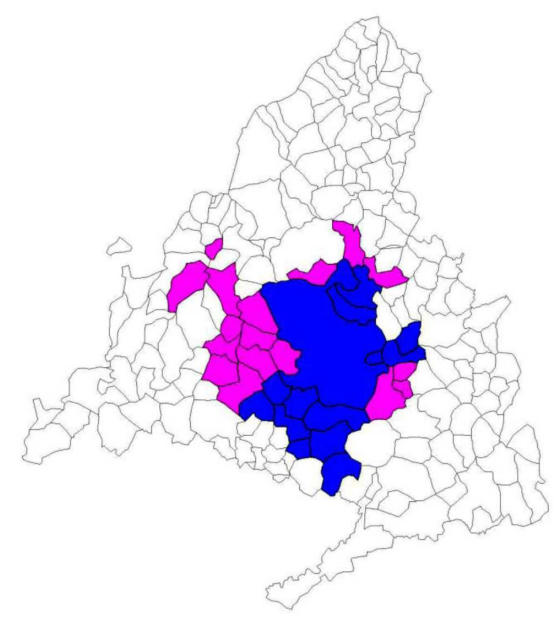

FIGURA 19: Distribución funcional por municipios del área metropolitana Fuente: Elaboración propia a partir de CubiLlo (2001).

\begin{tabular}{|l|l|}
\hline Más de $100 \mathrm{~m}^{3} / \mathrm{hab} /$ año \\
\hline Entre 90 y $100 \mathrm{~m}^{3} / \mathrm{hab} /$ año \\
\hline Entre 80 y $90 \mathrm{~m}^{3} / \mathrm{hab} /$ año \\
\hline Menos de $80 \mathrm{~m}^{3} / \mathrm{hab} /$ año \\
\hline
\end{tabular}

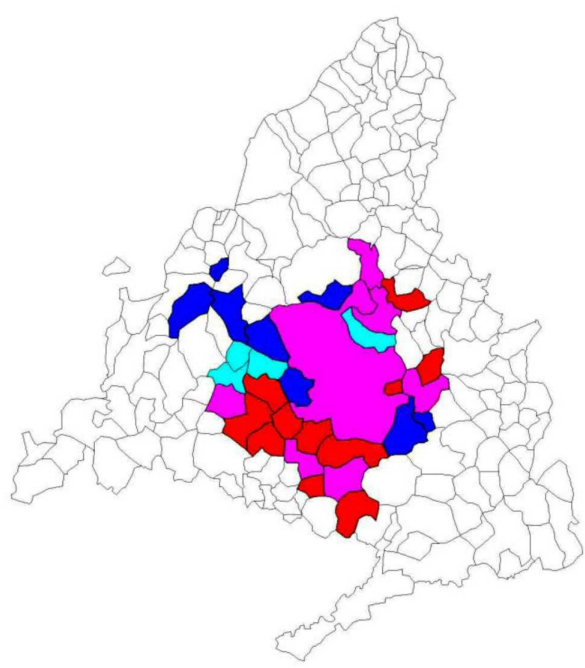

FIGURA 20: Facturación de agua por municipios del área metropolitana Fuente:Elaboración propia a partir de Anuario Estadístico de la Comunidad de Madrid.

\section{C.Consumo por municipios}

Para tratar de entender la correlación entre el modelo de desarrollo de la zona metropolitana de Madrid y el consumo general de agua en la región, en este trabajo se plantea relacionar algunos indicadores. Los 
resultados obtenidos, como se verá más adelante, no pueden ni pretenden comprobar definitivamente el impacto del modelo actual de desarrollo sobre el incremento en el consumo de agua, entendido como una simple relación de tipo causa y efecto, pero sí permiten intuir ciertas correspondencias que pueden ser ilustrativas sobre cómo ciertos elementos socioeconómicos se reflejan en el volumen de consumo de algunos recursos.

CuAdro 8: Relación de Municipios, consumos por habitante y renta anual Fuente: Anuario Estadístico de la Comunidad de Madrid.

\begin{tabular}{|c|c|c|}
\hline Zona & $\begin{array}{l}\text { Consumo por habitan- } \\
\text { te }\left(\mathrm{m}^{3} / \text { año } 2001\right)\end{array}$ & $\begin{array}{l}\text { Renta Bruta anual per } \\
\text { cápita (euros) }\end{array}$ \\
\hline Madrid + Corona Industrial & 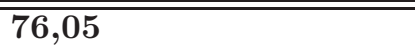 & "10.139 \\
\hline Madrid & 80,77 & 12.767 \\
\hline Alcobendas & 96,15 & 15.488 \\
\hline Alcorcón & 68,20 & 9.842 \\
\hline Coslada & 73,25 & 9.801 \\
\hline Fuenlabrada & 84,75 & 8.464 \\
\hline Getafe & 75,82 & 9.552 \\
\hline Leganés & 66,47 & 8.877 \\
\hline Móstoles & 65,26 & 9.068 \\
\hline Parla & 56,44 & 7.955 \\
\hline Pinto & 88,05 & 9.665 \\
\hline Sn. F. de Henares & 81,53 & 9.681 \\
\hline Sn. S. de los Reyes & 72,15 & 11.800 \\
\hline Torrejón de A. & 77,30 & 9.427 \\
\hline Valdemoro & 78,65 & 9.568 \\
\hline Cinturón Residencial & $\overline{94,83}$ & 14.678 \\
\hline Algete & 47,98 & 14.358 \\
\hline Alpedrete & 123,05 & 12.459 \\
\hline Boadilla del Monte & 74,05 & 17.609 \\
\hline Brunete & 82,92 & 11.507 \\
\hline El Escorial & 121,5 & 12.162 \\
\hline Galapagar & 121,49 & 13.593 \\
\hline Majadahonda & 93,31 & 18.002 \\
\hline Mejorada del Campo & 89,17 & 8.991 \\
\hline Pozuelo de Alarcón & 100,57 & 20.711 \\
\hline Rivas-Vaciamadrid & 105,06 & 12.703 \\
\hline Las Rozas & 118,21 & 18.017 \\
\hline Sn. Ag. De Guadalix & 87,73 & 15.398 \\
\hline Tres Cantos & 101,3 & 16.174 \\
\hline Velilla de Sn. Antonio & 95,14 & 11.000 \\
\hline Villanueva de la $\mathrm{C}$. & 96,71 & 17.641 \\
\hline Villaviciosa de Odón & 59,1 & 14.530 \\
\hline
\end{tabular}

En el lustro de 1996 a 2001 el volumen de agua facturado en la Comunidad de Madrid aumentó de $372,58 \mathrm{hm}^{3}$ a $433,98 \mathrm{hm}^{3}$. Durante este periodo de tiempo, el porcentaje del consumo realizado por los municipios de Madrid y la corona industrial disminuyó, al pasar de representar el $83 \%$ del total a sólo el $80 \%$. Por su parte, el consumo en los municipios periféricos abastecidos por el Canal de Isabel II aumentó de manera proporcional su participación en la facturación total del agua de la Comunidad (del 17 al $20 \%$ ) (Figura 21).

Este fenómeno se puede entender como una consecuencia directa del crecimiento poblacional y urbano en los municipios periféricos del área metropolitana de Madrid; sin embargo, es posible que el aumento del consumo no solamente se corresponda con el poblacional, sino que también se vea influenciado por el tipo de crecimiento urbano de algunos municipios, especialmente los del norte y el oeste, donde predomina la construcción de vivienda aislada con jardín, y donde probablemente los hábitos de consumo son más intensos que en las zonas del sur y del este de la metrópoli. 

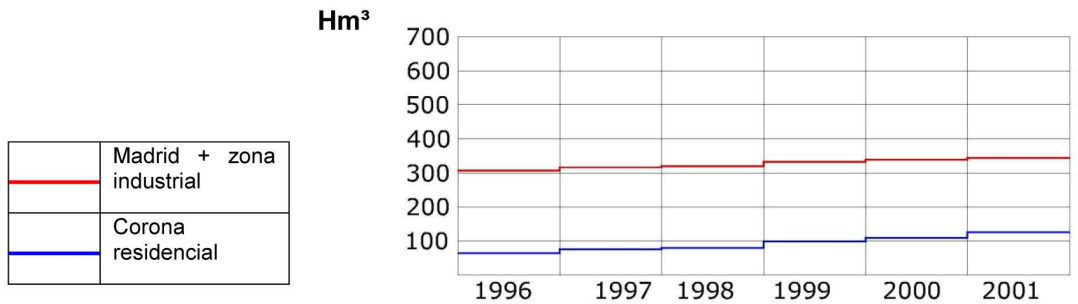

Figura 21: Evolución del consumo de agua por zonas.

Fuente: Elaboración propia a partir del Anuario Estadístico de la Comunidad de Madrid.

Con respecto a la tendencia anterior, resulta ilustrativo el relacionar el consumo de agua con ciertos indicadores que puedan mostrar las diferencias socioeconómicas de los distintos municipios que conforman el área metropolitana de Madrid. En este caso, los indicadores seleccionados han sido: la renta bruta anual per cápita, como indicador del poder socioeconómico; la producción de residuos sólidos, como indicador de los hábitos de consumo y la densidad poblacional del municipio que, a pesar de depender de varios posibles matices ilustra el nivel de compacidad o dispersión del municipio.

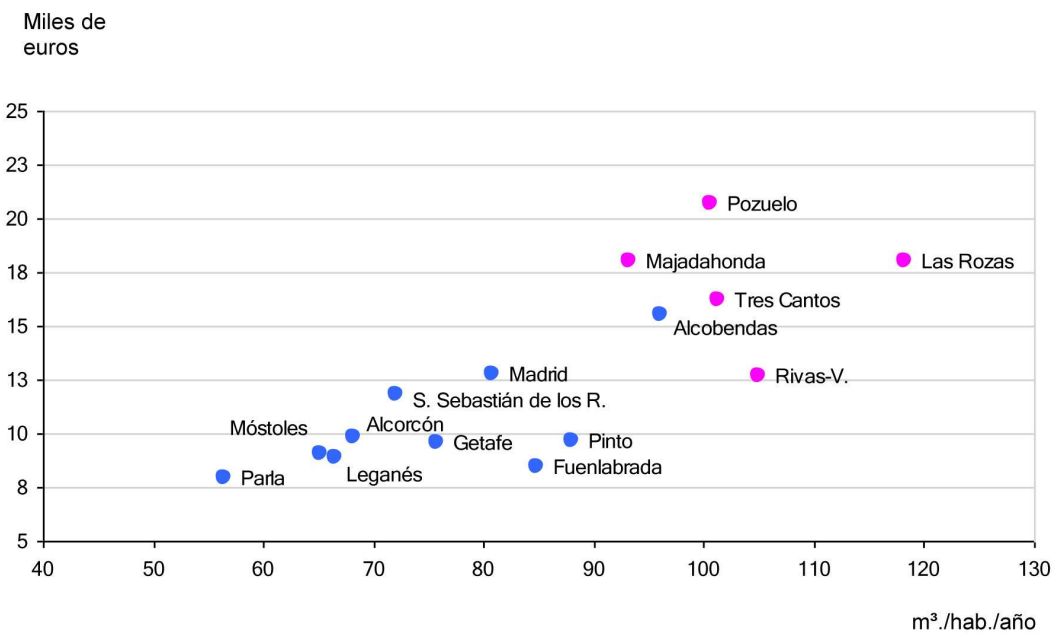

Figura 22: Relación entre consumo de agua $(\mathrm{X})$ y renta bruta anual per cápita (Y) . Fuente: elaboración propia a partir de Anuario Estadístico de la Comunidad de Madrid, 2003.

Como se aprecia en la gráfica anterior, se puede identificar una tendencia similar entre un grupo de municipios con renta anual superior a 15 mil euros y consumo anual mayor a los $90 \mathrm{~m}^{3}$ por habitante, constituido por Pozuelo, Majadahonda, Tres Cantos, Alcobendas y las Rozas, todos ellos pertenecientes a la periferia residencial. Curiosamente, el Municipio de Madrid actúa no sólo como centro geográfico sino también como escalón intermedio, tanto de ingresos como de consumo. El extremo opuesto lo componen los municipios industriales del sur, que no sólo se caracterizan por un nivel económico más bajo, sino también por un menor consumo. Dado que el agua no es un bien de lujo, se puede descartar la idea de que las diferencias en la demanda se deban a la falta de disponibilidad económica de los habitantes.

En esta gráfica, que relaciona la producción de residuos sólidos con el consumo de agua, se repite hasta cierto punto la tendencia anterior, donde existe una correspondencia casi geográfica entre los municipios más consumidores del norte y los menos del sur. Gracias a esta gráfica y a la anterior se puede asumir que existen unos marcados y muy diferenciados hábitos de consumo en el área metropolitana de Madrid.

En esta última gráfica, que relaciona la densidad de población con el consumo de agua, no aparece una tendencia tan evidente como en las dos anteriores, probablemente a causa de que la menor densidad de los municipios periféricos puede deberse a una importante presencia de parques industriales y comerciales 


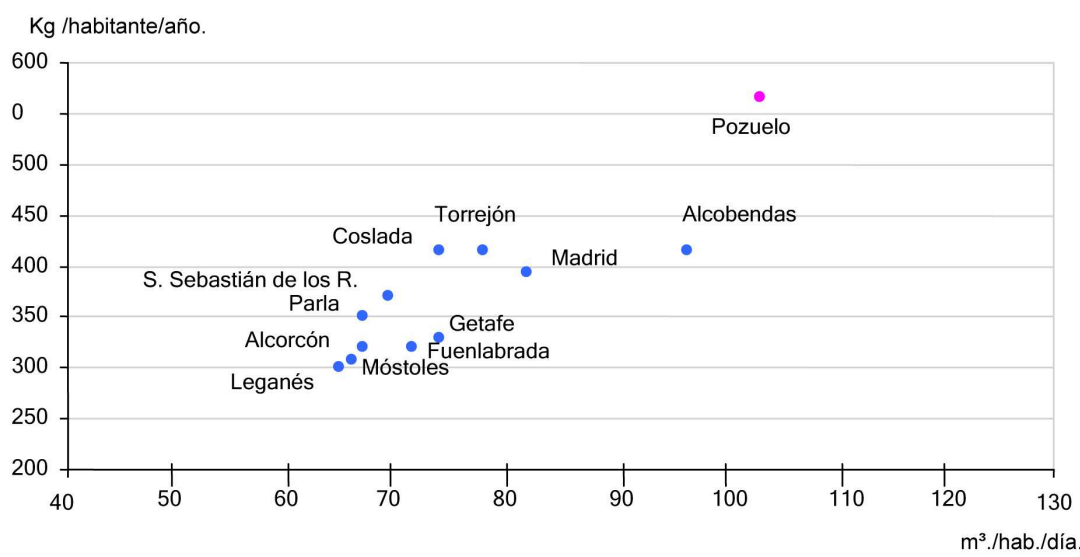

Figura 23: Relación entre consumo de agua (X) y producción de residuos sólidos (Y). Fuente: Consejería de Medio Ambiente de la Comunidad de Madrid, 1998.

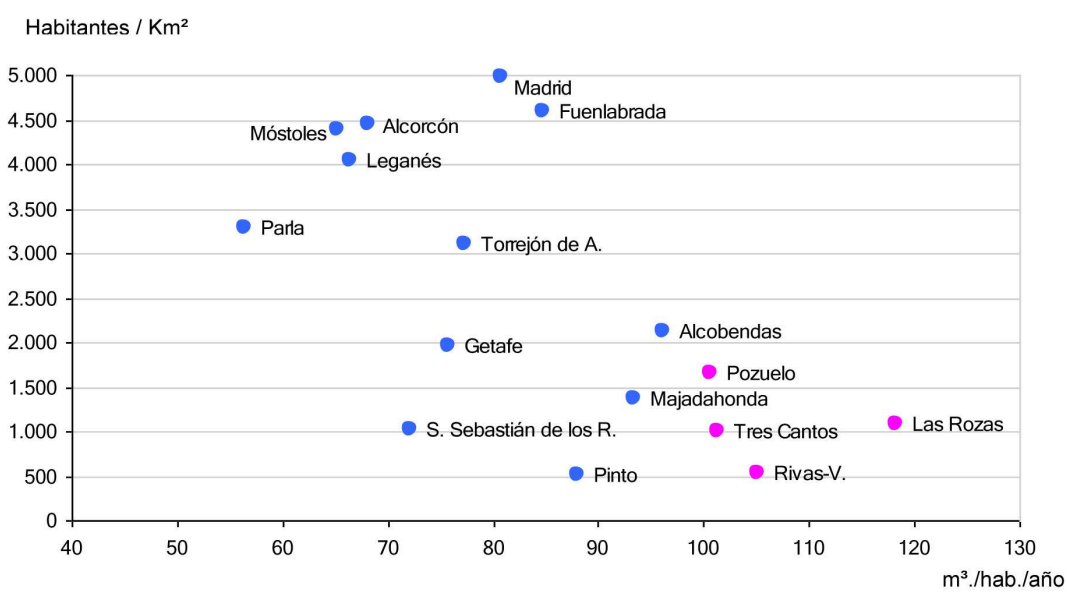

Figura 24: Relación entre consumo de agua $(\mathrm{X})$ y densidad de población $(\mathrm{Y})$. Fuente: elaboración propia a partir de Anuario Estadístico de la Comunidad de Madrid, 2003. 
(como por ejemplo en el caso de San Sebastián de los Reyes o Getafe), a los desarrollos dispersos de enclaves de viviendas unifamiliares o a las distintas extensiones de suelo no urbanizable de cada municipio. Sin embargo, vuelve a aparecer un grupo de municipios de baja densidad y máximo consumo constituido por Las Rozas, Rivas Vaciamadrid, Tres Cantos, Majadahonda y Pozuelo, y en el extremo contrario Móstoles, Alcorcón y Leganés. El Municipio de Madrid destaca por ser el más densamente poblado y por tener un consumo medio.

Como ya se ha explicado anteriormente, de los modelos de previsión de demanda del Canal de Isabel II se desprende una correspondencia directa entre el crecimiento del número de unidades de vivienda y la reducción del margen de garantía del organismo abastecedor. Sin embargo, resulta también interesante explorar cómo la segmentación social de la población en los distintos municipios trasciende a los volúmenes demandados de agua, lo que demuestra sin duda el papel fundamental de los hábitos de consumo y la probable injerencia que tiene el modelo de crecimiento de la ciudad sobre éstos.

\section{Los límites de las fuentes actuales: Las infraestructuras de abastecimiento}

La capacidad de abastecimiento de la institución responsable de la gestión integral del ciclo del agua en la Comunidad de Madrid, el Canal de Isabel II, depende de tres ejes principales:

- Las aportaciones del ciclo hidrológico natural de la región. Estos insumos están condicionados principalmente por el clima y las precipitaciones, pero sobre todo por la calidad de las aguas de los caudales de los ríos, de lo que dependen en gran medida los usos a los que se destinarán.

- La capacidad de las infraestructuras existentes, su correcto funcionamiento y mantenimiento y la eficiencia de su operación, que debe optimizar el volumen existente según las necesidades prioritarias.

- Disponibilidad de acuíferos subterráneos, ya que estas fuentes, aunque limitadas debido a su periodo de recarga (4 años de recarga por cada año de explotación) y su fragilidad ante posibles contaminaciones, son de vital importancia por ser menos susceptibles a las variaciones climáticas y contar con un grande y relativamente constante volumen del recurso.

Para el abastecimiento de casi la totalidad de la población de la Comunidad de Madrid, cuya gran mayoría reside en su región metropolitana, el Canal de Isabel II cuenta con: 14 embalses, ubicados en las principales zonas de captación de agua de la Cordillera Central; 61 pozos, que van desde los 250 a los 700 metros de profundidad y se ubican principalmente en el acuífero terciario detrítico; 22 grandes sistemas principales de conducción, que se extienden a lo largo de 530 kilómetros; 12 estaciones de tratamiento potabilizador (ETAPs), con capacidad para tratar hasta 43 metros cúbicos por segundo; 12 grandes depósitos reguladores, con capacidad para almacenar 2,6 millones de $\mathrm{m}^{3}$; 18 plantas de elevación, con una potencia total de 78 megavatios, y 211 depósitos de menor capacidad. La distribución se realiza mediante 10.000 kilómetros de conducciones de diámetros de entre 50 milímetros y 2 metros.

Sin duda alguna, las presas y embalses han sido la pieza primordial de la ingeniería hidráulica del siglo XX alrededor del mundo, y Madrid no ha sido la excepción. Los embalses de la región cubren una superficie total aproximada de 5.100 hectáreas, lo que representa un promedio de casi 10 metros de superficie de embalse por cada habitante de la Comunidad de Madrid (el equivalente a que cada habitante de la Comunidad tuviese una plaza de aparcamiento en la sierra).

Para el abastecimiento de la región, además de contar con los recursos provenientes de los embalses, que básicamente fluyen hacia la capital gracias a la acción de la gravedad, el Canal de Isabel II cuenta con una serie de recursos complementarios provenientes del río Alberche y de los pozos del acuífero cretácico de la zona de Torrelaguna, que precisan algún tipo de impulsión y el consiguiente gasto energético para alcanzar la cota necesaria para su posterior distribución. Los campos de pozos del acuífero terciario detrítico constituyen la reserva estratégica del sistema, pensadas para ser utilizados, en teoría, sólo en casos de escasez. Además, para algunos usos, principalmente el riego de jardines y limpieza de calles, se ha tratado de implementar la reutilización de aguas residuales depuradas, que en el año 2002 alcanzó el poco significativo volumen de 1 hectómetro cúbico.

Teóricamente, durante un año de normalidad la distribución de estos recursos debería ser la siguiente (Cubillo GonzÁlez, 2003): el $79 \%$ del abastecimiento proveniente de recursos ordinarios (embalses y azudes), el $19 \%$ de complementarios (Alberche y pozos del cretácico de Torrelaguna) y el $2 \%$ restante de la reserva estratégica (pozos del terciario detrítico). En caso de episodios de sequía, la falta de recursos ordinarios, que descenderían a un $61 \%$, tendría que compensarse con un mayor uso de recursos complementarios (un $21 \%$ ), especialmente de la reserva estratégica (14\%), además de un $4 \%$ de otras fuentes, como por ejemplo concesiones temporales desde otras cuencas. 


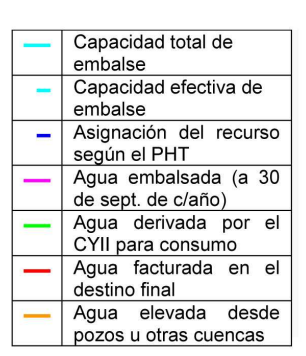

$\mathrm{Hm}^{3}$

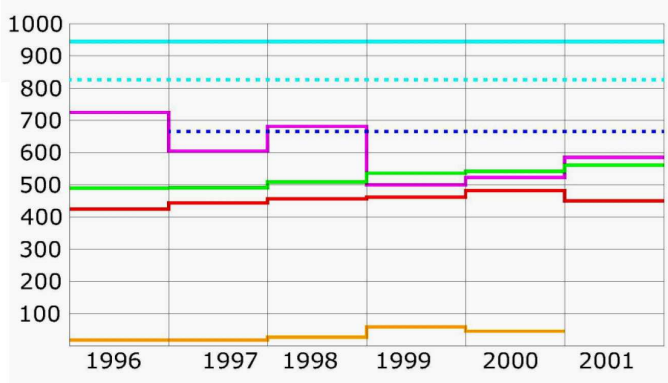

Figura 25: Agua consumida según procedencia

Fuente: Elaboración propia a partir del Canal de Isabel II.

\section{Los embalses}

Los embalses regulan los cauces de todas las cuencas principales de la Comunidad de Madrid, e incluso otras supracomunitarias como las del Sorbe y el Alberche. La mayor parte del caudal regulado corresponde a la cuenca del Lozoya, en total $558 \mathrm{hm}^{3}$ — que equivalen a más de la mitad de la capacidad total de almacenamiento - repartidos en cinco embalses, siendo el más importante el del Atazar, construido en 1972, cuya capacidad es de $425 \mathrm{hm}^{3}$. La cuenca del Guadarrama tiene un caudal regulado de 131,6 hm

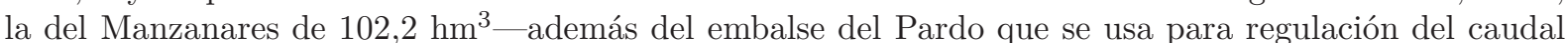
pero no para el consumo-, la cuenca del Jarama $55,7 \mathrm{hm}^{3}$, la del Guadalix de 40,9 $\mathrm{hm}^{3}$ y la de los Morales de $26 \mathrm{hm}^{3}$.

La capacidad combinada de los 14 embalses del Canal de Isabel II es de 945,9 hm³. La aportación media anual histórica (desde 1914 a 2002) ha sido de 789,433 hm³. Cabe destacar que, por motivos de seguridad, los embalses se han diseñado para que nunca se llenen al $100 \%$ de su capacidad. Para ello se han establecido valores de seguridad que son efectivos durante los meses de mayor aportación de los ríos, con el fin de evitar posibles avenidas que colmarían los cauces, actualmente invadidos por gran número de urbanizaciones, lo que resultaría catastrófico. Los meses con mayor riesgo son diciembre y enero, en los que se acumulan $169 \mathrm{hm}^{3}$ (un $17 \%$ del total de la capacidad de embalse) y los meses de menor riesgo son junio, julio y agosto, en los que el valor de seguridad se reduce a $31,3 \mathrm{hm}^{3}$ (un $3 \%$ del total de la capacidad).

De igual forma que con los valores de seguridad, hay que restar al total de la capacidad de embalse los volúmenes muertos en los fondos de los vasos de las presas que, debido a las diferencias de alturas entre el lecho bajo del embalse y las compuertas, no pueden ser desaguados mas que con sistemas de bombeo alternativos y contemplados únicamente para situaciones de extrema urgencia. En este caso, el total combinado alcanza los $20,68 \mathrm{hm}^{3}$. A partir de estos condicionantes, el total efectivo de capacidad de abastecimiento desde los embalses se reduce a $755 \mathrm{hm}^{3}$ en los periodos de alto riesgo y a $890 \mathrm{hm}^{3} \mathrm{en}$ los de baja afluencia.

\section{Captaciones}

Captaciones es el término que se utiliza para los recursos hídricos consumidos en Madrid que son adquiridos desde otras cuencas o cotas más bajas, lo que impide su conducción por simple gravedad y requiere la introducción de medios de bombeo mecánico para ser conducidos a su destino de consumo final. Debido a que las captaciones se consideran como recursos estratégicos, su nivel de explotación depende de la disponibilidad de agua existente en los embalses. Durante los años secos de 1992 y 1993 , las captaciones significaron una aportación del $28 \%$ y $38 \%$ respectivamente, mientras que en años normales su aportación ronda entre el 5 y el $10 \%$.

En el caso de la Comunidad de Madrid, los recursos que requieren este tipo de esfuerzo son los provenientes desde la cuenca del río Sorbe, la del Alberche y las aguas bombeadas desde el subsuelo. En el caso del río Sorbe, los recursos son trasvasados desde el azud del Pozo de los Ramos hasta el embalse de El Vado.

El bombeo de agua desde el río Alberche implica uno de los gastos energéticos más importantes. Para esta labor se utilizan las cuatro estaciones de bombeo más importantes de la Comunidad, ya que son las que cuentan con el mayor caudal de elevación y la mayor potencia instalada. Las dos más antiguas (1967) 
CuAdro 9: Crecimiento de las infraestructuras de abastecimiento y conducción, en relación al crecimiento de la población

Fuente: Elaboración propia a partir de Canal Isabel II, INE y Ayuntamiento de Madrid.

\begin{tabular}{|c|c|c|c|c|c|c|}
\hline Ã̃o & Infraestructuras & $\begin{array}{l}\text { Sup. de } \\
\text { embalse } \\
\text { (ha) }\end{array}$ & $\begin{array}{l}\text { Longitud } \\
\text { de con- } \\
\text { ducción } \\
(\mathrm{km})\end{array}$ & $\begin{array}{l}\text { Población } \\
\text { (hab) }\end{array}$ & $\begin{array}{l}\text { Sup/hab } \\
\left(\mathrm{m}^{2} / \mathrm{hab}\right)\end{array}$ & $\begin{array}{l}\text { Long/hab } \\
\text { (m/hab) }\end{array}$ \\
\hline & $\begin{array}{l}\text { Embalse } \\
\text { va(1858) }\end{array}$ & \multirow[t]{2}{*}{136} & \multirow[b]{2}{*}{85,5} & \multirow[b]{2}{*}{775.034} & \multirow[t]{2}{*}{1,75} & \multirow[b]{2}{*}{0,11} \\
\hline 1900 & $\begin{array}{l}\text { Canal Bajo (1858) } \\
\text { Canal de la Parra (1904) } \\
\text { Canal de Guadalix (1906) }\end{array}$ & & & & & \\
\hline \multirow[b]{2}{*}{1910} & Embalse de Santillana (1912) & \multirow[t]{2}{*}{636} & \multirow[b]{2}{*}{138,2} & \multirow[b]{2}{*}{878.641} & \multirow[t]{2}{*}{7,23} & \multirow[b]{2}{*}{0,15} \\
\hline & $\begin{array}{l}\text { Canal de Santillana (1912) } \\
\text { Canal del Villar (1912) }\end{array}$ & & & & & \\
\hline 1920 & & & & 1.067 .637 & & \\
\hline$\overline{1930}$ & 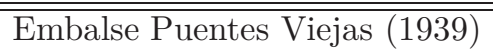 & 928 & & $\overline{~ 1.383 .951}$ & 6,7 & \\
\hline 1940 & $\begin{array}{l}\text { Canal Alto (1940) } \\
\text { Canal del Este (1945) } \\
\end{array}$ & & 207,9 & 1.579 .793 & & 0,13 \\
\hline 1950 & Embalse Riosequillo (1958) & 1.254 & & 1.926 .311 & 6,5 & \\
\hline 1960 & $\begin{array}{l}\text { Embalse EI Vado (1960) } \\
\text { Embalse Pinilla (1967) } \\
\text { Embalse Pedrezuela (1968) } \\
\text { Embalse Navalmedio (1969) } \\
\text { Embalse La Jarosa (1969) } \\
\text { Embalse Navacerrada (1969) } \\
\text { Canal del Jarama (1960) } \\
\text { Canal depósitos B. Murillo - } \\
\text { Pza. de Castilla (1966) } \\
\text { Canal Atazar (1966) } \\
\text { Canal Picadas (1967) } \\
\text { Canal del Oeste (1968) } \\
\text { Canal del Vellón (1968) } \\
\text { Canal Trasvase Navalmedio- } \\
\text { Navacerrada (1969) }\end{array}$ & 2.518 & 424 & 2.606 .254 & 9,6 & 0,16 \\
\hline & $\begin{array}{l}\text { Embalse Manzanares el Real } \\
(1971) \\
\text { Embalse el Atazar (1972) } \\
\text { Embalse Valmayor (1976) }\end{array}$ & \multirow[t]{2}{*}{4.886} & \multirow[b]{2}{*}{486,9} & \multirow[b]{2}{*}{3.792 .561} & \multirow[t]{2}{*}{12,88} & \multirow[b]{2}{*}{0,12} \\
\hline 1970 & $\begin{array}{l}\text { Canal del Sorbe (1971) } \\
\text { Canal Majadahonda- } \\
\text { Retamares (1973) } \\
\text { Canal Principal del Este } \\
\text { (1973) } \\
\text { Canal Valmayor (1976) } \\
\text { Canal Trasvase de las Nieves } \\
(1976)\end{array}$ & & & & & \\
\hline 1980 & Embalse Los Morales (1988) & 4.919 & & 4.726.986 & $\overline{10,4}$ & \\
\hline \multirow[b]{2}{*}{1990} & Embalse La Aceña (1991) & 5.034 & \multirow[b]{2}{*}{529,1} & \multirow[b]{2}{*}{5.030 .958} & \multirow[t]{2}{*}{$\overline{10,0}$} & \multirow[b]{2}{*}{0,11} \\
\hline & $\begin{array}{l}\text { Canal La Aceña-La Jarosa } \\
\text { (1991) } \\
\text { Canal San } \\
(1993) \\
\end{array}$ & & & & & \\
\hline
\end{tabular}




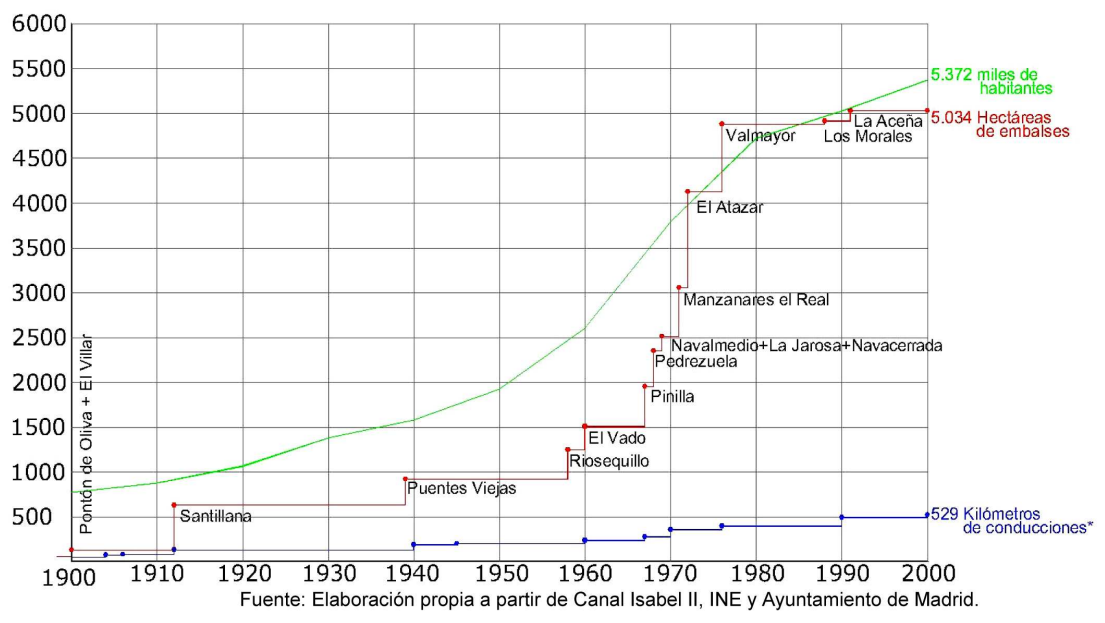

Figura 26: Crecimiento histórico de la población, de la superficie cubierta por los embalses y de la longitud de las conducciones ${ }^{15}$

Fuente: Elaboración propia a partir del Canal de Isabel II, INE y Ayuntamiento de Madrid.

son la de Picadas, con una columna de elevación de 216 metros, y Colmenar del Arroyo, de cien metros; ambas con un caudal de elevación de 3,80 metros cúbicos por segundo y una potencia instalada de 13.425 y 8.243 kilovatios respectivamente. El servicio de éstas fue complementado en 1994 por dos estaciones más: la de San Juan, situada en el entorno del embalse del mismo nombre, con una altura de 190 metros, y la de Colmenar el Arroyo II, de 130. Ambas están dotadas de un caudal de elevación de $6 \mathrm{~m}^{3} / \mathrm{s}$ y una potencia instalada de 19.000 y 13.000 kilovatios respectivamente.

Sin embargo, a pesar del consumo energético, la cuenca del Alberche es actualmente la única fuente accesible para una futura ampliación a corto y medio plazo de la capacidad de suministro del sistema (Cubillo, 2002), que consistiría en el aumento en la concesión de bombeo de los $120 \mathrm{hm}^{3}$ a $220 \mathrm{hm}^{3}$ anuales, que se realizaría sin ampliar las infraestructuras existentes, y en una segunda etapa, la regulación del río mediante el embalse de Venta del Obispo, situado en la provincia de Ávila.

CUADRo 10: Aportaciones naturales y procedencia de las aguas para consumo urbano $\left(\mathrm{hm}^{3}\right)$ Fuente: Aguiló (1983) y Canal de Isabel II.

\begin{tabular}{|l|l|l|l|l|l|}
\hline Cuenca de origen & Aportación natural media & \multicolumn{4}{|c|}{ Vol.derivado } \\
\cline { 3 - 6 } & & $\mathbf{1 9 9 7}$ & $\mathbf{1 9 9 8}$ & $\mathbf{1 9 9 9}$ & $\mathbf{2 0 0 0}$ \\
\hline Lozoya & 264 & 265 & 249,8 & 227 & 141,3 \\
\hline Jarama & 155 & 82 & 98,5 & 70,1 & 115,8 \\
\hline Guadalix & 60 & 30,6 & 40,0 & 12,9 & 23,4 \\
\hline Manzanares & 108 & 11,5 & 12 & 70,5 & 83,4 \\
\hline Guadarrama & 154 & 81,0 & 78,3 & 93,7 & 127,7 \\
\hline Alberche & 460 & \multicolumn{5}{|c|}{ Concesión actual $=120$} \\
\hline Sorbe & 135 & 17,22 & 26,0 & 3,1 & 27,1 \\
\hline
\end{tabular}

\section{El acuífero terciario detrítico}

Constituye una de las reservas más importantes de agua de la región. Su superficie equivale a 2.500 $\mathrm{km}^{2}$. Contiene unas reservas máximas de entre 2.000 y $4.000 \mathrm{hm}^{3}$, de las cuales se pueden extraer tan solo entre 130 y $150 \mathrm{hm}^{3}$ al año, debido a su lenta tasa de renovación. Para la utilización de esta fuente, el Canal de Isabel II ha implementado un programa de explotación sostenible (Domínguez BAUTisTA, 2000) según el cual no se debe rebasar el ritmo de renovación, debiendo dejar que el acuífero se recupere durante un periodo del doble a cuatro veces el equivalente al volumen extraído por cada año de bombeo, es decir, de 4 a 5 años por cada año de bombeo. 
Sin embargo, la explotación de esta fuente ha ido en aumento desde 1988 - cuando se extrajeron 0,2 $\mathrm{hm}^{3}$ - hasta el año 2000, que ha sido hasta el momento el año de mayor extracción, con $54 \mathrm{hm}^{3}$, de los cuales $22 \mathrm{hm}^{3}$ se destinaron a urbanizaciones extra-metropolitanas, 14 a industria y ganadería, 9 al abastecimiento de la capital y $9 \mathrm{hm}^{3}$ para regadíos.

Para la explotación del acuífero terciario detrítico, el Canal de Isabel II cuenta con cinco campos de pozos que constituyen un total de 75 unidades. Los sistemas de pozos se dividen entre los que pertenecen al sistema general, que aportan sus aguas a la red general de abastecimiento de la ciudad, y los que forman parte de los sistemas locales, que suministran de agua a las poblaciones cercanas a la explotación. En total, los campos de pozos pueden aportar un volumen aproximado de agua de buena calidad equivalente de entre 61 y $76 \mathrm{hm}^{3}$.

Los campos de pozos del sistema general son, de noreste a suroeste:

- Campo de pozos de Torrelaguna: se ubica en las inmediaciones de este municipio, en la cuenca del río Jarama. Está constituido por siete unidades que explotan el acuífero subterráneo de las calizas cretácicas de Somosierra. Su capacidad máxima de aportación es de $20 \mathrm{hm}^{3}$.

- Campo de pozos de Canal Alto-Canal Bajo: se sitúa en la cuenca del río Manzanares, al sur del embalse de El Pardo, en las inmediaciones del municipio de Tres Cantos. Está compuesto por 18 pozos que alcanzan a producir hasta $24 \mathrm{hm}^{3}$ anualmente.

- Campo de pozos de Fuencarral: se encuentra en el centro de la Comunidad de Madrid, al norte de la zona metropolitana. Está constituido por nueve pozos que alcanzan a producir $18 \mathrm{hm}^{3}$ al año.

- Campo de pozos de la zona oeste: como su nombre indica, este campo se ubica al oeste de la zona metropolitana, en el municipio de Majadahonda, y está constituido por 12 pozos que producen 17 $\mathrm{hm}^{3}$.

- Campo de pozos Batres-Móstoles: se ubica al sur-oeste de la Comunidad, en los municipios que le dan nombre, en el costado izquierdo de la cuenca del Guadarrama. Está compuesto por 13 unidades que aportan una media de $5 \mathrm{hm}^{3}$ al año.

Otro problema significativo que condiciona la utilización de los recursos subterráneos de agua para el abastecimiento urbano es la actual explotación de éstos para fines de riego. Cabe destacar que la Ley de Aguas, a pesar de garantizar el dominio público del recurso, respeta el derecho de explotación de pozos privados durante un lapso determinado de tiempo para comunidades regantes. A esto se suma la existencia dentro de todo el territorio español de un número significativamente alto de extracciones ilegales y no registradas, que generan incertidumbre sobre la capacidad actual real de los acuíferos. Específicamente, en la cuenca del Tajo en 1997 existían 97.332 sitios de explotación de aguas subterráneas, de los cuales 12.422 estaban declarados pero aún en manos de agentes privados debido a las concesiones de la Ley de Aguas, y sólo 9.579 estaban controlados por las autoridades municipales correspondientes (Libro blanco del agua).

Tras haber estudiado las distintas fuentes de captación de agua existentes en la región y los esfuerzos hidráulicos realizados para la explotación de éstas, resulta evidente que el área metropolitana de Madrid, además de ser el principal foco consumidor de la región, ejerce una presencia importante a nivel territorial al alterar los caudales de los ríos e inundar grandes superficies rurales y detraer sus aguas y verterlas en otros cauces (a menudo en condiciones cualitativas inferiores). De esta manera, el desarrollo de la gestión hidráulica ha contribuido a enfatizar la condición territorial de desequilibrio entre el norte y el sur característico de esta provincia (AguiLó, 1983).

Con respecto a este desequilibrio regional, mayoría de los textos descriptivos mencionan en el ciclo del agua de la Comunidad de Madrid la existencia de tres zonas con respecto a su respectiva vocación hidrológica: zona de producción en la sierra, zona de consumo en el área metropolitana y zona de vertido al sur de la Comunidad. En realidad parece más preciso el distinguir cinco en total. La primera, la zona de la sierra donde se ubican las cabeceras de los ríos madrileños y que por sus condiciones ambientales son las únicas capaces de producir un excedente constante de agua y, debido a su topografía, es una zona relativamente libre de la acción urbanizadora. La segunda, la zona del zócalo serrano y hasta la periferia norte del área metropolitana, en la superficie de gran parte del acuífero terciario detrítico, donde discurren los cauces medios de los ríos que se caracterizan por su escaso caudal, producto de la regulación de los embalses; esta zona sufre una gran presión urbanizadora al ser el área de tensión entre la creciente mancha urbana y los atractivos naturales de la sierra. La tercera zona, la correspondiente al área metropolitana, destino de los trasvases realizados gracias a las distintas canalizaciones desde los embalses, donde se realiza la mayor parte del consumo de agua de la Comunidad y punto de transformación de recurso a residuo. La cuarta, la correspondiente a la zona de vertido, es decir, el área sur de la Comunidad, donde los ríos 
recuperan o superan su caudal natural debido a los desagües provenientes de las depuradoras. La quinta y última, correspondiente a las reservas estratégicas, incluye el extremo occidental de la Comunidad, desde donde se elevan las aguas del río Alberche.

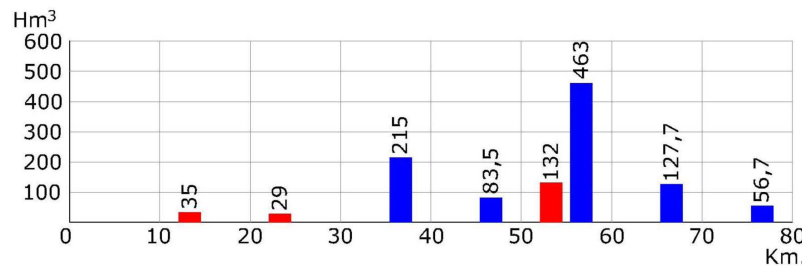

Figura 27: Distancia del centro de Madrid a las principales fuentes de abastecimiento Fuente: Elaboración propia a partir de Canal de Isabel II

\section{Caudales ecológicos}

Los caudales ecológicos, también llamados caudales ambientales, son una figura incorporada recientemente en el planeamiento hidrológico, a raíz de la Directiva Marco del Agua de la Unión Europea, y posteriormente adoptados como tales en el Plan Hidrológico Nacional y en los respectivos planes de cuenca.

El cambio de enfoque aportado por la Directiva Europea consiste en centrar la atención del planeamiento hidrológico, ya no en la visión clásica de satisfacción de demandas mediante construcción de infraestructuras, sino en la calidad del agua como elemento fundamental para la protección y conservación del medio ambiente y de la salud humana. Una de las repercusiones más directas sobre los modelos de gestión ha sido la implementación de los mencionados caudales ecológicos, que más que un uso o un fin en si, representan un medio para la conservación de la calidad de las aguas superficiales y de los ecosistemas que de éstas dependen. La aplicación de estos caudales significa una restricción sobre el total del volumen regulado de agua, que no podrá ser utilizado para abastecimientos urbanos, industriales o agrícolas, y que deberá ser desembalsado para mantener una cantidad suficiente de agua fluyendo por los cauces de los ríos.

Con el fin de definir el volumen necesario para estos caudales, el Plan Hidrológico de la Cuenca del Tajo (PHT) establece que para cada río se deben realizar estudios específicos. Sin embargo, y mientras esto ocurra, a fin orientativo, se establecerán los caudales en ríos regulados como el $50 \%$ de la aportación media de los meses de verano. A pesar de que resulta evidente la necesidad de establecer caudales mínimos para el mantenimiento de la calidad ecológica de los ríos, su puesta en práctica implica varias contradicciones que se analizan a continuación.

Según el PHT, la aplicación de los caudales ecológicos está supeditada a la prioridad del abastecimiento urbano, tanto para el consumo doméstico como para el productivo. Para ello, se establecen una serie de valores que representan el nivel mínimo de explotación normal ${ }^{16}$ que especifican la reserva mínima que debe garantizar en este caso el Canal de Isabel II, que oscila entre un mínimo de $553 \mathrm{hm}^{3}$ en los meses de noviembre y diciembre y $643 \mathrm{hm}^{3}$ en el mes de junio. Estos valores resultan muy cercanos al que el mismo plan establece como reserva anual vigente para un horizonte a diez años, fijada en 665,57 $\mathrm{hm}^{3}$, que incluye todas las fuentes del Canal de Isabel II: embalses, acuíferos y captaciones; por lo tanto, la satisfacción de los caudales ecológicos y de la demanda urbana tiene durante los meses estivales sus puntos más críticos y difíciles de compatibilizar. Dentro del apartado de «asignación y reserva de recursos» del PHT quedan establecidas las demandas medioambientales para el sistema de abastecimiento de la Comunidad de Madrid. Éste indica las siguientes reservas para el horizonte de los próximos 10 años:

\footnotetext{
${ }^{16}$ Plan Hidrológico de la Cuenca del Tajo.
} 
Demanda medioambiental embalse del Atazar:

Demanda medioambiental embalse El Vado:

Demanda medioambiental embalse El Pardo:

Total demanda medioambiental:

$$
\begin{array}{r}
27,84 \mathrm{hm}^{3} / \text { año } \\
9,36 \mathrm{hm}^{3} / \text { año } \\
31,10 \mathrm{hm}^{3} / \text { año } \\
\mathbf{6 8 , 3 0} \mathbf{h m}^{3} \text { /año }
\end{array}
$$

22 Demandas no satisfechas con los recursos disponibles» indica que actualmente no es posible satisfacer la demanda necesaria para los programas de regeneración de las cabeceras del Jarama y el Guadarrama, ni las demandas medioambientales de los embalses de El Vado y El Pardo. Además, las demás demandas ambientales sólo se satisfarán cuando el nivel de agua embalsado esté por encima de la cantidad que se fija en el mismo Plan como 'normal' para cada embalse.

Suponiendo que el Canal de Isabel II pueda satisfacer las necesidades medioambientales una vez cumplidos los mínimos indicados por la ley para el cumplimiento de las necesidades humanas, el PHT deja desprovistos de reserva ambiental al resto de los ríos de la Comunidad de Madrid, como son el tramo alto del Lozoya bajo el embalse de Pinilla, el río Guadalix bajo el embalse de la Pedrezuela y el río Guadarrama-Aulencia, por debajo del embalse de Valmayor. En el caso de estos ríos, queda en manos de la voluntad del Canal de Isabel II la implementación de medidas que permitan mantener y mejorar su situación ecológica (CUBILlo, 2002).

Para el caso de los ríos madrileños, cuyos caudales ambientales no han sido definidos dentro del plan de cuenca, el Canal de Isabel II ha establecido sus propios parámetros de asignación de reservas, tomando como referencia el $50 \%$ del caudal mínimo de cada uno:

Río Guadalix, bajo el embalse de la Pedrezuela:

Río Guadarrama-Aulencia, bajo el embalse de Valmayor:

Río Manzanares, bajo el embalse de Santillana:

Río Lozoya, bajo el embalse de Pinilla:

Total de caudales ambientales según CYII:

Total caudales ambientales según el PHT:

Demanda ambiental total de los ríos de Madrid (CYII+PHT):

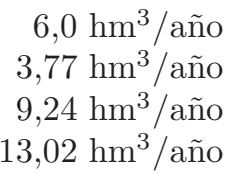

$32,03 \mathrm{hm}^{3} /$ año

$68,30 \mathrm{hm}^{3} /$ año

$100,33 \mathrm{hm}^{3} /$ año

Como se analizó en el apartado dedicado al límite de las fuentes de abastecimiento actuales, el cada vez más reducido margen existente entre la demanda actual y el abastecimiento garantizable por el Canal Isabel II presenta un panorama poco esperanzador para la satisfacción sistemática de los caudales ambientales. El hecho de estar restringido a las necesidades del consumo humano implica que, sobre todo en los meses de verano, cuando los caudales naturales presentan sus menores aportaciones, casi de forma segura será imposible la aportación desde los embalses, por ser ésta la época de mayor demanda en la ciudad.

Ante las predicciones ${ }^{17}$ elaboradas por el Canal de Isabel II sobre el crecimiento de la demanda, queda claro que, de cumplirse éstas, la satisfacción de los caudales ecológicos requerirá de la aportación de aguas desde las fuentes estratégicas (acuíferos) o desde nuevas concesiones de cuencas más alejadas, probablemente con la necesidad de construir nuevas infraestructuras (CuBILlo, 2002), lo que implicaría alejar la fuente del problema más que solucionarlo de manera sustancial.

\section{Los límites de los sumideros: la depuración de agua en la Comunidad de Madrid}

El desarrollo y crecimiento continuo de la zona metropolitana de Madrid y de sus actividades productivas, especialmente durante la segunda mitad del siglo XX, ha planteado también el problema, no sólo del abastecimiento, sino del impacto ambiental del creciente caudal de aguas residuales y vertidos industriales. Esto provocó que a fines de la década de los setenta de ese siglo se emprendiera un esfuerzo por parte de las autoridades municipales para depurar la calidad de sus vertidos urbanos y recuperar, en la medida de lo posible, la dignidad ambiental del río Manzanares, lo cual se concretó en el Plan de Saneamiento Integral de Madrid (PSIM), de horizonte temporal 1978-1984. Este plan, además de precursor a nivel español, se adelantó en casi diez años a lo que después serían las exigencias de calidad de las aguas planteadas en la Directiva de la Unión Europea de tratamiento de las aguas residuales urbanas $^{18}$, que actualmente marca los parámetros europeos de calidad de este tipo de recursos.

\footnotetext{
${ }^{17} \mathrm{El}$ pronóstico para la demanda según el Canal de Isabel II indica que entre los años 2012 a 2018 se alcanzará la cifra de $740 \mathrm{hm}^{3}$, dependiendo de las posibles variaciones climáticas.

${ }^{18}$ La Directiva Europea de Tratamiento de Aguas Residuales Urbanas 91/271/CEE afecta de manera importante a la planificación hidrológica, al exigir que en el 2005 todas las poblaciones de más de 2.000 habitantes deben depurar el $100 \%$ de sus aguas residuales.
} 
El problema de contaminación de las aguas superficiales en la Comunidad de Madrid se ha manifestado en dos frentes distintos. Por un lado, los vertidos residuales sin tratamiento alguno de los poblados ubicados en la zona de captación en el noroeste de la región han puesto en peligro la calidad de las aguas controladas en los embalses, que en algunas de estas infraestructuras han alcanzado niveles graves de eutrofización por el excesivo vertido de desechos orgánicos. El segundo problema ha sido la pérdida de calidad de los caudales de prácticamente todos los ríos de la Comunidad, debido al excesivo vertido de residuos urbanos e industriales, cuyo efecto contaminante es potencialmente dañino al estar los caudales naturales en sus valores mínimos por su regulación para abastecimiento, lo que reduce su capacidad de autodepuración. El ejemplo más dramático es el del río Manzanares, que a la salida del embalse de El Pardo tiene una aportación cercana a $0,5 \mathrm{~m}^{3} / \mathrm{s}$, y tras recibir los vertidos de las depuradoras de la zona metropolitana de Madrid puede llegar hasta los $16 \mathrm{~m}^{3} / \mathrm{s}$ (VARGAS López, 1995).

Sin embargo, la inquietud por la calidad de las aguas para el abastecimiento y el peligro que sufren éstas debido a los vertidos urbanos no es nueva en tiempos del PSIM, sino que se remontan casi a la puesta en funcionamiento del mismo Canal de Isabel II (GonzÁlez REGLERo, 2002). Durante la construcción de éste, se realizan los primeros estudios de calidad de las aguas del río Lozoya, que demuestran ser mejores que las de otros ríos utilizados para el abastecimiento de grandes ciudades, como París o Nueva York. Posteriormente, durante la epidemia de cólera de Madrid de 1885, el ayuntamiento de la capital toma medidas destinadas a terminar definitivamente con el uso de los antiguos viajes de agua y recurrir únicamente a las aguas traídas del Lozoya.

En 1907, a partir del establecimiento del régimen del Canal de Isabel II basado en un consejo de administración y una comisaría regia, se dedica atención preferente a las condiciones sanitarias de las fuentes de abastecimiento de la capital. En ese mismo año, el doctor CÉsAr Chicote, jefe del Laboratorio Municipal del Madrid, realiza un trabajo de investigación en el que monitorea la calidad de las aguas en diversos tramos del río Lozoya. Uno de los hallazgos mas importantes de su trabajo es el fuerte impacto contaminante que tiene la población de Buitrago, situada inmediata al río, la cual descarga sus desechos orgánicos directamente al cauce. A pesar de que los efectos contaminantes se reducen considerablemente por el efecto de la autodepuración de las aguas de la presa de El Villar, se decide en 1911 la realización de sendos proyectos, tanto para el abastecimiento del pueblo mediante agua entubada, como para el tratamiento de sus aguas para evitar que éstas enturbien el caudal del río. En 1912 se realizó el primer proyecto de saneamiento de aguas residuales del Canal de Isabel II, que consistió en una serie de plataformas filtrantes construidas en las afueras del pueblo, que utilizaban el suelo como un filtro natural y que resultaba el sistema más económico y de mantenimiento más sencillo (GonzÁLEZ, 2002).

Será al final de los años setenta cuando las pésimas condiciones de los ríos de la ciudad de Madrid y del resto de la Comunidad obliguen a afrontar el problema del saneamiento de manera global. El Ayuntamiento de Madrid pone en marcha el PSIM, cuyo fin principal es la depuración de la totalidad de las aguas residuales de la capital, mientras que, por su parte, la Comunidad establece en 1984 la Ley Reguladora del Abastecimiento y Saneamiento de la Comunidad de Madrid que posteriormente trascendería en el Plan Integral del Agua en Madrid (PIAM).

La Ley Reguladora del Abastecimiento y Saneamiento de la Comunidad de Madrid, que surge también bajo la influencia de la Ley de Aguas, se desarrolla a partir de las siguientes líneas (VARGAS, 1995):

- Declara de interés de la Comunidad los servicios de abastecimiento y depuración, consolidando así el papel del Canal de Isabel II como gestor del ciclo integral del agua en la Comunidad de Madrid.

- Encarga la explotación y gestión de todas las infraestructuras hidráulicas (embalses, pozos, depuradoras, etc.) de la Comunidad, existentes y futuras, al Canal de Isabel II.

- Regula la tarifa del agua, bajo las premisas de que debe ser única, al incluir el coste de todos los servicios, igual para todos los usuarios, progresiva, para penalizar el despilfarro y suficiente, para compensar costes y garantizar el servicio eficiente.

A partir de esta ley se establecen los principios que habrán de regir el PIAM, que consideran la unidad del ciclo ecológico, la interdependencia de los conceptos de calidad y cantidad, la consideración del carácter de dominio público de los recursos hídricos, la solidaridad entre pueblos y regiones para la administración del recurso y la necesidad de considerar el proceso de ordenación territorial en la definición de planes y programas. En el PIAM de 1985 se establecen como frentes de acción la coordinación, legislación y gestión, la mejora de los abastecimientos, la creación y mejora de infraestructuras hidráulicas municipales y la depuración de las aguas residuales.

Sin embargo, tanto el PSIM como en PIAM de los ochenta se preocupan por los niveles de calidad que debe cumplir el agua al salir de las depuradoras, pero no valoran la calidad de los cauces de los ríos que recibían estos vertidos (Álvarez, 1998). Hasta la segunda fase de estos planes (1995-2005) no 
trascienden los cambios planteados por las directivas europeas ${ }^{19}$ en la concepción de la calidad de las aguas, ya no como un bien de consumo, si no como sustento de la vida y calidad del medio ambiente.

Antes de la entrada en vigor de estos planes la calidad de las aguas en la mayoría de los ríos de Madrid era poco menos que pésima. En un estudio de Francisco Cubillo realizado en 1985 (CubiLlo, 1986) se estableció que el $24 \%$ del total de los caudales de la Comunidad no era apto para ningún tipo de uso, mientras que sólo el $6 \%$ cumplía las condiciones idóneas de calidad para cualquier uso sin necesidad de tratamiento previo. Concluye que la mayor parte de la contaminación de las aguas de Madrid que llegan al Tajo es producida por vertidos urbanos (el equivalente al 49\%), seguidos en importancia por los industriales $(38 \%$ ) y finalmente los provenientes de la industria ganadera (el $13 \%$ ).

El mismo estudio establece el estado de deterioro de los principales ríos madrileños a partir de la escala de calidades del agua según su uso, establecida por el PIAM en 1985, en la que se indican siete niveles cualitativos:

Cuadro 11: Situación de la Calidad de las aguas en los ríos de la Comunidad de Madrid. Fuente: Cubillo, 1986.

\begin{tabular}{|l|l|r|}
\hline $\begin{array}{l}\text { Calidad de las aguas se- } \\
\text { gún su uso potencial }\end{array}$ & $\begin{array}{l}\text { Total de los ríos en 1985 } \\
(\mathbf{\%})\end{array}$ & $\begin{array}{l}\text { Objetivo del PIAM para } \\
\mathbf{1 9 9 0}(\mathbf{\%})\end{array}$ \\
\hline Nivel 1 & 6 & 11 \\
\hline Nivel 2 & 22 & 28 \\
\hline Nivel 3 & 9 & 9 \\
\hline Nivel 4 & 12 & 45 \\
\hline Nivel 5 & 13 & 4 \\
\hline Nivel 6 & 14 & 1 \\
\hline Nivel 7 & 24 & 2 \\
\hline
\end{tabular}

- Nivel 1: apta para cualquier uso.

- Nivel 2: potable con tratamientos convencionales. Piscicultura y baño.

- Nivel 3: riego, usos industriales. Potable con tratamientos especiales.

- Nivel 4: riego de plantas sin consumo directo.

- Nivel 5: navegación. Refrigeración industrial.

- Nivel 6: uso muy restringido.

- Nivel 7: ningún uso.

Según el estudio realizado por Miguel Álvarez Cobelas entre 1993 y 1996, en tres puntos clave de la cuenca del Jarama (Vaciamadrid antes de la desembocadura del Manzanares en el Jarama, Espinillos, en la desembocadura del Henares en el Jarama y en Puente Largo, en la confluencia del Jarama y el Tajo) se pudo observar en todas las muestras una mejoría de entre el 60 y el $90 \%$ de la demanda química de oxígeno gracias a la implementación del tratamiento primario, sin embargo, las mejorías en cuanto a sólidos en suspensión fueron mínimas debido al reducido número de plantas que contaban con ese tipo de tratamiento cuando se realizó el estudio. Tras el éxito obtenido por el Plan de Saneamiento Integral de Madrid (PIAM) en lo concerniente a disminuir el contenido contaminante de los vertidos urbanos en los ríos madrileños (Álvarez CoBElAs, 1998), en 1998 se pone en marcha la segunda etapa de este plan, con un horizonte temporal de seis años. Sus principales objetivos son la ampliación de la red de saneamiento, consecuente con el crecimiento urbano planteado en el Plan General de Ordenación Urbana Municipal (PGOUM) y la modernización de redes antiguas. El segundo frente importante es la ampliación de los sistemas de depuración de agua para darle a los caudales residuales un tratamiento más avanzado y cumplir parámetros más rigurosos, como por ejemplo que además de contaminantes biológicos

\footnotetext{
${ }^{19}$ La Directiva Europea 91/721/CEE establece la necesidad de definir áreas sensibles en los cauces de aguas continentales para su protección y preservación. En estas áreas el planeamiento habrá de hacer énfasis en sistemas de depuración más complejos.
} 
también se haga cargo de los sedimentos sólidos contaminantes, como son el nitrógeno y el fósforo, según los criterios temporales y de calidad indicados en las directivas europeas.

A partir de las normas de calidad impuestas por las directivas europeas, se ha establecido el monitoreo de la calidad de las aguas de los ríos con los criterios de clasificación A1, A2 y A3 (explicados en el apartado 5.1). Según su aptitud para la producción de agua potable, la clasificación A1 equivaldría a buena calidad, A2 a calidad normal, A3 a regular y mala cuando los niveles están por debajo de este valor. Según las observaciones realizadas en las cuencas españolas durante los últimos 15 años, la calidad de las aguas de la Comunidad de Madrid sigue siendo mala en los tramos bajos tras recibir los vertidos de la zona metropolitana, aunque son aptos para su posterior reutilización aguas abajo para usos de regadío. Los caudales de la zona norte se caracterizan por su elevada calidad.

\begin{tabular}{|l|l|}
\hline & baja contaminación \\
\hline & contaminación media \\
\hline contaminación elevada \\
\hline contaminación muy elevada \\
\hline
\end{tabular}

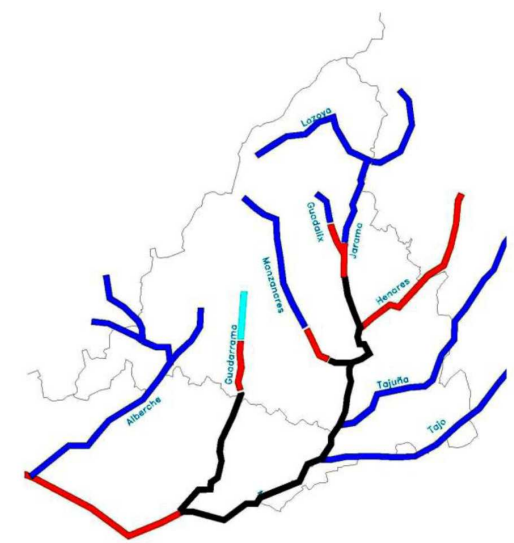

Figura 28: Calidad de los ríos en 1983
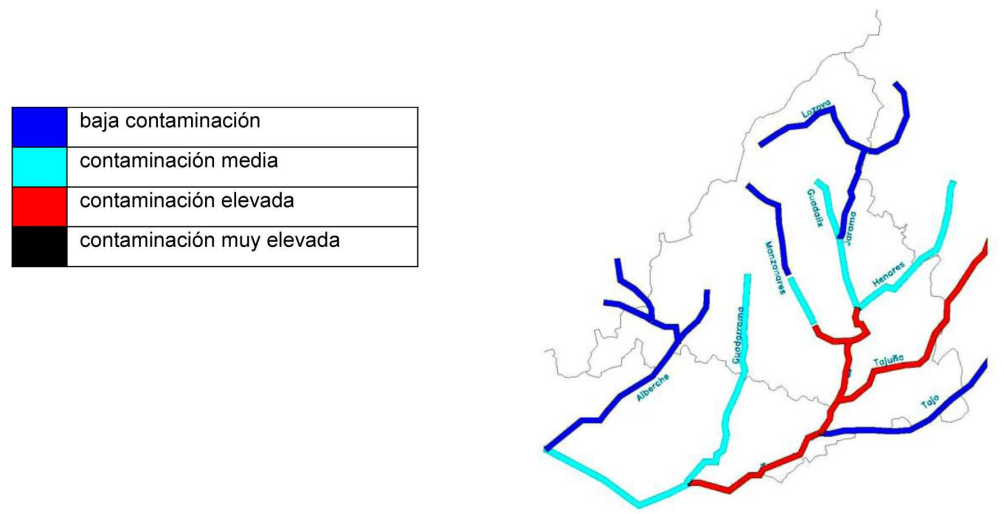

Figura 29: Calidad de los ríos en 1998

Pero los problemas de contaminación no son exclusivos de los cauces de los ríos, sino que actualmente la calidad en la mayoría de los embalses también ha empeorado (ver cuadro x).

Con criterios y objetivos muy similares a los del PSIM II, señalados anteriormente, la Comunidad de Madrid implementa a partir de 1995, y hasta el 2005, el Plan de Saneamiento y Depuración (PSD) que, además de la optimización de las plantas depuradoras, presenta como principal singularidad la protección de los niveles de calidad del agua de los embalses al clasificarlos como zonas sensibles, lo que implica criterios aún más rigurosos de control de los vertidos desde zonas adyacentes que puedan poner en peligro el nivel cualitativo del recurso.

En el caso del saneamiento de aguas residuales, a diferencia del abastecimiento de agua potable, la responsabilidad, gestión y operación de infraestructuras está dividida entre el Ayuntamiento de Madrid, responsable de la depuración de los vertidos del municipio y de la conservación y mantenimiento del río Manzanares en su tramo urbano, y el Canal de Isabel II, que se encarga de los vertidos y de la integridad de los ríos del resto de la Comunidad. 
CuAdro 12: Calidad del agua en los embalses

\begin{tabular}{|l|l|l|}
\hline Embalses & Calidad en 1983 (AGUILÓ, 1983) & $\begin{array}{l}\text { Calidad en 1998 (Libro } \\
\text { Blanco del Agua) }\end{array}$ \\
\hline San Juan (Alberche) & eutrófico & eutrófico \\
\hline Picadas (Alberche) & eutrófico & eutrófico \\
\hline La Aceña ( Aceña) & eutrófico & eutrófico \\
\hline Valmayor (Ausencia) & eutrófico & eutrófico \\
\hline La Jarosa (Guatel) & eutrófico & eutrófico \\
\hline Manzanares el Real (Manzanares) & eutrófico & eutrófico \\
\hline El Pardo (Manzanares) & eutrófico & eutrófico \\
\hline Pinilla (Lozoya) & eutrófico & eutrófico \\
\hline Riosequillo (Lozoya) & eutrófico & oligotrófico \\
\hline Puentes Viejas (Lozoya) & eutrófico & oligotrófico \\
\hline El Atazar (Lozoya) & oligotrófico 20 & oligotrófico \\
\hline El Vado (Lozoya) & oligotrófico & mesotrófico \\
\hline El Villar (Jarama) & eutrófico & mesotrófico \\
\hline Pedrezuela (Guadalix) & eutrófico & eutrófico \\
\hline
\end{tabular}

El Ayuntamiento de Madrid cuenta actualmente con siete Estaciones Regeneradoras de Aguas Residuales (ERARs) que afectan las cuencas del río Manzanares y del Jarama. Estas infraestructuras tienen desde 1984 la capacidad de dar tratamiento al 100\% de las aguas residuales del municipio, según lo establecido en la primera etapa del PSIM.

Por su parte, la Comunidad de Madrid, a través del Canal de Isabel II, cuenta con 67 Estaciones Depuradoras de Aguas Residuales (EDARs) repartidas a lo largo de las diferentes cuencas de la Comunidad, que depuran los vertidos de prácticamente toda la población (excluyendo, como ya se mencionó, al municipio de Madrid).

Las plantas depuradoras del Ayuntamiento de Madrid durante el año 2000 procesaron un caudal total de $533,67 \mathrm{hm}^{3}$, de los cuales aproximadamente un $30 \%$ corresponden a caudales derivados desde las infraestructuras de saneamiento de la Comunidad de Madrid, que a su vez depuraron ese mismo año un total de $185,9 \mathrm{hm}^{3}$. En total $719,6 \mathrm{hm}^{3}$, superando al total derivado por el Canal de Isabel II en ese mismo año, que fueron $542 \mathrm{hm}^{3}$. Esta diferencia entre caudal derivado y caudal depurado puede deberse a varias razones. La primera radica en que la escorrentía producida por precipitaciones pluviales en el área metropolitana es conducida a la misma red de saneamiento de las aguas negras, lo cual incrementa el volumen a depurar; también influye el hecho de que algunas poblaciones o comunidades regantes que no reciben abastecimiento directamente desde el Canal de Isabel II sí derivan sus aguas residuales hacia las infraestructuras de esta empresa.

Sin embargo, uno de los principales problemas a los que se enfrenta la gestión de depuración de aguas residuales, tanto para el Ayuntamiento de Madrid como para la Comunidad de Madrid, es al incremento constante en el consumo de agua registrado en los últimos años, cuya consecuencia lógica es el aumento sostenido del total del caudal a depurar, con el consiguiente consumo de energía y de producción de lodos. Durante el periodo 1995-2001, el caudal recibido por las infraestructuras del Ayuntamiento aumentó un total de $36,79 \mathrm{hm}^{3}$, pasando de $515,88 \mathrm{hm}^{3}$ a 552,67 . Por su parte, el caudal recibido por las infraestructuras de la Comunidad, que posteriormente derivan aproximadamente la tercera parte del caudal a las del Ayuntamiento, aumentó en $76 \mathrm{hm}^{3}$, de 197 a $273 \mathrm{hm}^{3}$. Resulta interesante observar como el caudal residual captado por la Comunidad se ha incrementado de manera mucho más acelerada que el del municipio y el área industrial, posiblemente como consecuencia del crecimiento poblacional e inmobiliario de los municipios periféricos de la comunidad de Madrid, y de que los consumos por habitante son más elevados en esta zona. 


\section{Conclusiones}

\section{Sobre los límites geográficos}

Desde la antigüedad, la abundante presencia de agua en la región madrileña ha permitido el desarrollo de asentamientos ${ }^{21}$ de mayor o menor escala, que con el paso del tiempo han constituido la actual región metropolitana. Sin embargo, el crecimiento poblacional, que hoy en día está por llegar a los seis millones de habitantes, en la Comunidad de Madrid ha provocado que la disponibilidad de este recurso en su territorio sea cada vez más insuficiente.

Los límites naturales de disponibilidad del recurso están definidos básicamente por dos aspectos. Los límites geográficos, que no coinciden necesariamente con la delimitación política de la Comunidad de Madrid, son el territorio de captación a través del cual la población puede ser abastecida simplemente por acción de la gravedad. Para el abastecimiento del área metropolitana de Madrid las cuencas que cumplen ese requisito son las de los ríos Guadarrama, desde sus cotas más altas hasta la cota media de la ciudad (650 metros), la del Jarama, incluyendo a los ríos Lozoya y Guadalix, y la del Manzanares, antes de su paso por la zona urbana y su posterior confluencia con el Jarama. La traída de aguas de la cuenca alta del río Sorbe también es posible mediante gravedad, sin embargo ha precisado una canalización de trasvase hacia las cuencas madrileñas. El hecho de que actualmente sea necesaria la elevación constante de agua desde otras cuencas mediante medios mecánicos, como en el caso del Alberche, pone de manifiesto que el límite natural ha sido sobrepasado. La aportación de agua desde este río representa casi el $20 \%$ del total del agua derivada para el consumo. El otro signo de que la capacidad de abastecimiento natural del territorio ha sido colmada es que parte de estas aguas traídas de otras cuencas tienen el objeto de satisfacer los caudales ecológicos de los ríos madrileños ${ }^{22}$, es decir, que de no ser por la importación del recurso, el ritmo de consumo actual implicaría la desaparición de los caudales de algunos ríos durante las épocas más secas del año, con todas las consecuencias ecológicas que esto puede acarrear.

El sobrepasamiento de los límites geográficos plantea varias cuestiones importantes, la primera y más básica es cuál es realmente la gravedad de este hecho, si es bien sabido que numerosas ciudades del mundo pueden satisfacer sus necesidades de agua solamente mediante la su importación desde regiones distantes.

La respuesta implica por un lado cuestiones económicas, cuya argumentación y desarrollo queda lejos de los alcances de este trabajo, pero que cabe tratar de intuir. Como se ha podido constatar recientemente con las discusiones sobre la derogación del trasvase del río Ebro contemplado en el Plan Hidrológico Nacional, a pesar del interés cada vez mayor por los aspectos medioambientales en la búsqueda de una gestión sostenible del recurso (que actualmente se encuentra concretado en la Directiva Marco), la problemática hidráulica sigue siendo hoy en día una cuestión de traer la mayor cantidad de agua posible al menor precio. Los verdaderos costes ambientales del abastecimiento están sujetos a distintas matizaciones e interpretaciones según los intereses del interlocutor de turno. En el caso del abastecimiento de la Comunidad de Madrid, la inminente situación de sequía producida por el aumento del consumo implicaría un dominio de la demanda sobre la oferta ${ }^{23}$ y, casi seguramente, una subida en el precio al consumidor, y la traída de agua de zonas lejanas repercutiría también en el precio para compensar la inversión en infraestructura ${ }^{24}$.

Aparte de las cuentas económicas, y haciendo referencia una vez más al debate en torno al trasvase del Ebro, la siguiente cuestión es si el agua es o no un recurso endógeno. Según la declaración de Dominio Público del agua, la totalidad del líquido pertenece al Estado Español y no a sus usuarios o a quienes viven más cerca de ella, y la gestión y distribución corresponde a los organismos de cuenca, por lo que la importación y exportación de agua de unas zonas a otras debería considerarse perfectamente normal. Sin embargo, esto implicaría caer de nuevo en el error de que el agua vale únicamente en función del líquido en sí, y olvidar que este recurso es el sustento de numerosos ecosistemas y ambientes que, a fin de cuentas, son parte del patrimonio de una comunidad. El asumir que el líquido falta en algunas partes y sobra en otras es ignorar por completo las funciones ecológicas del agua. Y así como el agua del Ebro ha generado hoy en día una tensión territorial entre el norte y el sur de la cuenca mediterránea, es de

\footnotetext{
${ }^{21}$ En el Valle del Jarama, por ejemplo, en la zona de Arganda del Rey, se han encontrado yacimientos arqueológicos que datan del Paleolítico, hace aproximadamente 350.000 años.

${ }^{22}$ Con los recursos disponibles actualmente, el Canal de Isabel II es capaz de garantizar solamente el $60 \%$ de las necesidades de los caudales ecológicos de la Comunidad de Madrid, que, como se mencionó anteriormente, están especificados en el Plan Hidrológico de la cuenca del Tajo (CuBiLlo, 2002).

${ }^{23}$ El verdadero impacto del precio sobre el consumo del agua en el contexto español es difícil de estimar con certeza, (ver Anejo 2) aunque es cierto que las comunidades autónomas que tienen un menor consumo por habitante son aquellas donde el agua es más cara (Canarias y Baleares) y las de mayor consumo registran el precio más barato (Castilla La Mancha, Andalucía y Aragón).

${ }^{24} \mathrm{El}$ Canal de Isabel II es una empresa pública, pero funciona con las reglas del mercado y depende de sus propios ingresos por facturación del líquido, que actualmente reportan beneficios. El precio del agua es teóricamente el costo de los servicios de captación, tratamiento, distribución y depuración, y no el del líquido en sí.
} 
esperar que este problema pueda presentarse en cualquier lugar desde donde el agua sea extraída para abastecer a regiones lejanas.

Este problema parece poner en evidencia que el hecho de abastecer de agua a una ciudad o a una región debe estar fundamentado en un concienzudo proceso de planificación territorial ${ }^{25}$ en el que las necesidades de agua (en este caso, pero también, por qué no, las de energía) sean consideradas a priori, y sobre todo, como resultado de un proceso de consenso entre las partes implicadas. De momento puede resultar ingenuo, pero en la búsqueda de los límites del crecimiento cabría preguntarse si algunas zonas son deficitarias de agua o más bien 'excedentarias' de desarrollo.

En relación a lo anterior, surge un nuevo interrogante en relación a la importancia que debería tener la disponibilidad del recurso en el desarrollo del planeamiento urbano. Aunque parece ilógico restringir el crecimiento a la capacidad de abastecimiento, sí existe un consumo diferenciado que tiene ciertas coincidencias con el tipo de ciudad que se promueve en distintas zonas del área metropolitana, como se ha podido constatar durante el desarrollo del trabajo. Cabría preguntarse si se puede comprobar la existencia de tejidos urbanos menos consumidores de recursos, o si estas diferencias dependen únicamente de los hábitos de consumo de los individuos.

Cabe mencionar, con respecto a lo anterior, que la Directiva Marco, en su Considerando 16, señala la necesidad de «una mayor integración de la protección y la gestión sostenible del agua en otros ámbitos políticos comunitarios, tales como las políticas en materia de energía, transporte, agricultura, pesca, política regional y turismo». De esta manera trata de abolir el enfoque sectorial que tiene actualmente la gestión del recurso.

\section{Sobre la incidencia del consumo de agua en el territorio}

Sin duda alguna, el consumo de agua en la ciudad de Madrid y la consiguiente construcción de infraestructuras para satisfacerlo han condicionado de forma importante el paisaje de la región. En primer lugar, la presencia de los embalses se ha convertido en una de las características más relevantes del paisaje serrano en la Comunidad de Madrid. Estas infraestructuras han provocado la pérdida de miles de hectáreas de uso rural, afectando hasta un punto difícil de estimar el desarrollo de las comunidades agrícolas y ganaderas adyacentes a éstas. Bajo los cuerpos de agua han desaparecido pueblos, vías de comunicación y pecuarias, y tal vez monumentos y yacimientos arqueológicos, así como numerosos ecosistemas de rivera que se caracterizaban por su diversidad y riqueza. Pero por otro lado, estos grandes lagos artificiales no dejan de ser un valor agregado para el paisaje, y son un punto de referencia para actividades recreativas, educativas y turísticas $^{26}$. Las enormes cortinas de hormigón que contienen el agua han sido aceptadas con el tiempo como un componente más del panorama, llamativo por la contundencia de sus dimensiones y de su irrupción en el medio natural.

A pesar de haber pasado treinta años desde la época del auge en la construcción de infraestructuras hidráulicas, los efectos de punto de atracción ${ }^{27}$ o barrera de comunicación que han tenido sobre el desarrollo social y económico de las comunidades serranas hoy en día han sido poco estudiados. También los ríos han sido afectados por la excesiva regulación de sus caudales para producción de agua potable, lo que ha potenciado las diferencias de caudal natural atribuibles a los cambios climáticos estacionales. Este efecto ha sido potenciado por la desaparición de afluentes bajo el asfalto y el hormigón del desarrollo inmobiliario y las infraestructuras.

\section{Sobre los límites del consumo}

Así como el consumo de agua ha sobrepasado la capacidad natural del territorio madrileño, parece que en el corto plazo también podría rebasar la capacidad del sistema de abastecimiento. Aunque teóricamente la disponibilidad natural de agua en las fuentes de Madrid se encuentra en torno a $1.100 \mathrm{hm}^{3}$ y la capacidad de regulación en casi $950 \mathrm{hm}^{3}$ (el equivalente a un año y medio de consumo), el hecho es que las variaciones climáticas provocan que rara vez se alcancen estos márgenes. Probablemente sea por ello que el PHT

\footnotetext{
${ }^{25}$ En una entrevista realizada por el autor de este trabajo al Director del Departamento del Canal de Isabel II, D. Francisco Cubillo, se pudo constatar que la participación actual de dicha empresa en la elaboración de Planes Regionales o Generales es prácticamente nula.

${ }^{26}$ Por mencionar un ejemplo, embalses como los de San Juan o Valmayor son utilizados actualmente para la práctica de deportes náuticos. El primero incluso es utilizado por lanchas con motor, actividad que resulta cuestionable al ser una presa destinada a la producción de agua potable.

${ }^{27}$ Por ejemplo, el caso de Manzanares el Real, ubicada a un costado del embalse del mismo nombre (antiguamente Santillana), que actualmente presenta un índice importante de crecimiento poblacional y de segunda residencia; aunque sería ingenuo pretender que ésto se debe a presencia del embalse, sobre todo con la presencia de la sierra de La Pedriza, es muy probable que la lámina de agua actúe como un atractivo más de la zona. Quedaría por averiguar si los sitios adyacentes a embalses tienen una mayor tasa de crecimiento o son más valorados que los del resto de la sierra.
} 
asigna solamente $665 \mathrm{hm}^{3}$ como garantía de reserva del abastecimiento de la Comunidad de Madrid, de los cuales, el Canal de Isabel II está comprometido a garantizar como mínimo el $90 \%$ en situación de normalidad, que serían $600 \mathrm{hm}^{3}$, cifra muy semejante a la del consumo del año 2003, lo cual quiere decir que existe un margen mínimo de actuación en caso de un episodio de sequía, lo que implicaría una situación de emergencia como la de principios de la década de los noventa.

Cabe destacar también el importante volumen de agua que se pierde debido a las fugas o deficiencias del control del sistema, que equivalen a prácticamente un $20 \%$ del total del recurso derivado para el consumo; a pesar de que el Canal de Isabel II destina casi el $26 \%$ de sus inversiones a las redes de abastecimiento y distribución, las estadísticas muestran que se ha logrado poco en este campo, especialmente debido a la antigüedad de algunos sectores de la red. Por otro lado, es importante también para la gestión de la demanda el problema del aumento en el consumo durante los meses de verano, precisamente cuando la aportación natural de agua es mínima y, sin embargo, de momento no existen medidas ni de difusión ni de costes enfocadas a compensar este desequilibrio estacional; esta situación se ve agravada por los riegos agrícolas, que siguen recibiendo el líquido a un precio relativamente barato y que en la época estival es cuando hacen una utilización más intensa del recurso, aprovechando sobre todo las fuentes subterráneas.

Parece evidente que la actual situación límite en la que se encuentra el suministro de agua en la Comunidad de Madrid ha sido provocada principalmente por el repentino incremento poblacional registrado durante la segunda mitad de la década de los noventa, como consecuencia de la fuerte inmigración proveniente del norte de África y de Latinoamérica. Además, el crecimiento demográfico de los municipios de la periferia metropolitana ha ido acompañado por un incremento del consumo por habitante dentro de los mismos, lo que ha agudizado el incremento de la demanda hacia casi una progresión geométrica. Ante esta situación, la actitud del Canal de Isabel II parece enfocarse principalmente hacia promover la construcción de nuevas infraestructuras ${ }^{28}$, especialmente el embalse de Venta del Obispo en el río Alberche.

Ante la delicada situación política actual acerca de la construcción de nuevas infraestructuras hidráulicas, así como la oposición de grupos ambientalistas y vecinos de las comarcas afectadas, no parece factible que se construya ningún embalse para el abastecimiento de Madrid en un futuro cercano. Sin embargo, tampoco parecen existir planes definidos para reducir el consumo de manera sustancial. La gestión de la demanda es hoy en día uno de los temas fundamentales en la gestión sostenible del agua y, en el caso de Madrid $^{29}$, ha probado su eficacia durante la sequía de principios de los noventa. Sin embargo, medidas como las tomadas entonces se consideran como coyunturales y de aplicación limitada en el tiempo.

Aunque los efectos benéficos de la gestión de la demanda pueden ser difíciles de cuantificar y de umbral temporal de respuesta difusa, cabría preguntarse hasta qué punto las autoridades responsables están haciendo un esfuerzo significativo por disminuir el consumo. Distintas iniciativas enfocadas al consumo racional de agua han puesto de manifiesto la importancia de las campañas de concienciación y educación (con el apoyo de los medios de comunicación) o la introducción de tecnologías domésticas que disminuyan el consumo. Sin embargo, ya sea por razones de costos o por no alarmar a la población, estas medidas siguen siendo la excepción y no la norma.

La reutilización de aguas residuales es también un tema recurrente en textos de sostenibilidad en el ciclo urbano del agua. Sin embargo, en la Comunidad de Madrid el volumen de líquido depurado que se reutiliza en el municipio es apenas de un hectómetro cúbico, que se destina al riego de parques y jardines. El elevado coste que implica la implementación de una doble red de agua puede ser una de las cusas del poco interés de las autoridades hacia este tema, así como el argumento de que los recursos depurados son reutilizados de cualquier forma para el regadío de las zonas agrícolas aguas abajo del río Tajo.

Ante la situación anterior cabría preguntarse dos cosas. La primera de ellas sería si el elevado coste de las infraestructuras de escala municipal y regional, que son con las que se cuenta actualmente, no justificaría la implementación de medidas de ahorro y reutilización en la pequeña y mediana escala. Ante el evidente ritmo constante de crecimiento de la ciudad podría ser sensato plantearse que desde su origen todas las nuevas urbanizaciones incluyan sistemas de regulación de consumo y de reutilización in situ mediante infraestructuras de escala menor.

\footnotetext{
${ }^{28}$ En la entrevista publicada por el diario El País, el 4 de febrero de 2004, el Director Gerente del Canal de Isabel II, Ildefonso DE Miguel, afirmó que para el año 2012 (o incluso antes) la ciudad de Madrid podría tener serios problemas de abastecimiento de no construirse desde ya las nuevas infraestructuras.

${ }^{29}$ Como se ha podido constatar en este trabajo, el incremento en la demanda actual ha sido potenciado más por el crecimiento poblacional que por el del consumo por habitante, que de hecho ha disminuido desde la crisis hídrica de los años noventa. El consumo por habitante en Madrid es más parecido al de ciudades subdesarrolladas como Ciudad de México o Bombay, que al de aquellas altamente desarrolladas como Nueva York o Tokio (ver Anejo 1), sin embargo, durante la realización de esta investigación no se ha encontrado ninguna referencia a lo que sería una aproximación a un consumo por habitante racional.
} 


\section{Sobre los límites de los sumideros y la depuración de aguas residuales}

Actualmente la depuración de aguas residuales representa el principal objetivo de las inversiones ${ }^{30}$ del Canal de Isabel II. Aunque es un requisito de la Directiva Europea, la depuración de agua de Madrid comenzó, como ya se explicó, varios años antes de que ésta entrara en vigor, con el objetivo primordial de rescatar las aguas del Manzanares, cuya pésima calidad en la década de los setenta había llegado ya a un punto inadmisible. Ahora que la depuración es necesaria para todos los municipios de la Comunidad de Madrid, parece que el problema tenderá a ser el coste económico y energético de tal esfuerzo. Estos problemas se agudizarán si se toma en cuenta que el consumo ha aumentado de forma constante, por lo que el caudal que debe depurarse también crecerá.

El principal objetivo de la depuración de aguas residuales es poder devolver el líquido a los cauces naturales después de ser utilizado sin provocar un deterioro de la calidad de los ecosistemas afectados. Aunque es evidente que es ejemplar el avance que se ha hecho en materia de depuración, sobre todo por la escala del volumen tratado, los ríos madrileños siguen padeciendo aún de graves problemas, especialmente en temporada de lluvias ${ }^{31}$, ya que la mezcla de aguas pluviales y negras en los colectores provoca la saturación de éstos, que descargan el exceso de líquido a través de sus aliviaderos y directamente al cauce del Manzanares, sin haber recibido tratamiento previo. De esta manera, ha quedado claro que el esfuerzo de la depuración por sí solo no garantiza la calidad de los caudales, sino que deberá ir acompañado de medidas de protección de cauces y riberas, que padecen el deterioro provocado por el desarrollo urbano ${ }^{32}$ e industrial.

\section{Sobre urbanismo y gestión sostenible del agua}

Uno de los principales interrogantes surgidos durante la realización de este trabajo ha sido el concerniente al papel que podría desempeñar el planeamiento urbano y territorial en una gestión sostenible de los recursos hídricos. Aunque de entrada se antoja lógico promover la importancia de la disponibilidad del recurso y la previsión de los consumos en el proceso del planeamiento, también es evidente que no se dejarán de construir desarrollos inmobiliarios por no tener el agua suficiente para abastecerlos, ya que en el transcurso de la historia se ha demostrado que, ante episodios de necesidad, se trae el recurso de donde sea posible, a pesar de los impedimentos físicos y tecnológicos, como sucedió con la construcción del Canal de Isabel II, de forma que es de esperar que el abastecimiento de agua se mantendrá supeditado a la aparición de situaciones extremas. Sin embargo, mientras las grandes ciudades (que cada día son más grandes) sigan dependiendo de la realización de infraestructuras de escala proporcional a éstas (grandes embalses, grandes depuradoras, grandes trasvases), será cada vez más difícil la factibilidad económica y medioambiental del suministro. Probablemente sea necesario plantearse la importancia de las escalas medias y bajas para infraestructuras locales de recolección de aguas pluviales, depuración de vertidos, reutilización de aguas depuradas, etc.

Por otro lado, el asumir que el ciclo hidrológico es un sistema cuya integridad depende de la calidad del agua, pero también de la del aire y del suelo, implica revisar el papel de la ciudad como gran centro contaminante. Además de las emisiones de las industrias y los vehículos que contaminan la atmósfera desde la cual recibimos el agua limpia, la transformación que produce la urbanización sobre las cualidades naturales del suelo puede ser igual de perjudicial. La impermeabilización de la superficie dificulta la recarga de acuíferos y contamina e incrementa los efectos negativos de la escorrentía superficial; la desaparición de cauces de arroyos que alimentan los ríos perjudica los caudales de los mismos, así como las grandes obras subterráneas y la extracción de agua pueden llegar a alterar el funcionamiento natural de los acuíferos subterráneos, lo que a la larga puede tener consecuencias nefastas ${ }^{33}$.

Siendo el agua «un patrimonio que hay que proteger, defender y tratar como tal $»^{34}$, parece evidente que esta afirmación se debería extender, no sólo al líquido en sí, sino a los ecosistemas, paisajes y patrimonios culturales que dependen de ella.

\footnotetext{
${ }^{30}$ En el presupuesto de inversiones del Canal de Isabel II para el año 2003, se destinaron, como principal partida, a las estaciones depuradoras unos 66.184 .000 euros, el $36 \%$ del total (http://www.cyii.es).

${ }^{31}$ El diario El País del miércoles 14 de abril de 2004 publicó que un informe del Ayuntamiento de Madrid, redactado como parte del proyecto de soterramiento de la M-30, afirmaba que la contaminación de las aguas en el cauce del Manzanares eran una catástrofe medioambiental.

${ }^{32}$ Por ejemplo, actuaciones tan importantes y recientes como las obras de ampliación del aeropuerto de Barajas han alterado significativamente la calidad del entorno ecológico del río Jarama.

${ }^{33}$ Se ha comprobado mediante diversos estudios que las excesivas extracciones de aguas subterráneas potenciaron el efecto destructor del sismo registrado en la Ciudad de México en septiembre de 1985, al haber alterado de manera sustancial las características de compacidad y resistencia del suelo.

${ }^{34}$ Directiva Marco del Agua 2000/60/CE.
} 


\section{Bibliografía}

Aguiló, Miguel

1983 El agua en Madrid.

Madrid : Diputación de Madrid, Área de Urbanismo y Ordenación Territorial.

Álvarez Cobelas, Miguel y Sanchez Carrillo, Salvador

1998 «Evaluación de los planes de saneamiento de la Comunidad de Madrid. Efecto sobre la calidad de las aguas de los ríos»

Revista Tecnoambiente, núm. 84, septiembre.

Ayuntamiento de Madrid

2003 "Infraestructuras básicas"

Anuario Estadístico 2001. Departamento de Estadística.

Bautista Parejo, Carmen

2002 Guía práctica jurídico-legal de la gestión del agua en la Comunidad de Madrid.

Madrid: Fundación Canal de Isabel II.

Bettini, Virginio et al.

1998 Elementos de ecología urbana.

Madrid: Editorial Trotta.

CAnal De Isabel II

1982 Cartografía de la infraestructura hidráulica de la Comunidad de Madrid.

Comunidad de Madrid, Agencia de Medio Ambiente.

CANAL DE ISABel II

1999 Manual de gestión de sequías.

Tercera revisión. Madrid: Canal de Isabel II.

Brundtland, Gro Harlem \& World Commission on Environment and Development et al. 1987 Our common future.

Oxford: Oxford University Press. Se cita Comisión Mundial del Medio Ambiente y del Desarrollo, Nuestro futuro común, 1989, Madrid: Editorial Alianza.

Confederación Hidrográfica del TAjo

1997 Plan Hidrológico del Tajo. Documento de síntesis.

Ministerio de Medio Ambiente, Gobierno de España.

Animación y Promoción del Medio, S.A.

1998 Los secretos de la ciudad.

Consejería de Medio Ambiente y Desarrollo Regional, Comunidad de Madrid.

Crespo Pinto, Virgilio (Dir.)

1995 Madrid, atlas histórico de la ciudad.

Centro de Documentación y Estudios para la Historia de Madrid. Se cita la revisión de 2001.

Madrid: Fundación Caja Madrid.

Cubillo, Francisco

1986 Situación actual de la calidad de las aguas en los ríos de la Comunidad de Madrid.

Madrid: Consejería de Obras Públicas y Transporte, Gobierno de España.

Cubillo, Francisco et al.

2001 Estudio de la demanda de agua para uso urbano en la Comunidad de Madrid.

Madrid: Fundación Canal de Isabel II.

Cubillo, Francisco y López-Camacho, Bernardo

2002 "Los caudales ambientales: compatibilidad con los abastecimientos, garantías y costes. Caso de la Comunidad de Madrid."

En Primer congreso de ingeniería civil, territorio y medio ambiente. Tomo I. Madrid: Colegio de Ingenieros de Caminos, Canales y Puertos.

Cubillo, Francisco

2003 Manual de abastecimiento del Canal Isabel II.

Madrid: Fundación Canal de Isabel II. 
Comisión EURopeA

2000 Directiva 2000/60/CE del Parlamento Europeo y del Consejo, de 23 de octubre de 2000, por la que se establece un marco comunitario de actuación en el ámbito de la política de aguas.

Diario Oficial de las Comunidades Europeas.

Diez-Cascón, Joaquín et al.

2003 Las presas y embalses en España. Historia de una necesidad.

Madrid: Ministerio de Medio Ambiente, Dirección General de Obras Hidráulicas y Calidad de las Aguas.

Dirección General de Planificación Territorial

1995 «Recursos hídricos y marco territorial»

Revista Ciudad y Territorio, Vol. III. Tercera época, núm. 105, otoño 1995. Madrid: Ministerio de Fomento, Direccion General de la Vivienda, la Arquitectura y el Urbanismo.

Domínguez Bautista, Ricardo

2000 "Las aguas subterráneas y el abastecimiento de Madrid."

En Fernández-Rubio, Rafael (ed.), Jornadas Técnicas sobre Aguas Subterráneas y

Abastecimiento Urbano. Madrid: Instituto Tecnológico Geominero de España.

García Otero, José

1853 Ideas generales sobre el proyecto del Canal de Isabel II y el estado de las obras en 31 de diciembre de 1852.

Madrid: Imp. y Fund. de Don Eusebio Aguado. Disponible en http://books.google.es/....

Gasco J. María \& SaA, Antonio

1996 "La calidad en la economía del agua"

En Cuadernos aragoneses de economía, vol. 6, núm. 1, págs. 101-112. Se cita NAREdo, José

Manuel, La economía del agua en España, 19997, Madrid: Fundación Argentaria.

González Reglero, JuAn

2002 "Los inicios de la preocupación por la calidad de las aguas de abastecimiento y por la depuración de las aguas residuales en el Canal de Isabel II."

En Primer congreso de ingeniería civil, Territorio y Medio Ambiente. Tomo I. Madrid: Colegio de

Ingenieros de Caminos, Canales y Puertos, D.L.

Iglesias, Helena \& Blanco, Manuel

1995 Viaje del agua.

Madrid: Fundación Canal de Isabel II.

Instituto NACional DE Estadística

2001-2003 Estadísticas del Medio Ambiente. Estadísticas del agua.

Juliá, Santos; R. Ringrose, David y Segura, Cristina

1994 Madrid, historia de una capital.

Madrid: Ed. Alianza Editorial, Fundación Caja de Madrid.

López de Lucio, Ramón (ed.); Boter Sans, Isabel et al.

1999 Madrid 1979-1999: la transformación de la ciudad en veinte años de ayuntamientos democráticos. Madrid: Gerencia Municipal de Urbanismo, Ayuntamiento de Madrid.

Segura, Cristina y Macías, José María (Coord.)

2000 Historia del abastecimiento y usos del agua en la villa de Madrid.

Madrid: Confederación Hidrográfica del Tajo y Canal de Isabel II.

COMUnidad DE MADRID

1992 Atlas de la Comunidad de Madrid.

Madrid: Consejería de Política Territorial.

COMUNidAd DE MADRID

2003 El medio ambiente en la Comunidad de Madrid.

Madrid: Consejería del Medio Ambiente.

Comunidad de Madrid

2004 Anuario Estadístico de la Comunidad de Madrid 2003.

Madrid: Consejería de Economía e Innovación Tecnológica. 
MARGALEF, RAMÓN

1974 Ecología.

Barcelona: Omega. Se cita la edición de 1992, Barcelona: Ed. Planeta.

Meadows, Donella H.; Meadows, Dennis L. \& Randerset, Jørgen

1991 Beyond the limits : confronting global collapse, envisioning a sustainable future.

Post Mills, Vt.: Chelsea Green Pub. Co. Se cita la segunda edición en castellano Más allá de los límites del crecimiento, 1993, Madrid: Ed. El País Aguilar.

Ministerio de Medio Ambiente

2000 Libro blanco del agua en españa.

Madrid: Secretaria de Estado de Aguas y Costas, Dirección General de Obras Hidráulicas y

Calidad de las Aguas.

Murase, Makoto

2001 "Sustainable water strategies for new development patterns"

En Enviroment in the 21st century and new development patterns. London: Ed. M. Matsushita. Kluwer Academic Publishers.

NARedo, José Manuel (ED.)

1996 La economía del agua en España.

Madrid: Fundación Argentaria.

Naredo, José Manuel y Valero, Antonio (Dirs.)

1999 Desarrollo económico deterioro ecológico.

Madrid: Fundación Argentaria.

Otero, José G.

1853 Ideas generales sobre el proyecto del Canal de Isabel II., y estado de las obras en 31 de diciembre de 1852,

publicadas por acuerdo del Consejo de Administracion en sesión de 5 de enero de 1853. Madrid: Canal de Isabel II.

PÉrez PÉrez, EMilio (DIR.)

1986 Legislación de aguas.

se cita la octava edición de 2003. Madrid: Ed. Tecnos.

Quesada, Heriberto ET AL.

1985 El agua de Madrid. Plan de Saneamiento Integral de Madrid.

Barcelona: Ed. Lunwerg.

TERÁn, Fernando de

1992 Madrid.

Madrid: Editorial Mapfre.

VARGAS LÓPEZ, RICARDO

1995 «El Plan de Saneamiento y Depuración de Aguas en la Comunidad de Madrid (1995-2005).» Revista Técnica del Medio Ambiente (RETEMA), núm. 45, año VIII. 
Cundro 13: Abastecimiento de agua en Tokio (Japón)

Fuente: Water supply in Tokio

\begin{tabular}{|l|r|}
\hline Población abastecida & 11.565 .864 \\
\hline Consumo total anual & $1.677 \mathrm{hm}^{3}$ \\
\hline Consumo habitante / día & $397 \mathrm{lts}$. \\
\hline Longitud de conducciones & $23.726 \mathrm{~km}$ \\
\hline Distancia a las fuentes & \\
\hline Sistema de abastecimiento & 15 embalses en las cuencas de los ríos \\
& Tama, Tone y Sagami, que nacen entre \\
& 2.000 y 500 metros sobre el nivel de la \\
& ciudad, en un sistema de bosques pro- \\
& tegidos como parques naturales. \\
\hline
\end{tabular}

Cuadro 14: Abastecimiento de agua en París (Francia) Fuente: Eau de París

\begin{tabular}{|l|r|}
\hline Población abastecida & 2.100 .000 \\
\hline Consumo total anual & $248 \mathrm{hm}^{3}$ \\
\hline Consumo habitante / día & $340 \mathrm{lts}$. \\
\hline Longitud de conducciones & $640 \mathrm{~km}$ \\
\hline Distancia a las fuentes & $173 \mathrm{~km}$ \\
\hline Fuentes & $\begin{array}{l}50 \% \text { superficiales, desde las cuencas de } \\
\text { los ríos Ivry, Orly y Joinville. 50\% sub- } \\
\text { terráneas con 94 pozos de bombeo. }\end{array}$ \\
\hline
\end{tabular}

\section{Cuadro 15: Abastecimiento de agua en Bombay (India)}

Fuente: http://theory.tifr.res.in/bombay/amenities/water/

\begin{tabular}{|l|l|}
\hline Población abastecida & 15.000 .000 \\
\hline Consumo total anual & $912,5 \mathrm{hm}^{3}$ \\
\hline Consumo habitante / día & 170 lts. \\
\hline Longitud de conducciones & - \\
\hline Distancia a las fuentes & \\
\hline Sistema de abastecimento & $\begin{array}{l}\text { Abastecimiento por gravedad desde seis } \\
\text { lagos distintos que se llenan gracias } \\
\text { a las lluvias monzónicas (aprox. 2.400 } \\
\text { mm anuales). El 75\% del agua suminis- } \\
\text { trada a diario es tratada en la planta de } \\
\text { Bhandup, la más grande de Asia. }\end{array}$ \\
\hline
\end{tabular}


Cundro 16: Abastecimiento de agua en México D.F. (México) Fuente: Sistema de aguas de la Ciudad de México

\begin{tabular}{|l|r|}
\hline Población abastecida & 10.000 .000 \\
\hline Consumo total anual & $1.095 \mathrm{hm}^{3}$ \\
\hline Consumo habitante / día & $300 \mathrm{lts}$. \\
\hline Longitud de conducciones & $514 \mathrm{~km}$ \\
\hline Distancia a las fuentes & $60-260 \mathrm{~km}$ \\
\hline Fuentes & $\begin{array}{l}\text { 63\% acuíferos subterráneos de la Cuen- } \\
\text { ca del Valle de México (970 pozos). 37\% } \\
\text { cuencas de los ríos Lerma (a 62 Km) y } \\
\text { Cutzamala (a 260 Km). El consumo de } \\
\text { energía para elevar el agua a la ciudad } \\
\text { equivale a la iluminación pública de una } \\
\text { ciudad de 4 millones de habitantes. }\end{array}$ \\
\hline
\end{tabular}

Cuadro 17: Abastecimiento de agua en Nueva York (Estados Unidos) Fuente: New York City Environmental Protection

\begin{tabular}{|c|c|}
\hline Población abastecida & 8.000 .000 \\
\hline Consumo total anual & $1.500 \mathrm{hm}^{3}$ \\
\hline Consumo habitante / día & 514 lts. \\
\hline Longitud de conducciones & - \\
\hline Distancia a las fuentes & $130-200 \mathrm{~km}$ \\
\hline Sistema de abastecimento & $\begin{array}{l}\text { Sistema de captaciones superficiales } \\
\text { desde las cuencas de los ríos Catskill y } \\
\text { Delawere, constituido por un total de } \\
19 \text { presas y } 3 \text { lagos controlados, y con- } \\
\text { ducción realizada } 90 \% \text { por gravedad }\end{array}$ \\
\hline
\end{tabular}

Cuadro 18: Abastecimiento de agua en Madrid (España) Fuente: Canal de Isabel II

\begin{tabular}{|c|c|}
\hline Población abastecida & 5.000 .000 \\
\hline Consumo total anual & $607 \mathrm{hm}^{3}$ \\
\hline Consumo habitante / día & 296 lts. \\
\hline Longitud de conducciones & $529,1 \mathrm{~km}$ \\
\hline Distancia a las fuentes & $20-80 \mathrm{~km}$ \\
\hline Sistema de abastecimento & $\begin{array}{l}\text { Sistema de } 14 \text { embalses ubicados en la } \\
\text { sierra al norte de la ciudad que aportan } \\
\text { el } 80-90 \% \text {; el resto proviene de campos } \\
\text { de pozos y elevaciones desde otras cuen- } \\
\text { cas. Capacidad máxima: pantanos: } 940 \\
\text { hm3; pozos: } 100 \mathrm{hm}^{3} \text {; elevaciones desde } \\
\text { otras cuencas: } 120 \mathrm{hm}^{3} \text {. }\end{array}$ \\
\hline
\end{tabular}


Los límites territoriales del consumo urbano de agua en la Comunidad de Madrid JAIME J.

\section{Anejos}

Anejo 1: El consumo de agua en algunas grandes ciudades Anejo 2: Relación precio-consumo del agua por Comunidades Autónomas

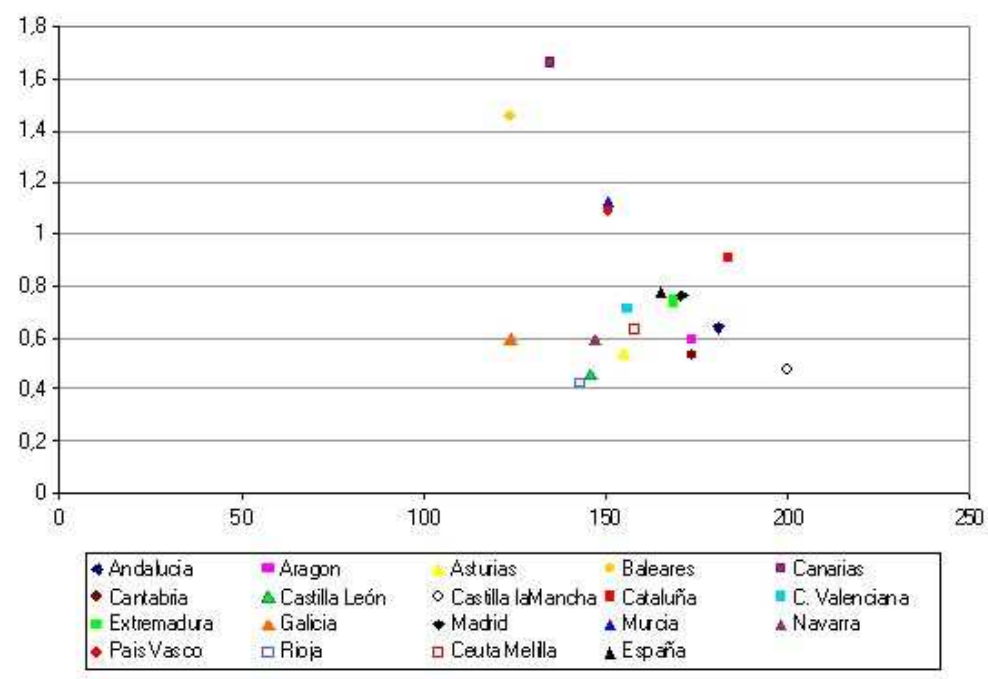


